\title{
Reactivity features of cyclododecanone
}

\author{
Hanafi H. Zoorob, Mohamed S. Elsherbini, and Wafaa S. Hamama* \\ Chemistry Department, Faculty of Science, Mansoura University, El-Gomhoria Street, 35516 \\ Mansoura, Egypt \\ E-mail:wshamama@yahoo.com
}

\begin{abstract}
Cyclododecanone is a highly important synthetic intermediate for macrocyclic systems. This review is the sole and comprehensive one that covers the different aspects of cyclododecanone chemistry over the period from 1950 to 2010.
\end{abstract}

Keywords: Cyclododecanone, muscone, fragrances, macrocylic ketones, ring enlargement and heterocycles

\section{Table of Contents}

1. Introduction

2. Synthesis of Cyclododecanone

3. Chemistry of Cyclododecanone

3.1. Halogenation

3.2. Oxidation

3.3. Alkylation

3.4. Mannich reaction

3.5. Ring enlargement

3.5.1. Macrocyclic ketones and esters

3.5.2. Macrocyclic lactames and lactones

3.5.3. Macrocyclic Acetylenes

3.6. Ring contraction

3.7. Construction of spiro and fused heterocyclic systems

3.7.1. Spiro heterocyclic systems

3.7.2. Fused heterocyclic systems

3.8. Photochemistry

3.9. Miscellaneous reactions

4. Conformational Characteristics of Cyclododecanone

5. Conclusion 
6. Appendix: Abbreviations and Acronyms

7. References

\section{Introduction}

Cyclododecanone $\mathbf{1}$ is a commercially available ketone, and important synthetic intermediate in the synthesis of natural products containing macrocyclic ring systems such as the anticancer rosphellin $2,{ }^{1}$ the potent microglial activation modulators tocopherol fatty alcohols (TFAs) $3{ }^{2}$ cytotoxic sponge alkaloids motuporamine A 4, motuporamine B 5, ${ }^{3}$ ingenes 6 and $7,{ }^{4,5}$ (Scheme 1).

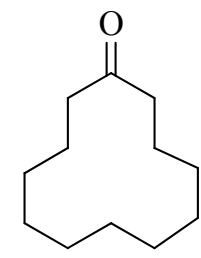

Cyclododecanone

1

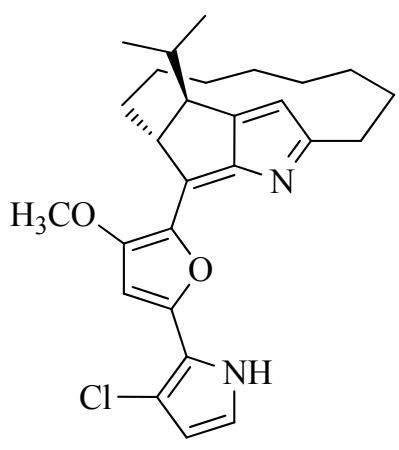

roseophilin

2<smiles>[R20]c1c(C)c(C)c2c(c1C)CCC(C)(C)O2</smiles>

$\mathrm{R}=\mathrm{H}, \mathrm{Me}, \mathrm{Ac}$

$\mathrm{n}=11$ to 15

TFAs

3

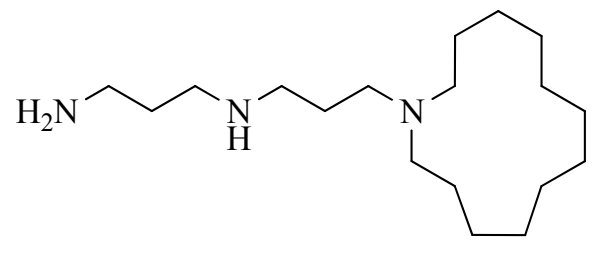

Motuporamine A

4

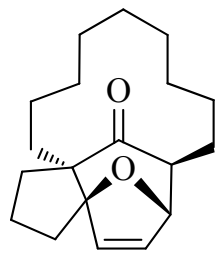

6a

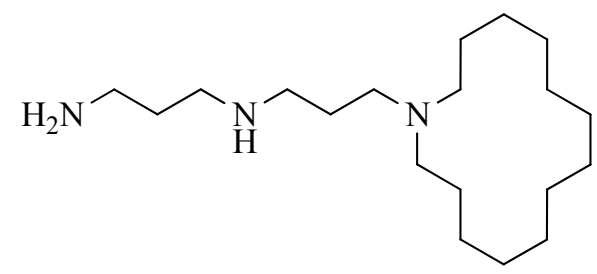

Motuporamine B

5

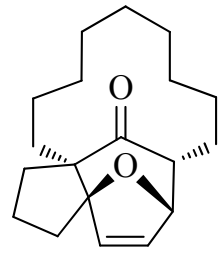

7

\section{Scheme 1}

Cyclododecanone is also an important intermediate for synthesis of natural muscone $\mathbf{8}$ and macrocyclic fragrances of musk like odor e.g. (S)-muscolides: $\mathbf{9}$ and $\mathbf{1 0}$ as well as $(R)-12$ methyltridecanolide 11. ${ }^{6-10}$ In addition, it is also a starting material used for synthesis of the 
expensive compounds having the greatly appreciated woody-amber odor, ${ }^{11}$ such as Hydroxyambran ${ }^{\circledR} \mathbf{1 2},{ }^{12}$ and Lignoxan ${ }^{\circledR} \mathbf{1 3},{ }^{13}$ (Scheme 2).

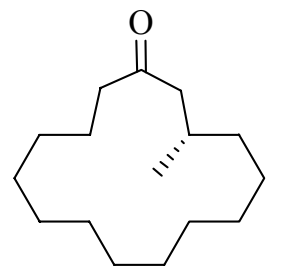

(S)-muscone (8)

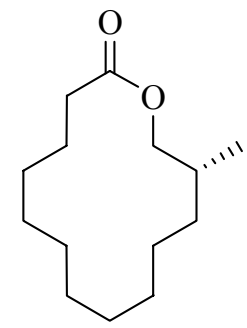

(R)-12-methyltridecanolide (11)

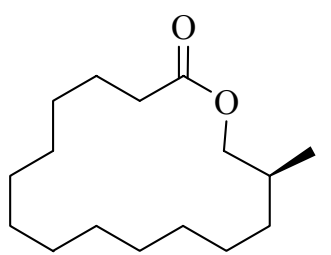

(S)-muscolide (9)<smiles>CC(CO)C1CCCCCCCCCCC1</smiles>

Hydroxyambran ${ }^{\circledR}$ (12)<smiles>C[C@H]1CCCCCCCCCCCOC(=O)CC1</smiles>

(S)-muscolide (10)<smiles>CC1CC2CCCCCCCCCCC2O1</smiles>

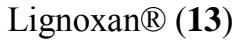

\section{Scheme 2}

Besides, it is served as a precursor for preparation of 1,1-dihydroperoxy-cyclododecane (DOD) $\mathbf{1 4}$ which in turn used as starting material for synthesis of a series of antimalarial agents such as $\mathbf{1 5}$ and 16 (Scheme 3). ${ }^{14-18}$

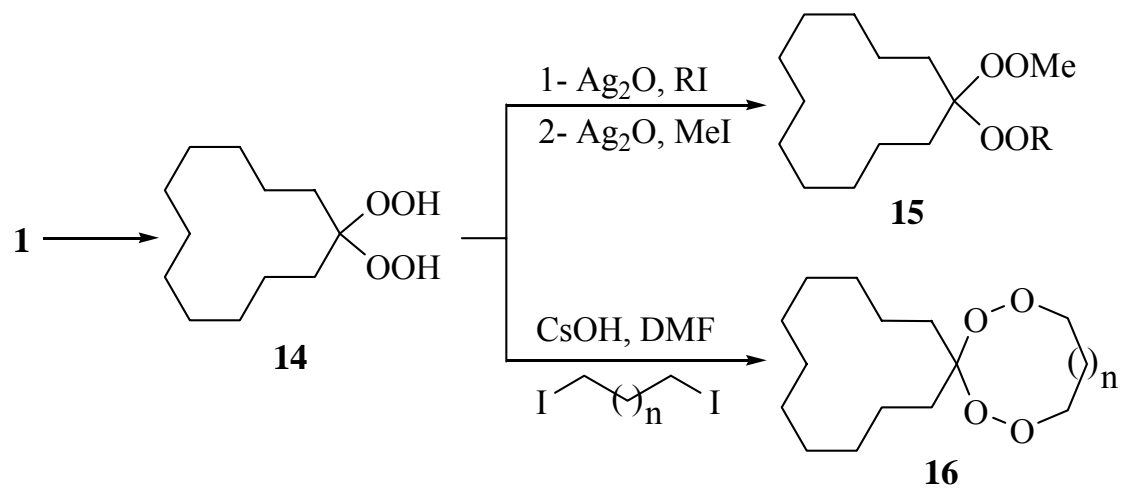

\section{Scheme 3}

1,1-Dihydroperoxy-cyclododecane (DOD) $\mathbf{1 4}$ is also proved to be a useful oxidizer applied in polynucleotide synthesis. ${ }^{19}$ 

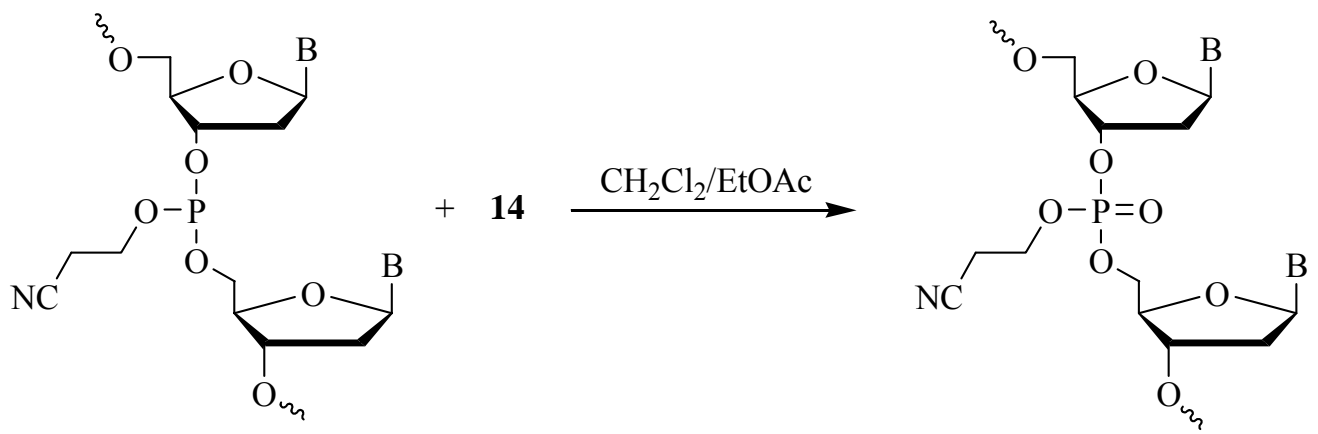

Once more, Beckmann rearrangement of cyclododecanone oxime $\mathbf{1 7}$ into laurolactam 18 is a highly important industrial process, where ring opening polymerization of lactam 18 is used industrially for production of Nylon and its copolymers (Scheme 4). ${ }^{20}$

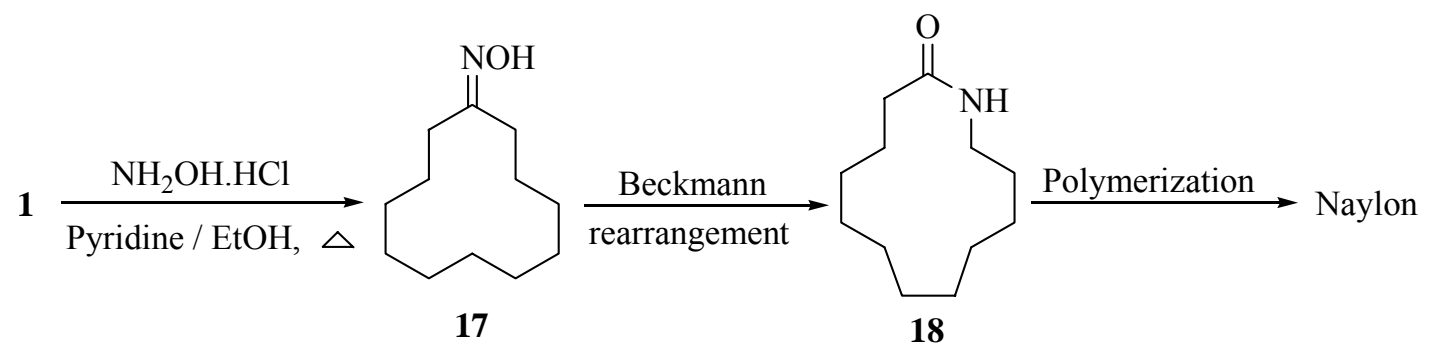

\section{Scheme 4}

\section{Synthesis of Cyclododecanone (1)}

Generally speaking, the twelve-membered ring is easily assembled through cyclotrimerization of butadiene 19. Butadiene cyclotrimerization process is performed in presence of various catalytic systems comprised transition metal compounds: $\mathrm{Ti}, \mathrm{Cr}, \mathrm{Ni}, \mathrm{Mn}$ and organic compounds of aluminium. $^{21-24}$ The butadiene cyclotrimerization product 1,5,9-cyclododecatriene 20 is the key intermediate for production of various twelve-membered ring systems belonging to different classes of organic compounds. In this context, 1,5,9-cyclododecatriene is easily converted into $\mathbf{1}$ in several ways (Scheme 5). ${ }^{25-35}$ 


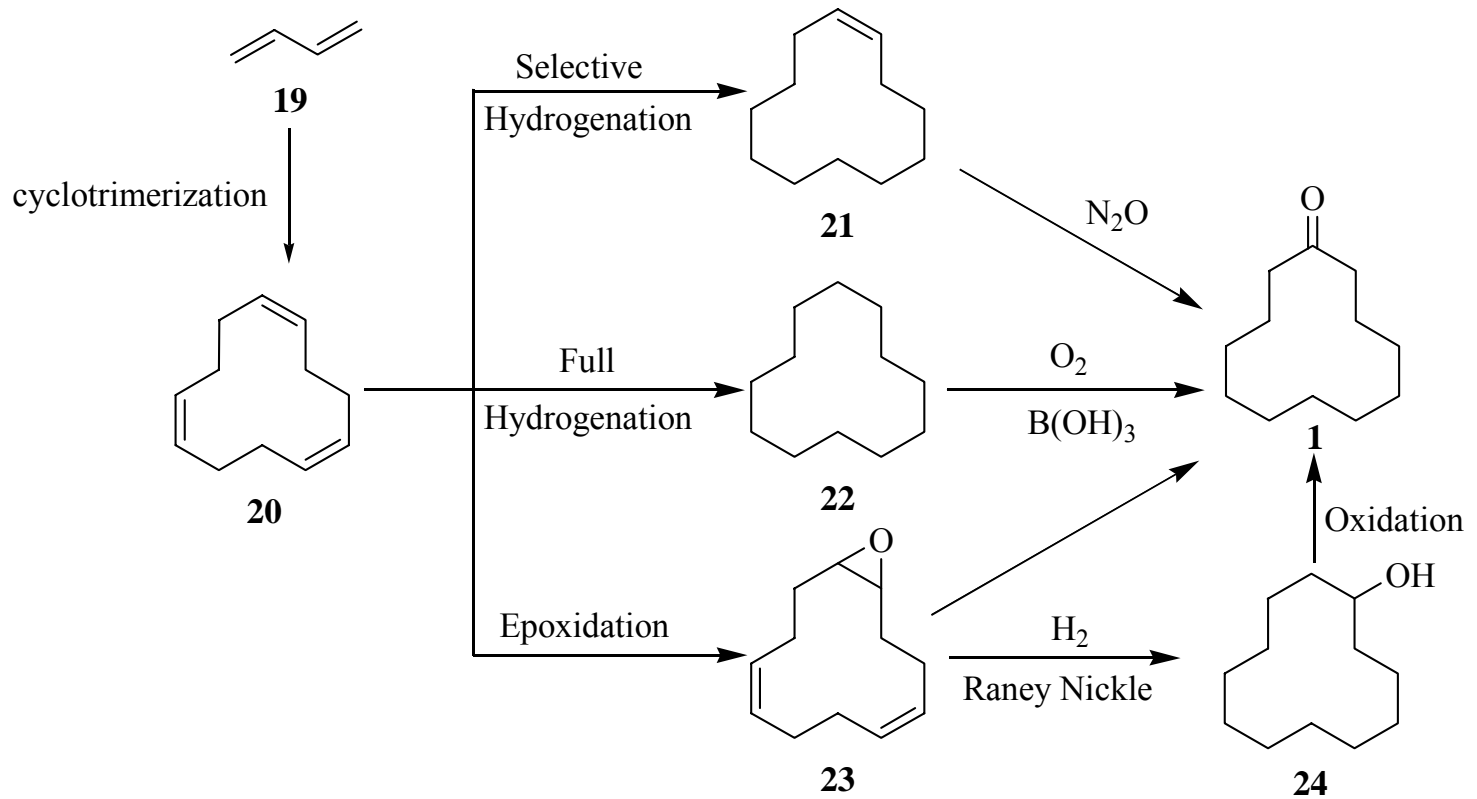

\section{Scheme 5}

\section{Chemistry of Cyclododecanone}

\subsection{Halogenation}

2-Bromocyclododecanone 25 can be obtained almost in quantitative yield by using $N$ bromosuccinimide (NBS) under photochemical conditions. ${ }^{36}$ Bromoketone 25 is also prepared in an excellent yield using $\mathrm{CuBr}_{2}$ in a mixture of chloroform and ethyl acetate under stream of nitrogen gas. ${ }^{37}$ On the other hand, $\mathbf{1}$ can be regenerated by debromination of $\mathbf{2 5}$ through dithionite reduction of the pyridinium salt 26 (Scheme 6). ${ }^{38}$

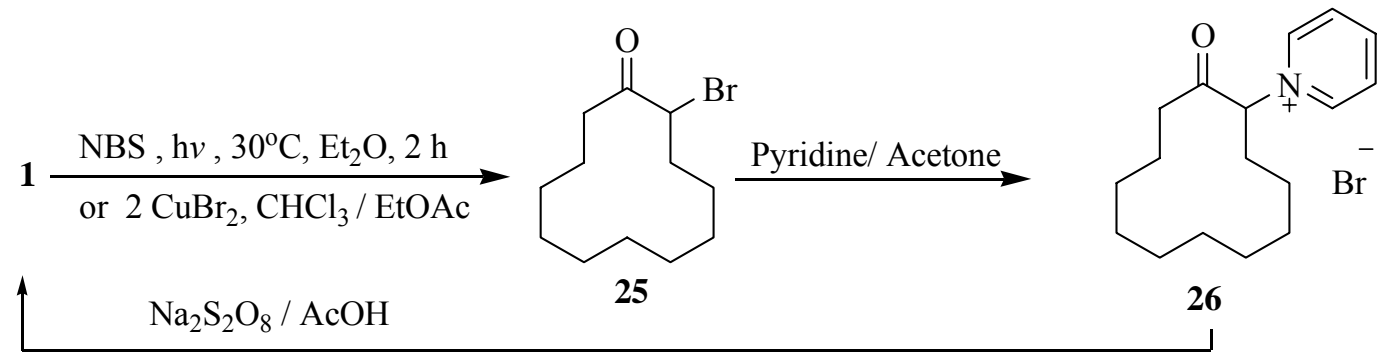

\section{Scheme 6}

Selective $\alpha$-iodination of $\mathbf{1}$ was accomplished in the solid state within a very short reaction time with excellent yield using elemental iodine and oxone as a catalyst, by grinding in a mortar to afford 27. ${ }^{39}$ Iodoketone $\mathbf{2 7}$ is also prepared efficiently using elemental Iodine and hydrogen peroxide. ${ }^{40,41}$ 
While, $\alpha$-chlorocyclododecanone $\mathbf{2 8}$ was achieved in very good yield via treatment of cyclododecanone 1 with LDA followed by $p$-toluenesulfonyl chloride. ${ }^{42}$

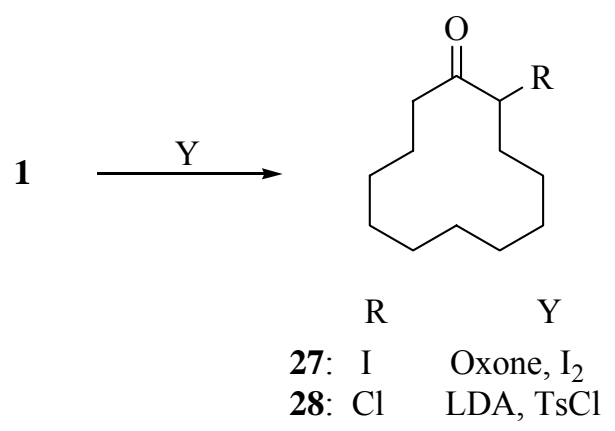

\subsection{Oxidation}

Cyclododecanone 1 was efficiently converted into the corresponding gem-dihydroperoxide 14 in high yield within a short period of time on treatment with aqueous $\mathrm{H}_{2} \mathrm{O}_{2}$ in the presence of catalytic amount of CAN in acetonitrile at room temperature. ${ }^{43-45}$ While, treatment of $\mathbf{1}$ with $\mathrm{H}_{2} \mathrm{O}_{2}$ in fluorinated alcohol (HFIP) afforded the corresponding anti-malarial agent tetraoxane derivative 29 in $55 \%$ yield (Scheme 7). ${ }^{46}$

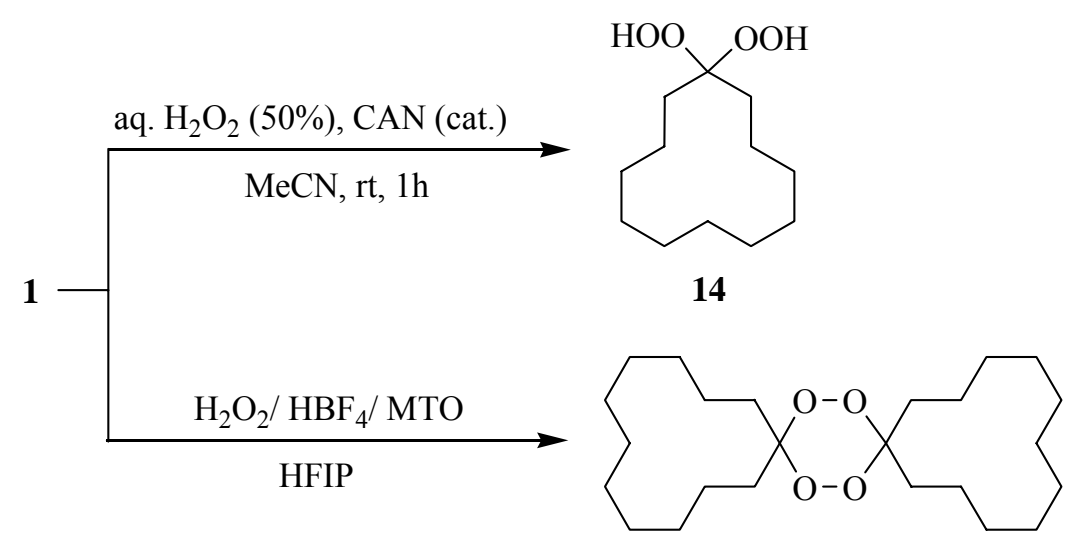

29

\section{Scheme 7}

The industrially important 1,12-dodecanedioic acid 31 is the major oxidation product of cyclododecanone dimethyl acetal $\mathbf{3 0}$ by in situ generated performic acid, besides the minor products 32 and $33 .{ }^{47}$ 


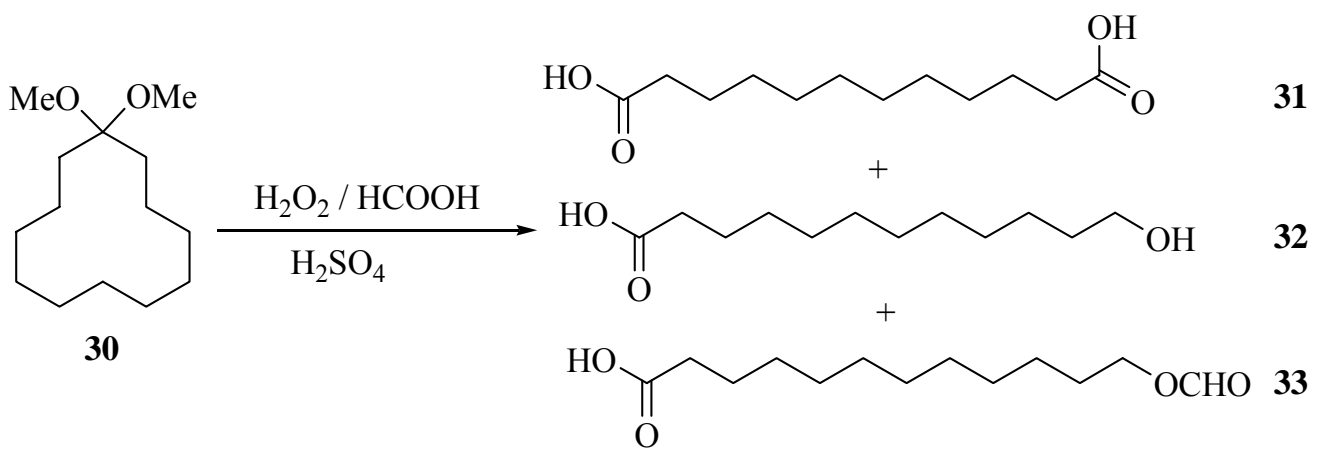

While Gauthard et al. reported that 1,12-dodecanedioic acid 31 can be obtained by air oxidation of $\mathbf{1}$ in presence of metal-free and platinum loaded carbon catalysts. ${ }^{48}$ Alternatively, the diacid $\mathbf{3 1}$ is also obtained in $86 \%$ yield by oxidation of cyclododecanone 1 in presence of rhenium carbonyl and polyethylene glycol as phase transfer catalyst. ${ }^{49}$ In addition, the dibutyl ester of $\mathbf{3 1}$ was achieved by oxidation of $\mathbf{1}$ with hydrogen peroxide in butanol. ${ }^{50}$

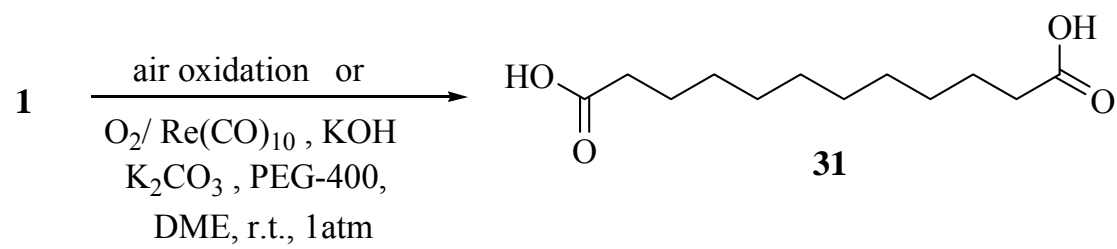

Alternatively, 11-cyanoundecanoic acid 34 was obtained by reaction of $\mathbf{1}$ with sodium pentacano nitrosyl ferrate(II) (NP) under basic conditions to give a colored complex which underwent acid hydrolysis to give $34 .{ }^{51}$

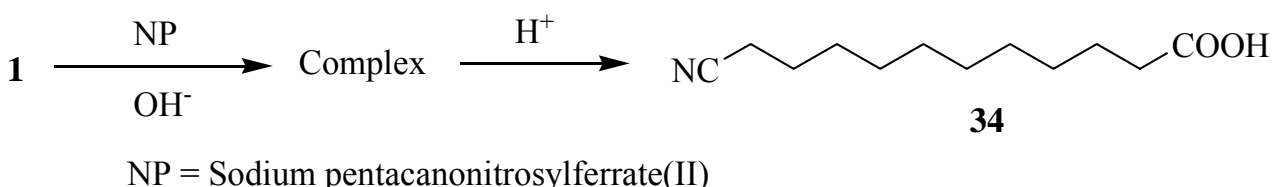

1,2-Cyclododecanedione 38 was achieved in a good yield, ${ }^{52-54}$ by a variety of oxidation methodologies (Scheme 5): (a) by treatment of 1 with excess sodium nitrite and aq. $\mathrm{HCl}^{55}$ (b) through treatment of 2-hydroxycyclododecanone 35 with either $\mathrm{DMSO} / \mathrm{CF}_{3} \mathrm{COOH}$ at $-78{ }^{\circ} \mathrm{C}$ or $\mathrm{Cu}(\mathrm{OAc}) / \mathrm{AcOH}$, (c) when 2-bromo-cyclododecanone 25 is oxidized using DMSO in presence of $\mathrm{KI} / \mathrm{K}_{2} \mathrm{CO}_{3}$. Moreover, 38 was also obtained through chemical or photochemical oxidation of 2(methylthio)cyclododecanone $\mathbf{3 6},{ }^{56}$ and 2 -((dimethylamino)methylene)cyclododecanone $37,{ }^{57}$ respectively (Scheme 8). 


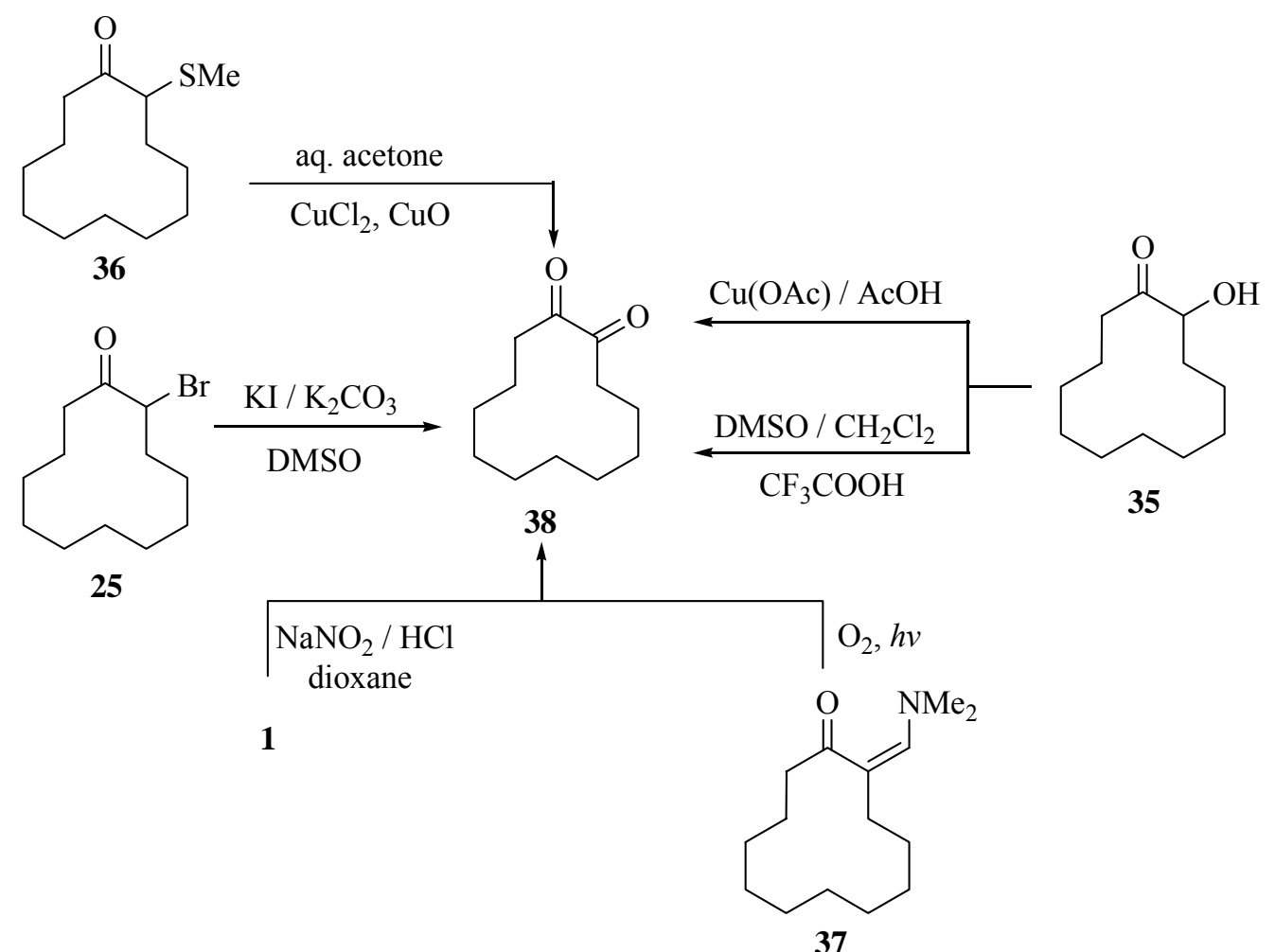

\section{Scheme 8}

Altohyrtin C 39 was found to be exceedingly potent against human colon (HCT116) and ovarian (A2780) cell lines. ${ }^{58}$

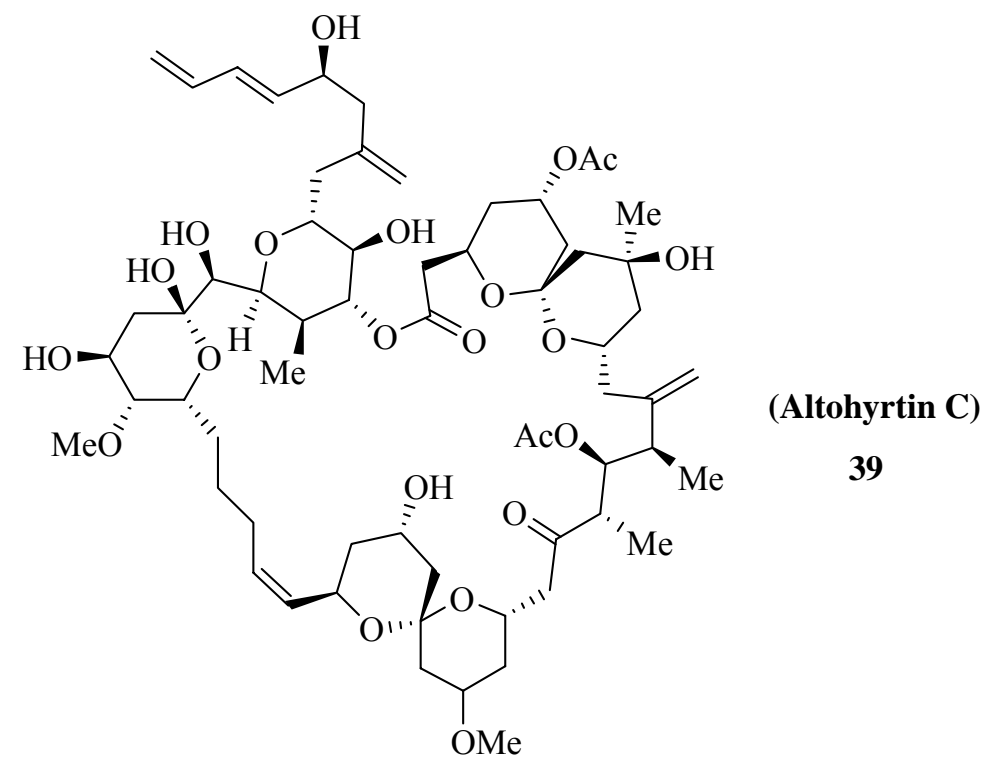

Cyclododecanone $\mathbf{1}$ is the source of $\mathbf{4 0}$ which is a main building block in the total synthesis of Altohyrtin C analogue 44 (Scheme 9). ${ }^{58}$ 


$$
1 \underset{2-\mathrm{O}_{3}, \mathrm{MeOH}, \mathrm{CH}_{2} \mathrm{Cl}_{2}}{\stackrel{1-\mathrm{TIPSCl}, \mathrm{NaI}, \mathrm{Et}_{3} \mathrm{~N}, \mathrm{MeCN}}{3-\mathrm{Me}_{2} \mathrm{~S}}}
$$

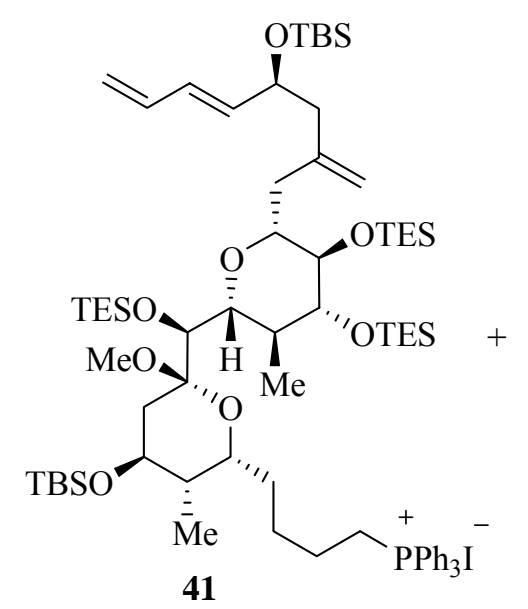

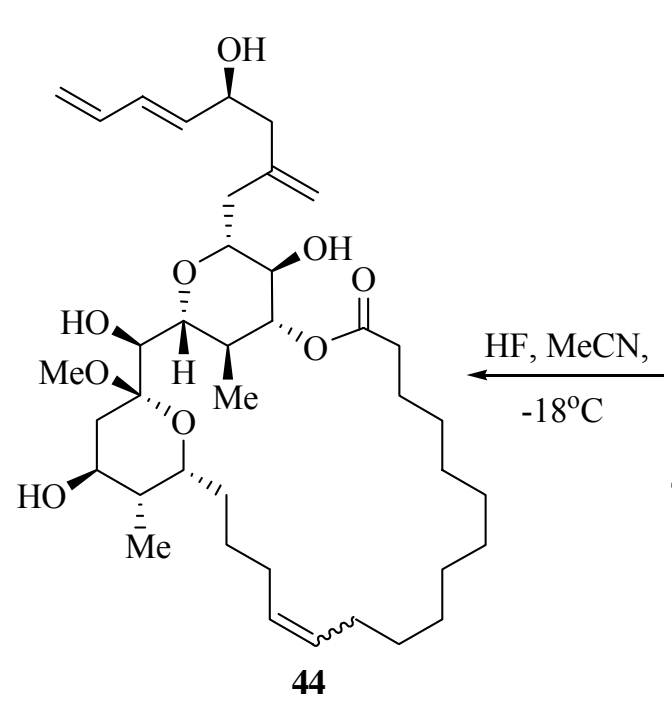

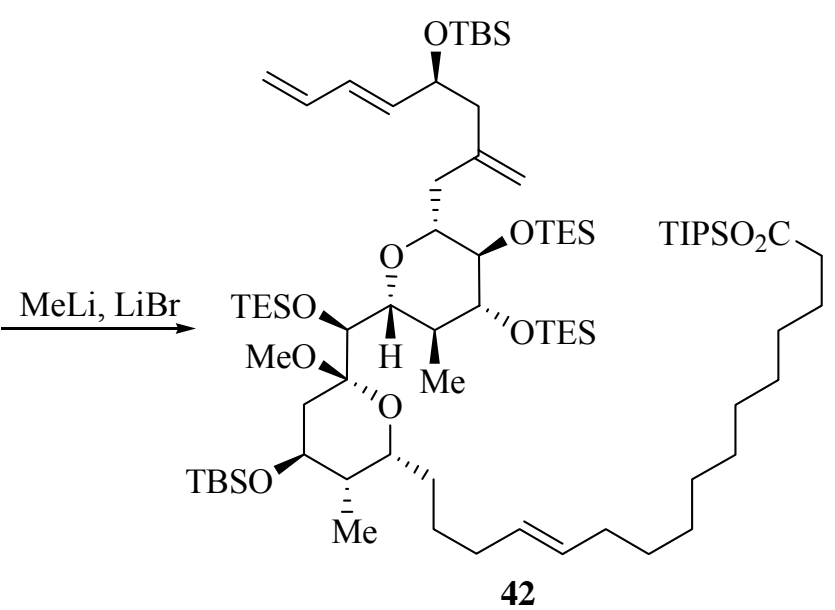

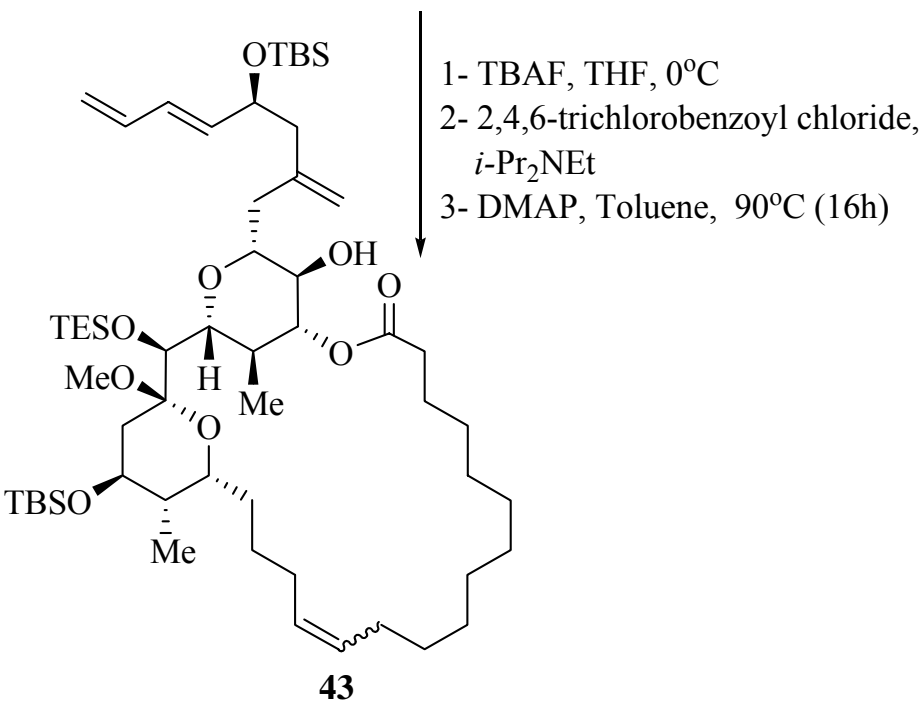

\section{Scheme 9}

\subsection{Alkylation of cyclododecanone}

Cyclododecanone $\mathbf{1}$ easily undergoes alkylation on its $\alpha$-carbon under phase-transfer catalysis (PTC). $\beta$-Halopropionic aldehyde acetals 45a, b react readily with 1 to give the respective 2-(3oxopropyl) cyclododecanone acetals 46a, b. Acid hydrolysis of acetals 46 resulted in formation of 12-hydroxybicyclo[9.3.1]pentadecan-15-one 48 probably formed due to intramolecular aldol condensation of ketoaldehyde 47. ${ }^{59}$ 3-(2-Oxocyclododecyl)propionic acid and its esters are interesting starting materials for the synthesis of valuable aromatic substances such as decamethylene-8-valerolactone, ${ }^{60}$ pentadecanolide (exaltolide), ${ }^{61}$ and cyclopentadecanone (exaltone), ${ }^{62}$ as well as macrocyclic ketoimides and $\mathrm{N}$-acetylketolactams. ${ }^{63}$ Accordingly, $\omega$ - $(2$ - 
oxocyclododecyl)alkanoic acids 49-51 were prepared based on alkylation of 1 with alkyl $\omega$ haloalkanoates under conditions of phase-transfer catalysis (PTC) in a solid alkali-liquid system in the presence of crown-ethers (Scheme 14) ${ }^{64}$ In addition, $\mathbf{1}$ is readily alkylated with benzyl halides $\left(\mathrm{ArCH}_{2} \mathrm{X}\right)$ to give 2-benzylcyclododecanones 52a-c under conditions of phase transfer catalysis. Then, polyphosphoric acid promotes cyclization of 2-benzylcyclododecanones 52a,b into 1,2,3,4,5,6,7,8,9,10-decahydrocyclododeca[ $b]$ indenes 53a,b. While, 52a reacted with $\mathrm{NOCl}$ to give 12-hydroxyimino-2-benzylcyclododecanone 54, which enters the Beckmann rearrangement followed by hydrolysis to afford 2-benzyl-1,12-dodecandioic acid $55 .{ }^{65}$ 2-Alkylcyclododecanones are starting compounds for the preparation of higher normal carboxylic and ketocarboxylic acids and alcohols. Unlike simple aliphatic ketones and lower cycloalkanones, $\mathbf{1}$ is smoothly alkylated by $n$-alkyl halides under phase-transfer catalysis conditions in the presence of solid potassium or sodium hydroxide in a medium of hydrocarbons with the formation of 2-alkylcyclododecanones $\mathbf{5 6}$ in high yield (75-85\%) (Scheme 10). ${ }^{66}$

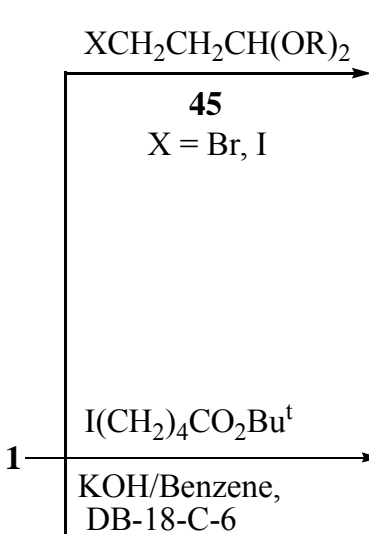

DB-18-C-6

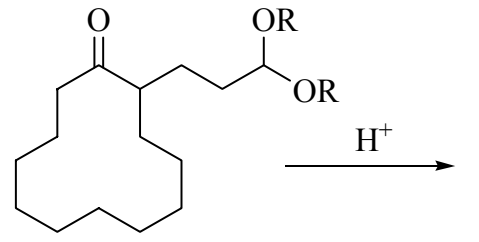

46a: $\mathrm{R}=\mathrm{Et}$ 46b: $\mathrm{R}=-\left(\mathrm{CH}_{2}\right)_{2}-$

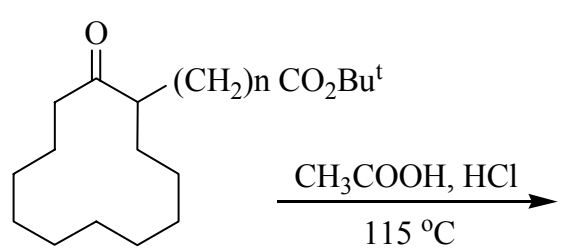

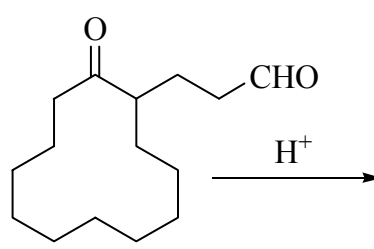

47<smiles>O=C1CCC2CCCCCCCCC1C2O</smiles>

48

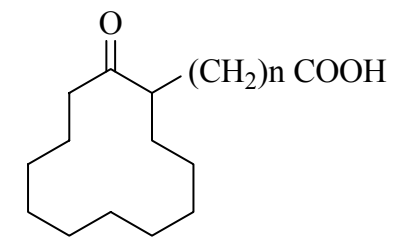

49, $\mathrm{n}=2$

50, $\mathrm{n}=4$

$\mathbf{5 1}, \mathrm{n}=10$

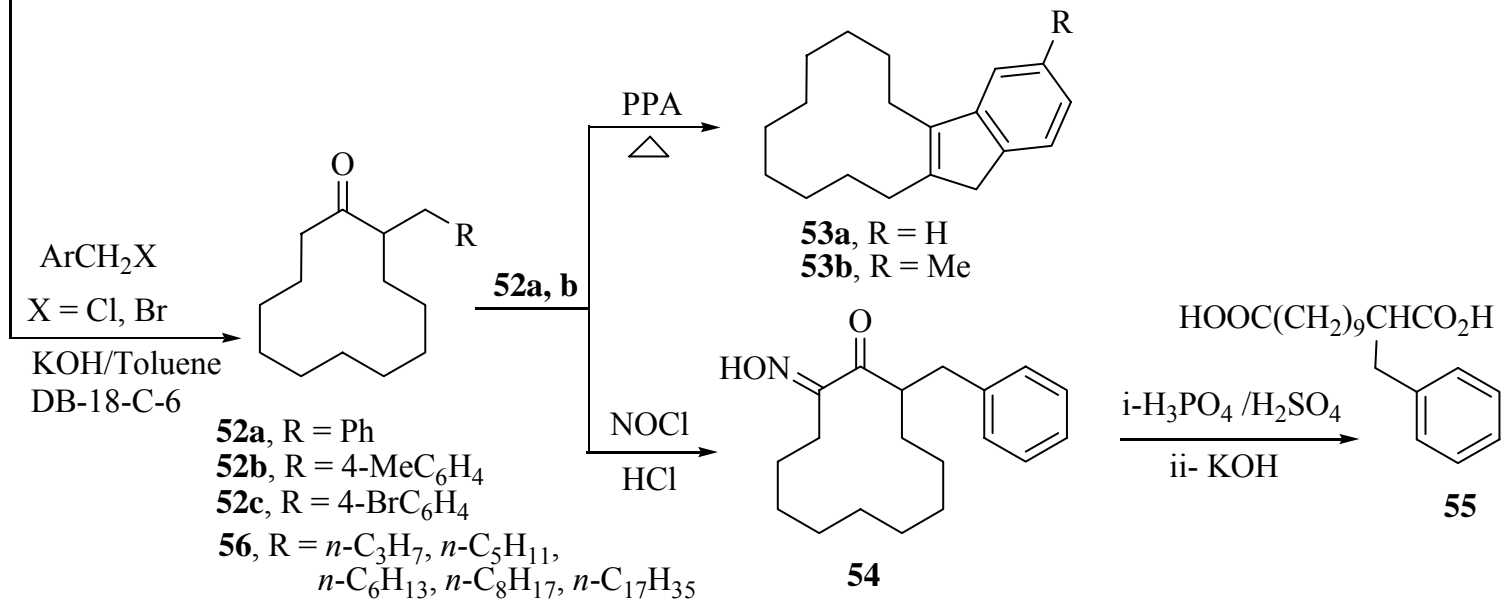

\section{Scheme 10}


Bicyclic ketones obtained from cyclododecanone, such as, bicycle[9.3.1]pentadecan-15-one and bicyclo[9.4.1]hexadecan-16-one, are highly important starting materials for syntheses of metacyclophanes ${ }^{67,68}$ and macrocyclic ketones, viz, cyclopentadecanone and muscone. ${ }^{69}$ Alkylation of 1 with $\alpha, \omega$-dibromoalkanes under conditions of phase-transfer catalysis (PTC) was investigated in the aim of obtaining bicyclic ketones. ${ }^{70}$ Thus, reaction of 1,3-dibromopropane with $\mathbf{1}$ in toluene at $80-100{ }^{\circ} \mathrm{C}$ in presence of $\mathrm{KOH}$ and crown ether (DB-18-C-6) as phase-transfer catalyst afforded trans bicycle[9.3.1]pentadecan-15-one $\mathbf{5 7}$ and 2-allylcyclododecanone 58 in 3:2 ratio with 67\% total yield. Ketone $\mathbf{5 8}$ is formed as a mixture of cis- and trans-isomers if 2ethoxycarbonylcyclododecanone is used as the starting material. ${ }^{67}$

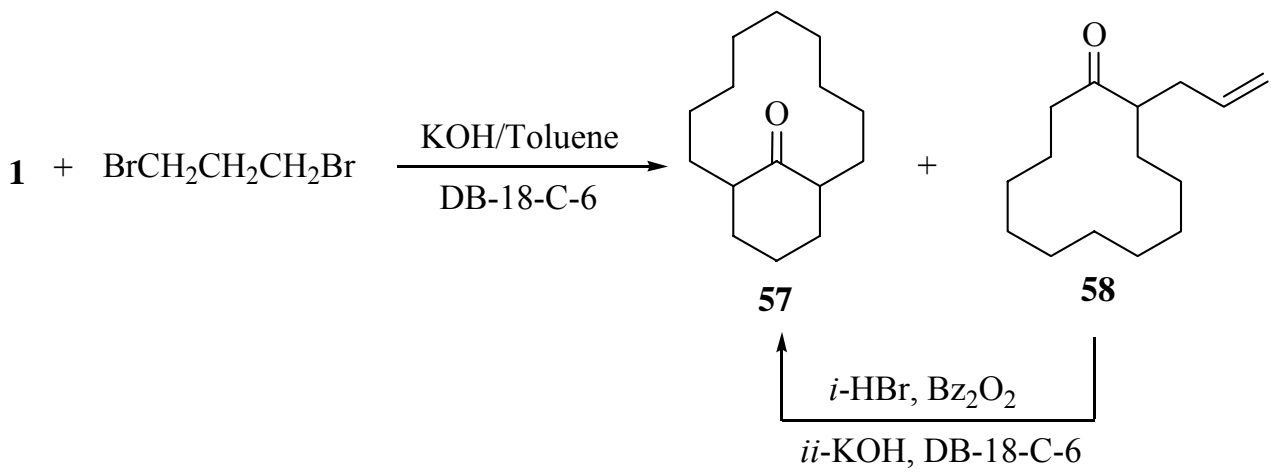

In the same manner, reaction of $\mathbf{1}$ with 1,4-dibromobutane 59 gives bicyclic ketone $\mathbf{6 1}$ and spirocyclic ketone $\mathbf{6 2}$ in 5:4 ratio in addition to small amount of 1,4-bis(2-oxocyclododecyl)butane 63 via cyclization of $\mathbf{6 0}$ (Scheme 11). ${ }^{70}$

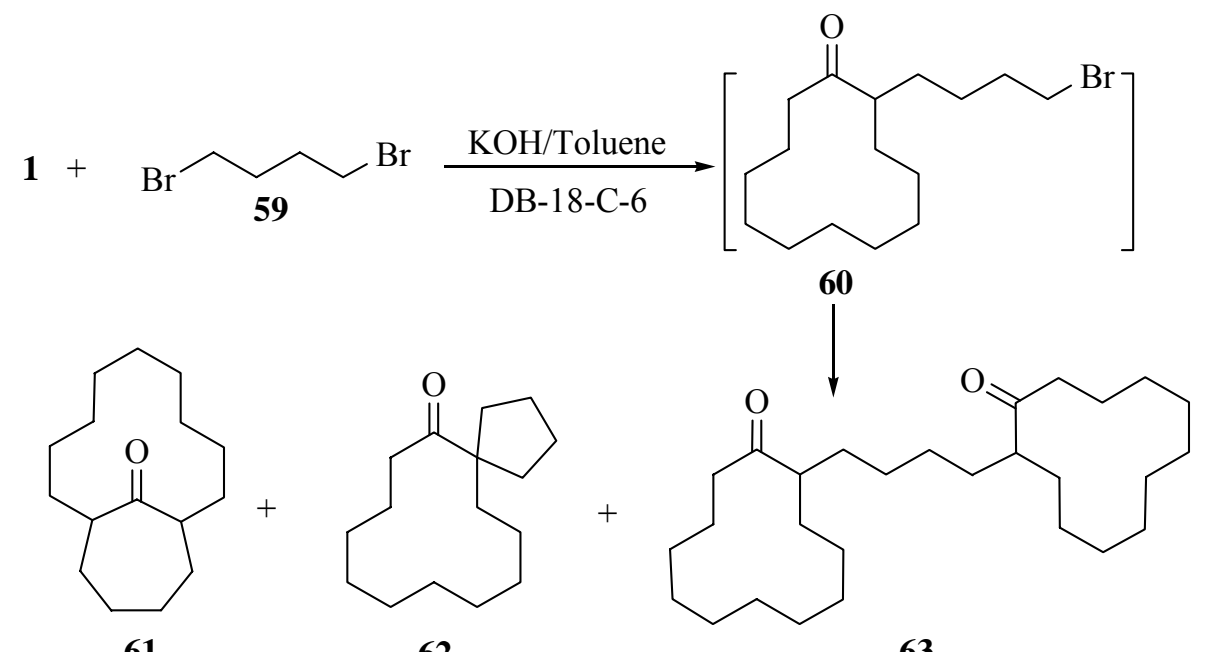

61

62

63

\section{Scheme 11}

While alkylation of 1 with 1,5-dibromopentane $\mathbf{6 4}$ under the same conditions followed by cyclization of intermediate 65 didn $t$ give the expected 7-oxospiro[5.11]heptadecane 66, but 
afforded bicyclo[9.5.1]hepta-decan-17-one 67 exclusively, the structure of which was established by ${ }^{13} \mathrm{C}$ NMR (Scheme 12). ${ }^{70}$

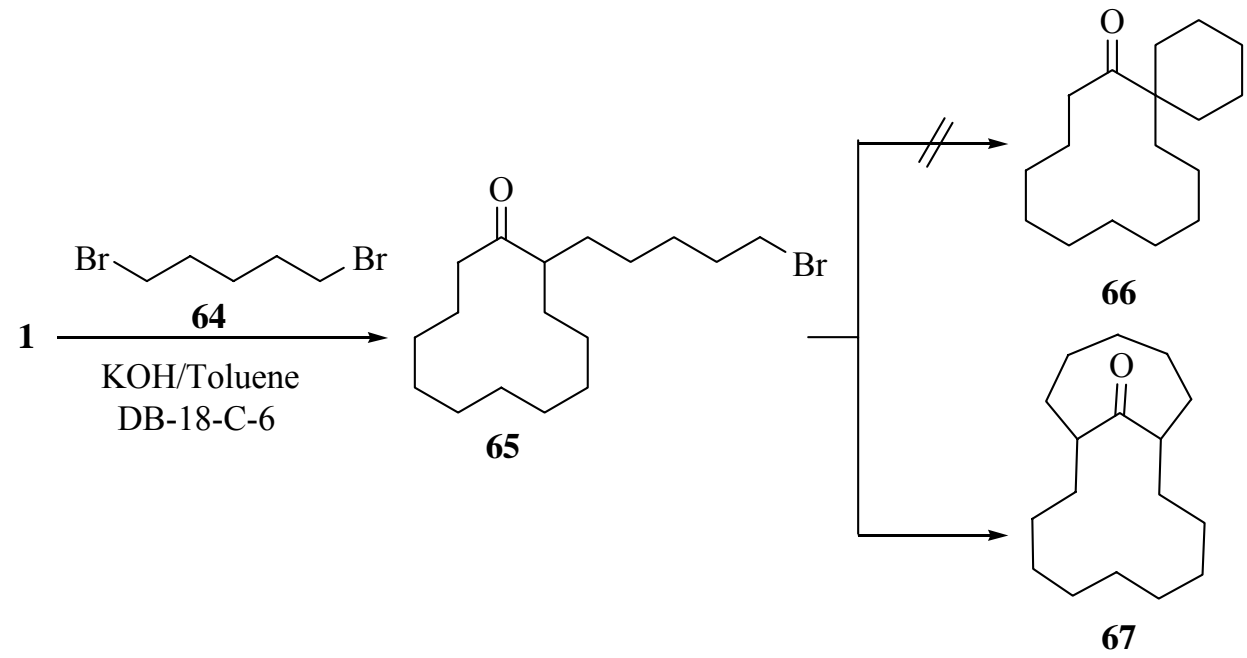

\section{Scheme 12}

The desired spirocyclic ketone $\mathbf{6 6}$ was alternatively achieved based on Diels-Alder reaction in a separate experiment (Scheme 13). ${ }^{70}$<smiles>C=C(CC)C(=O)CCCCCCCCCC</smiles>

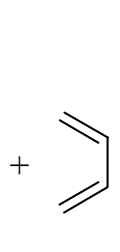

19

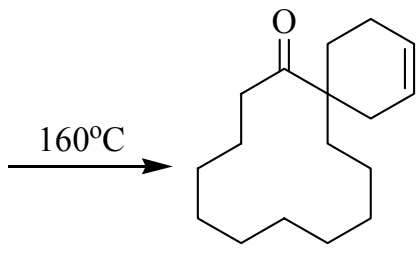

68

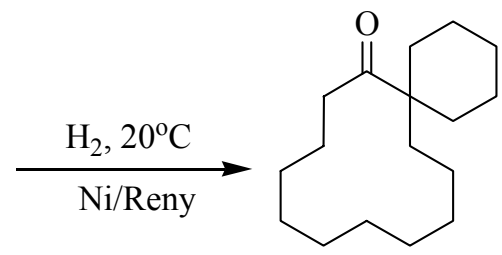

66

\section{Scheme 13}

Furthermore, interaction of $n-\mathrm{BuMgBr}$ and $n$-BuLi with 1 proceeds through three pathways (Scheme 14), ${ }^{71} i$. Addition to the carbonyl group to give the alcoholate of the tertiary alcohol (A). $i i$. Reduction of the ketone resulting in the alcoholate of cyclododecanol (B), and butene. iii. Deprotonation-enolization of the ketone with the formation of enolate $(\mathbf{C})$ and liberation of butane. Hydrolysis of intermediates A, B and C afforded 1-butylcyclododecanol 69, cyclododecanol 24, and the original ketone $\mathbf{1}$, respectively. 


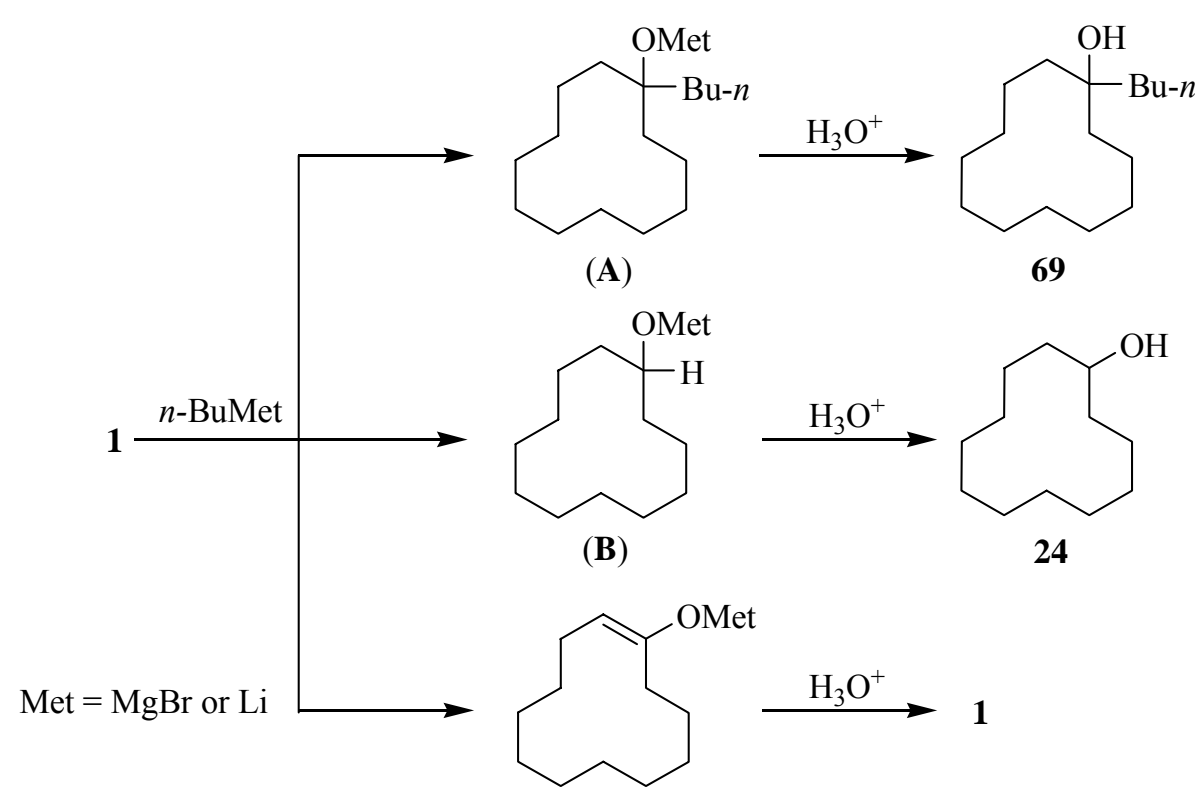

(C)

\section{Scheme 14}

Furthermore, dehydration of 69 gave a mixture of olefins, $(Z)$-1-butylcyclododec-1-ene 70, $(E)$ 1-butylcyclododec-1-ene $\mathbf{7 1}$ and butylidenecyclododecane $\mathbf{7 2 .}$

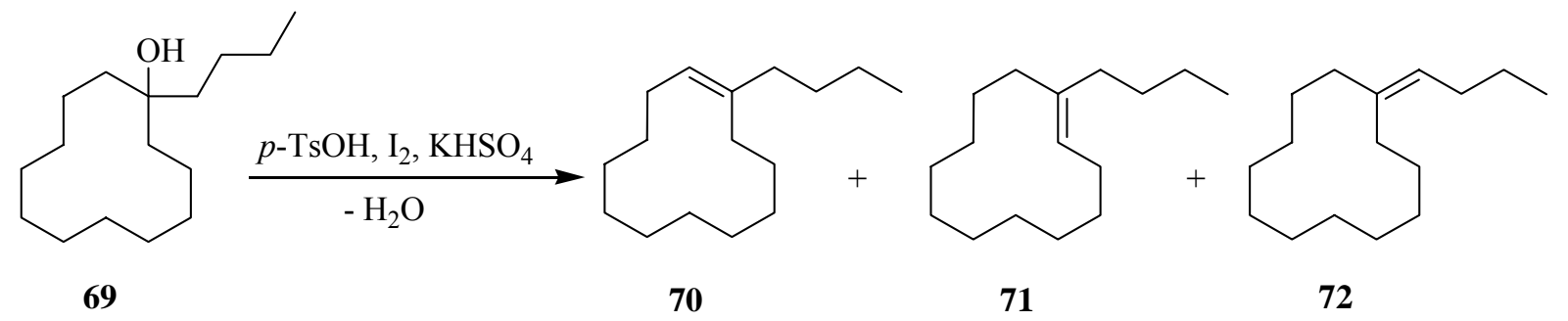

Acetylenic alcohols are widely used in organic synthesis owing to their high reactivity. In this context, 1-(3-hydroxy-3-methylbut-1-ynyl)-cyclododecanol 73 was prepared by the action of lithium (3-methyl-3-oxidobut-1-ynyl)lithium on 1. The product reacts with acetonitile under Ritter reaction conditions. Therewith, in the presence of 8 g-equivalent of sulfuric acid, a (2:1) mixture of $\mathrm{N}$-(1-(3-acetamido-3-methylbut-1-ynyl)-cyclododecyl)acetamide 74 and $\mathrm{N}$-(1-(3-acetamido-3methylbutanoyl)cyclododecyl)acetamide 75 is formed. Whereas, in the presence of 2 g-equivalent of the acid, a mixture of 74 and 1-acetylamino-1-(3-methyl-2-butenoyl)cyclododecanone 76 is formed (Scheme 15). ${ }^{72}$ 


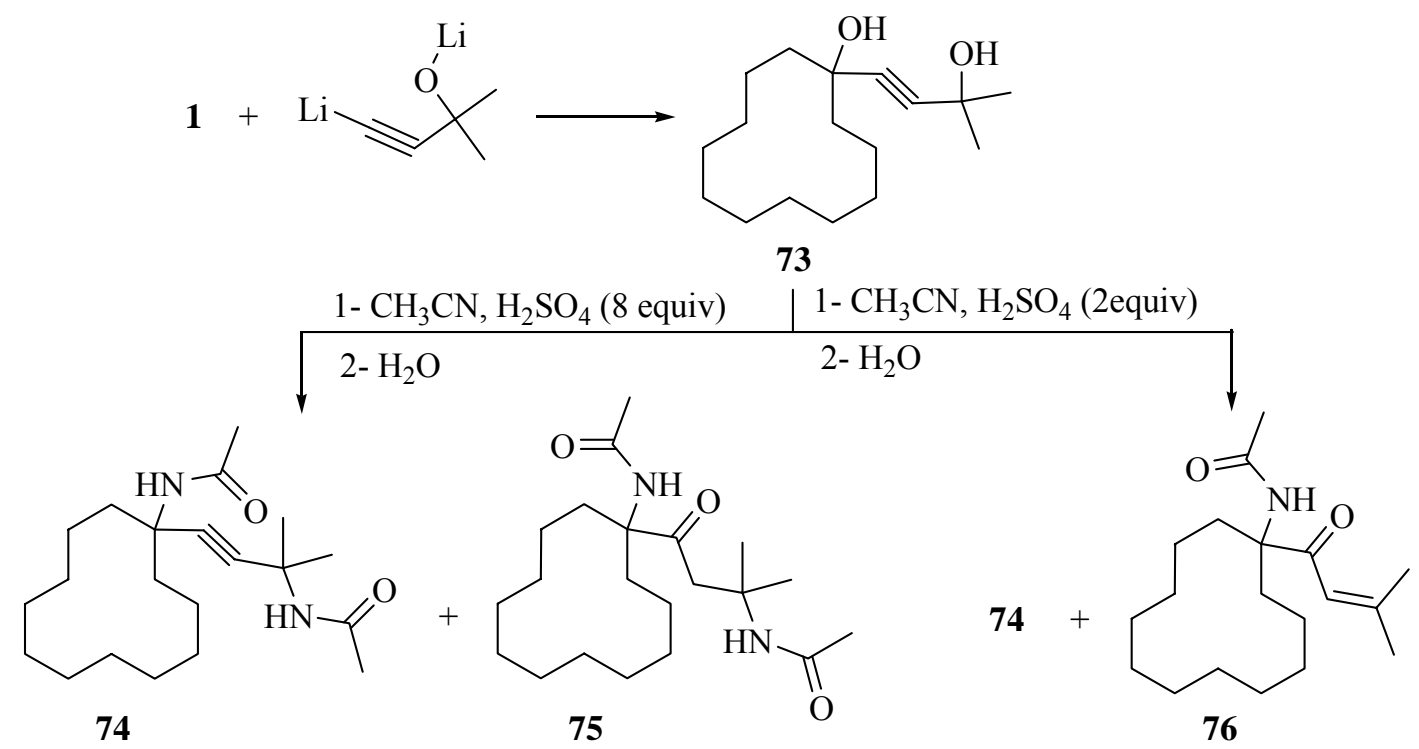

\section{Scheme 15}

In a similar manner, a series of peroxy containing tertiary acetylenic alcohols $\mathbf{7 9}$ were obtained through the intermediates $\mathbf{7 8}$ by reaction of lithium peroxyacetylides $\mathbf{7 7}$ with $\mathbf{1}^{73}$

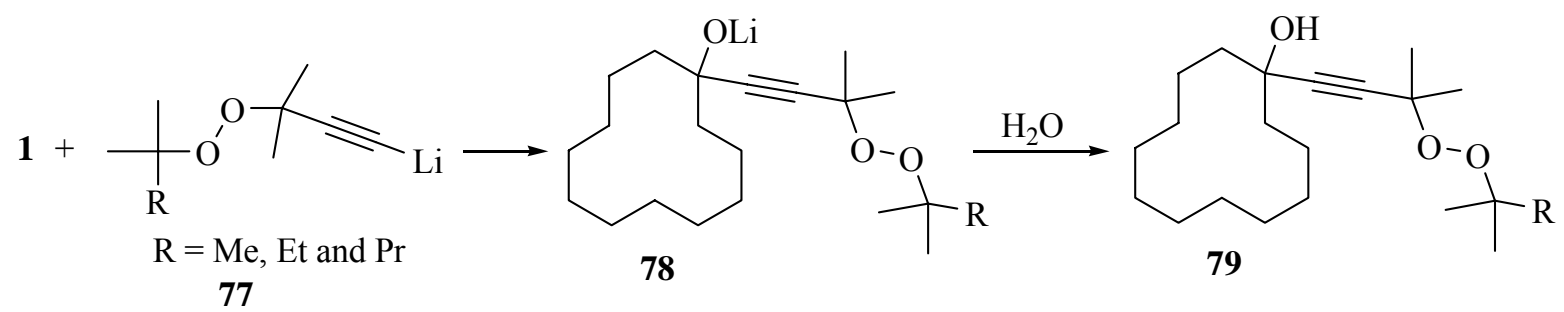

2-Acetonylcyclododecanone $\mathbf{8 2}$ is an important intermediate in the preparative synthesis of cyclopentadecanone (exaltone) and 3-methyl-cyclopenta-decanone (muscone) which are valuable fragrances. ${ }^{70}$ Cyclododecanone $\mathbf{1}$ is readily alkylated by propargyl bromide or chloride $\mathbf{8 0}$ under phase transfer catalysis conditions with solid $\mathrm{KOH}$, toluene, and dibenzo-18-crown-6 to give 2propargylcyclododecanone $\mathbf{8 1}$ in high yield. The hydration of ketone $\mathbf{8 1}$ provides a simple approach to 2-Acetonylcyclododecanone 82. Also, alkylation of $\mathbf{1}$ by 1,2-dichloropropene $\mathbf{8 3}$ under phase transfer catalysis conditions gave 2-(2-chloropropen-2-yl)cyclododecanone 84, which, upon hydrolysis in acetic acid in presence of $\mathrm{Hg}^{2+}$ ions and $\mathrm{BF}_{3} \cdot \mathrm{OEt}_{2}$ gave 2-acetonylcyclododecanone 82. ${ }^{74}$ Cyclododecanone 1 undergoes an allylation reaction with tetra-allyltin 85 in presence of a catalytic amount of $\mathrm{Cu}(\mathrm{OTf})_{2}$ to afford 1-allyl-cyclododecanol $\mathbf{8 7}$ in $98 \%$ yield. $^{75,76} 1$ Allylcyclododecanol 87 was alternatively obtained in $82 \%$ yield by reaction of $\mathbf{1}$ and allyl bromide 86 under the Influence of $\mathrm{CrCl}_{3} / \mathrm{NaBH}_{4}$ reagent (Scheme 16). ${ }^{77}$ 


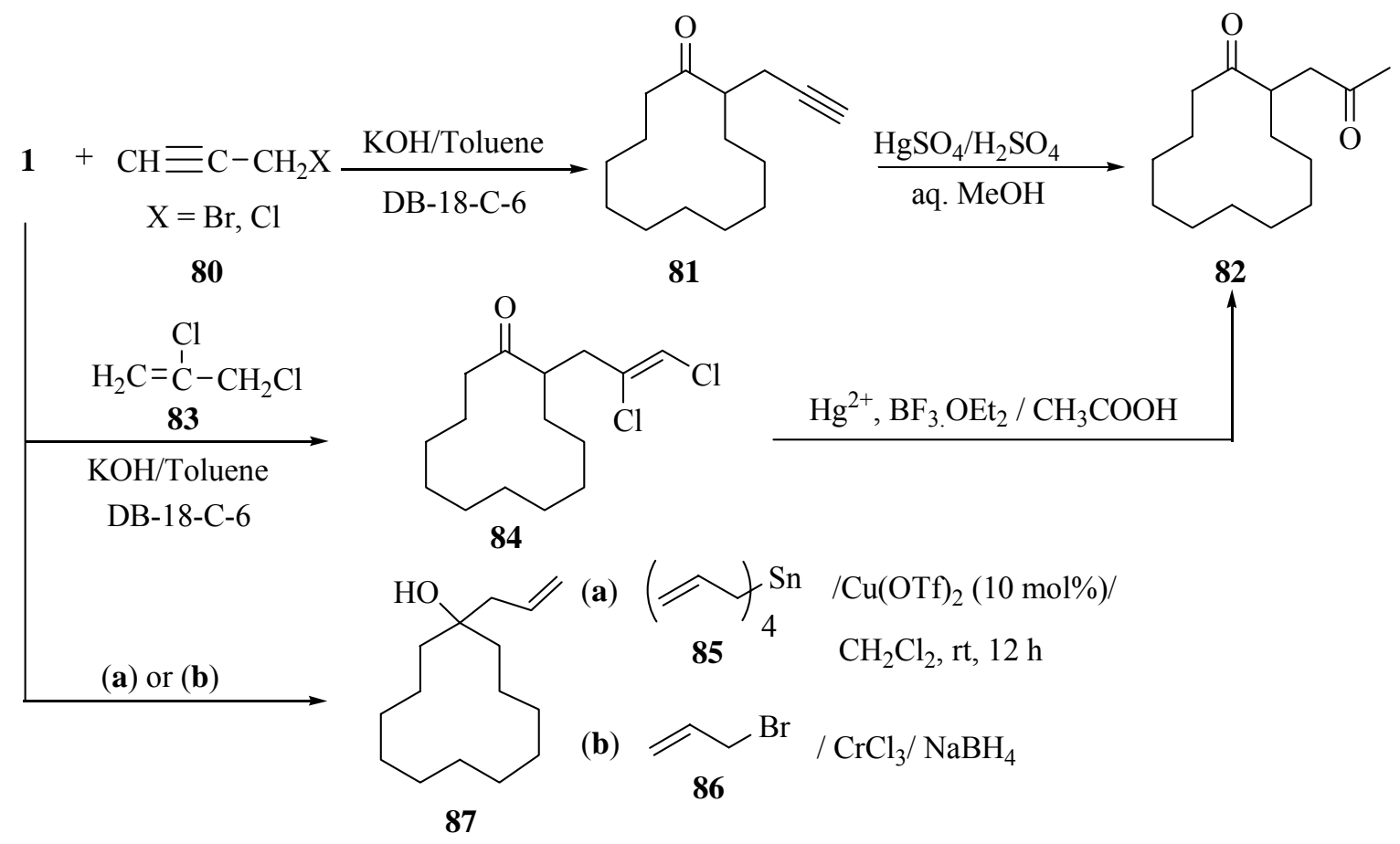

\section{Scheme 16}

Alkylation of 2-ethoxycarbonylcyclododecanone 88 with 1,3-dibromo-propane, followed by hydrolysis and decarboxylation, afforded the bicyclic ketone 49, which on bromination with pyridinium hydrobromide $\left(\mathrm{PyHBr}_{3}\right)$ and subsequent dehydrobromination gave the bicyclic enone 89. Dehydrogenative aromatization of $\mathbf{8 9}$ was accomplished by heating with sulfur to afford 15 hydroxy[9]metacyclophane 90. Analogously, 12-methyl substituted derivative 92 was obtained from the enone $\mathbf{9 1}$ by simple dehydrogenation with sulfur or $\mathrm{Pd} / \mathrm{C}$ (Scheme 17). ${ }^{78}$

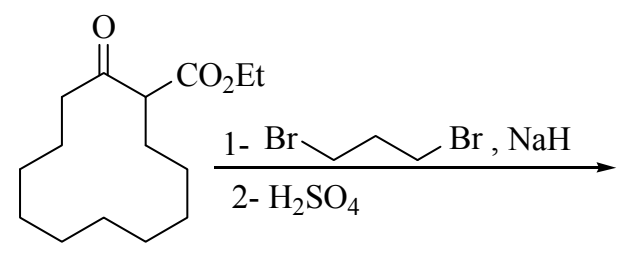

88<smiles>O=C1CCCC2CCCCCCCCCCC12</smiles>

49

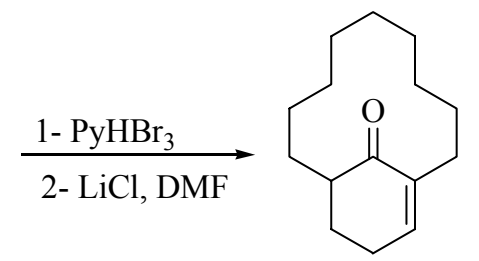

89

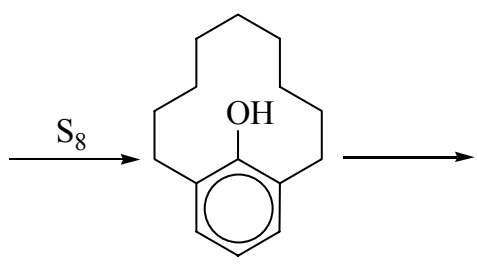

90<smiles>C=C1CC2CCCCCCCCCC(C1)C(=O)C2</smiles>

91

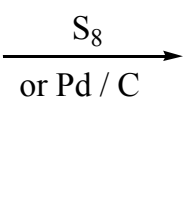<smiles>Cc1cc2c(O)c(c1)CCCCCCCC2</smiles>

92

\section{Scheme 17}


Treatment of 2-bromocyclododecanone $\mathbf{2 5}$ with zinc powder and methyl iodide in benzeneDMSO mixture yielded 2-methylcyclododecanone 93 quantitatively. Also, the reaction of 2bromocyclododecanone 25 with acetaldehyde and propionaldehyde under the same conditions afforded 2-(1-hydroxyethyl)cyclododecanone $\mathbf{9 4}$ and 2-(1-hydroxypropyl)cyclododecanone 95, respectively. Dehydration of the aldols 94 and 95 furnished 2-ethylidenecyclododecanone 96 and 2propylidenecyclododecanon $\mathbf{9 7}$, respectively (Scheme 18) ${ }^{79}$

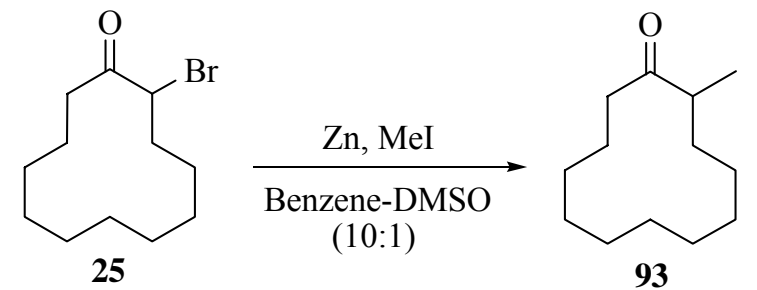

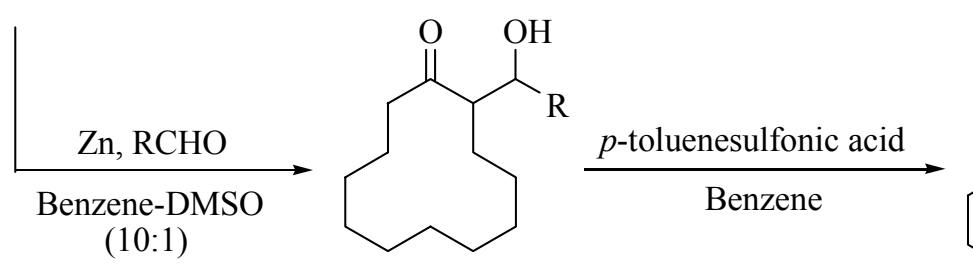

94: $\mathrm{R}=\mathrm{Me}$

95: $\mathrm{R}=\mathrm{Et}$<smiles></smiles>

96: $\mathrm{R}=\mathrm{Me}$ 97: $\mathrm{R}=\mathrm{Et}$

\section{Scheme 18}

Ynthesis of molecules having musk odor is a very attractive topic. Hence, Zakharkin et al. reported the synthesis of 2-alkylidene-and 2-alkylcyclododecanones which had a very delicate musk odor. In this context, $\mathbf{1}$ was treated with ethylformate in the presence of sodium methoxide to give 2-hydroxymethylene cyclododecanone $\mathbf{9 8}$ in a high yield. Its treatment with diethylamine yielded 2$\mathrm{N}$-diethylaminomethylenecyclododecanone 99. Treatment of $\mathbf{9 9}$ with alkyl magnesium halides afforded 2-alkylidenocyclododecanones $\mathbf{1 0 0}$ which upon catalytic hydrogenation gave 2alkylcyclododecanones 101 (Scheme 19). ${ }^{80}$

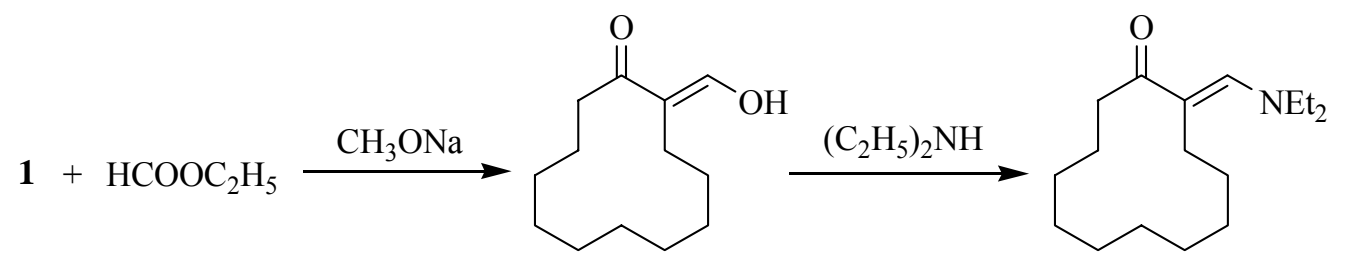

98

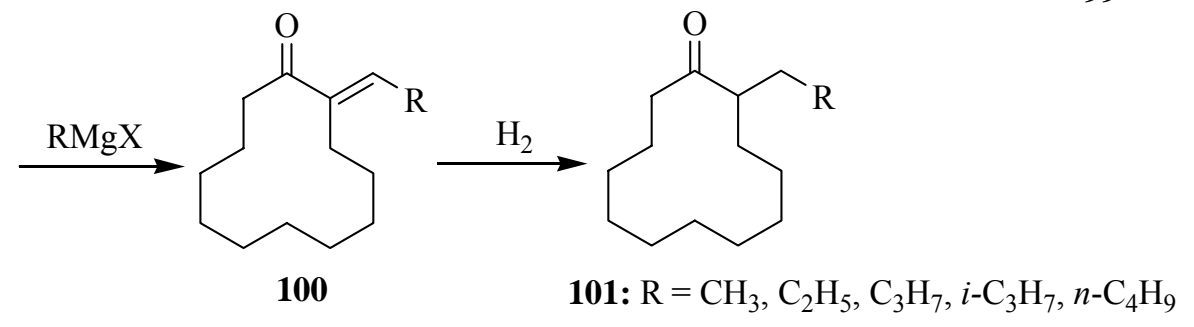

\section{Scheme 19}




\subsection{Mannich reaction}

A series of mono Mannich bases of cyclododecanones 102a-f were synthesized and their cytotoxicity was evaluated. Also, the double Mannich base 103 was synthesized for the same purpose (Scheme 20). ${ }^{81,82}$

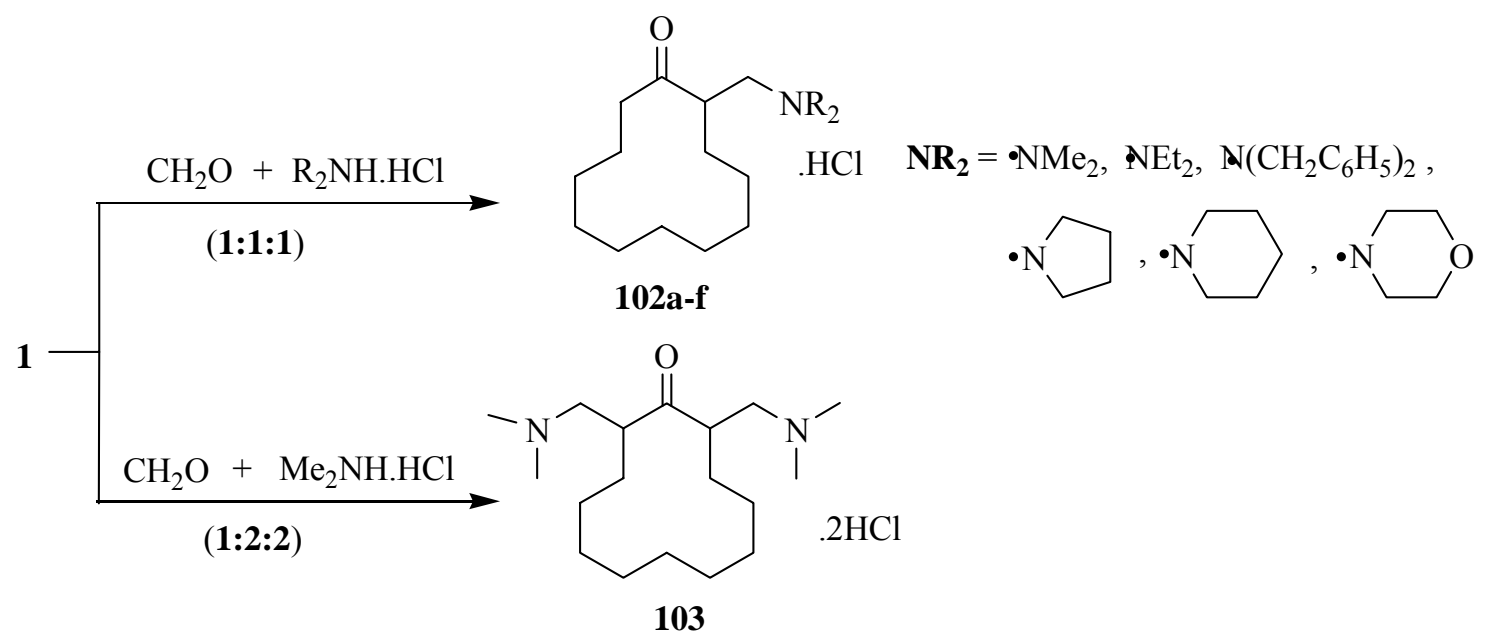

\section{Scheme 20}

In the same context, when 1 was heated under reflux for 2 days with aqueous ethanolic formaldehyde (2.0 mol equiv.) and methylamine (1.0 mol. equiv.) a complex products mixture was obtained. Consequently, three compounds were isolated from the basic fraction by column chromatography on silica-gel and crystallization. In addition to the expected azabicyclopentadecanone 104, there was found the bis-pidone, (the diazatricyclooctadecanone) 105. The major component isolated from the reaction mixture was the dihydropyridin-4-one 106 (20\%). Similar condensations carried out with shorter reaction times have allowed the isolation of the simpler bases 107 and 108 (Scheme 21). ${ }^{83}$

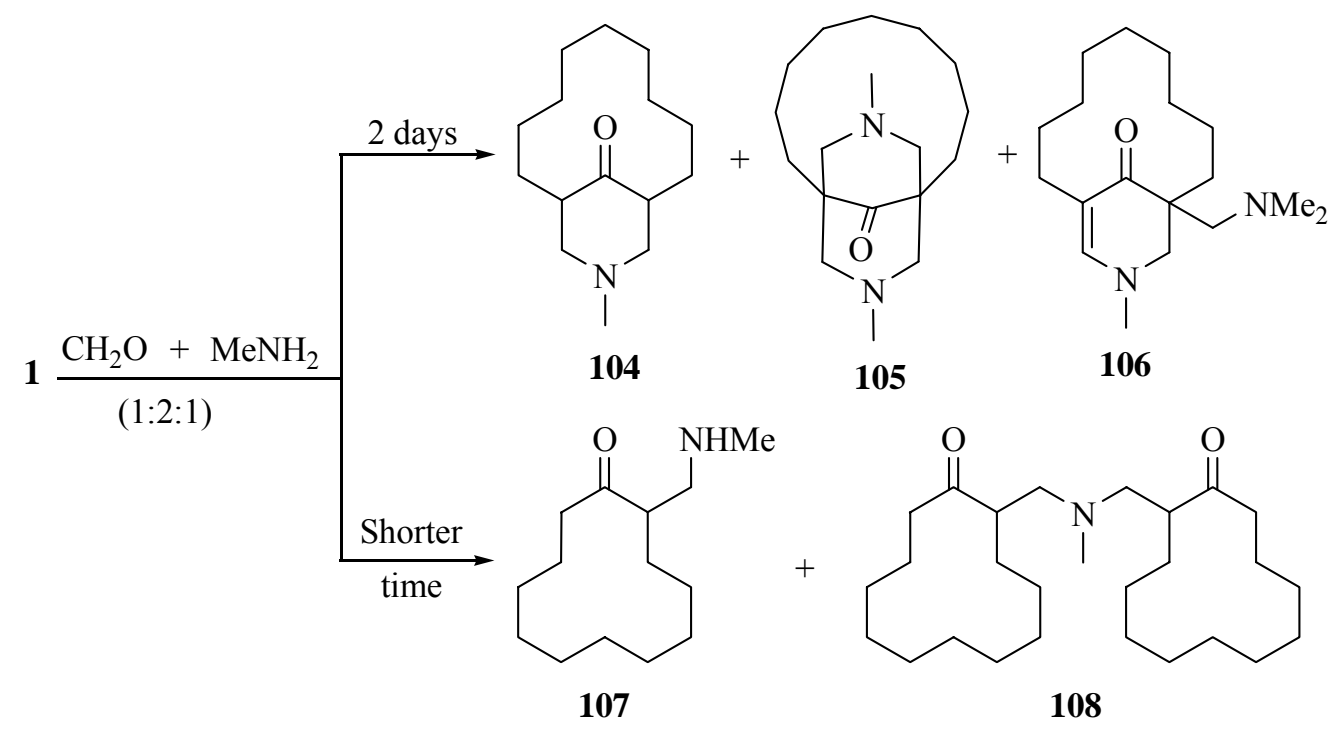

\section{Scheme 21}




\subsection{Ring enlargement}

3.5.1 Macrocyclic ketones and esters. Cyclododecanone 1 was transformed into its next higher ring homologue ${ }^{84}$ chlorinated at the $\alpha$-carbon $\mathbf{1 1 0}$ under the influence of (dichloromethyl)lithium 109 and butyl lithium. ${ }^{85}$
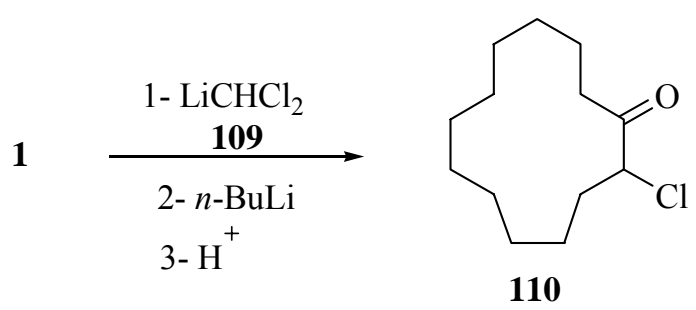

The proposed mechanism for transformation of $\mathbf{1}$ into 2-chlorocyclotridecanone $\mathbf{1 1 0}$ was illustrated by the following reaction sequences compounds 111-113 (Scheme 22).

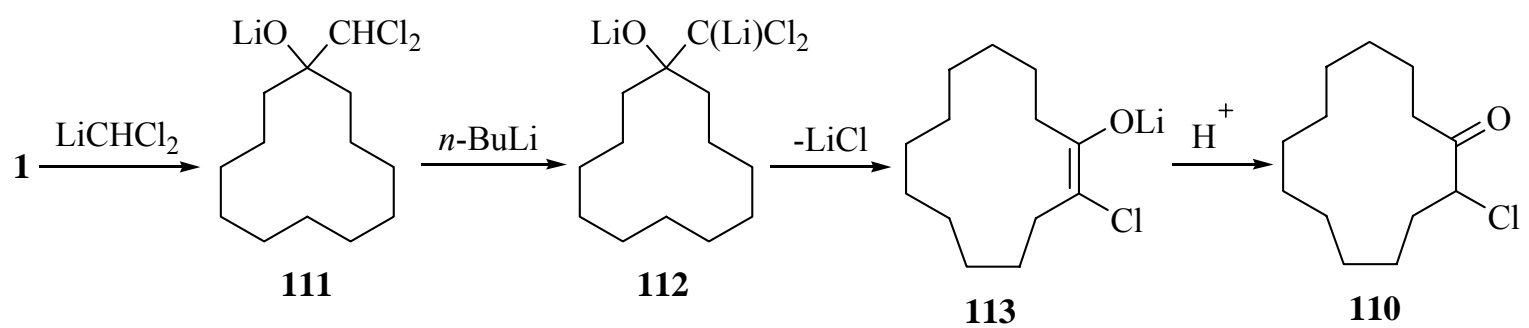

\section{Scheme 22}

Condensation of 2-(2,2-dimethoxyethyl)cyclododecanone 114 with 2-propenyllithium 115 at $78{ }^{\circ} \mathrm{C}$ gave the two epimeric alcohols 116 and silylated 117. Both alcohols are silylated to give $\mathbf{1 1 8}$ and 119, respectively. Prins-Pinacol reaction of $\mathbf{1 1 8}$ gave cis-bicyclo[11.3.0]hexadecandione $\mathbf{1 2 0}$ as the major product (55\%), besides the unusual inside-outside bicyclic dione 121 in $13 \%$ yield. Identical treatment of epimeric alkenyl acetal 119 produced neither 120 nor 121, but rather transbicyclo[11.3.0] hexadecandione $\mathbf{1 2 2}$ in $61 \%$ yield (Scheme 23). ${ }^{86}$

The morpholino enamine of cyclododecanone 123 was synthesized by the acid-catalyzed condensation of morpholine and cyclododecanone. A [2+2] cycloaddition of the enamine 123 and suberoyl chloride $\mathbf{1 2 4}$ produced the macrocyclic tetraketone $\mathbf{1 2 5}$ (Scheme 24). ${ }^{87}$ 
<smiles>COCC(CC1CCCCCCCCCC1=O)OC</smiles>

114

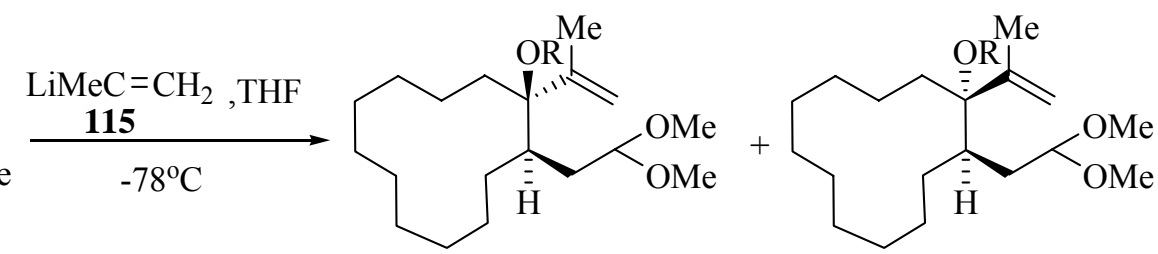

$$
\begin{gathered}
\text { TMSCl 116: } \mathrm{R}=\mathrm{H} \\
\text { Imidazole } \longrightarrow \text { 118: } \mathrm{R}=\mathrm{TMS}
\end{gathered}
$$

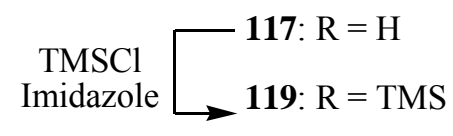

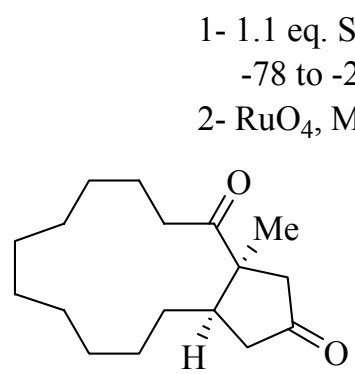

120

1- 1.1 eq. $\mathrm{SnCl}_{4}, \mathrm{CH}_{2} \mathrm{Cl}_{2}$ -78 to $-23^{\circ} \mathrm{C}$

2- $\mathrm{RuO}_{4}, \mathrm{MeCN}-\mathrm{H}_{2} \mathrm{O}$

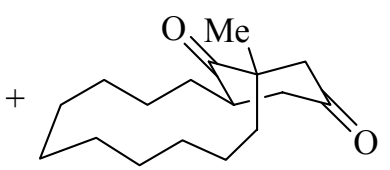

121

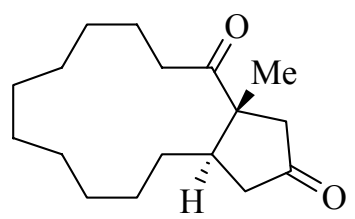

122

\section{Scheme 23}
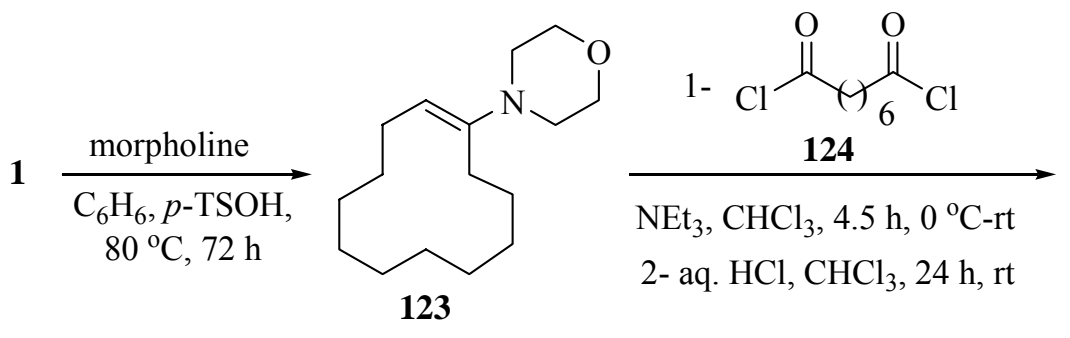<smiles>O=C1CCCCCCCCCCC1CCCCC1C(=O)CCCCCCCCCCCCC1=O</smiles>

125

\section{Scheme 24}

An efficient ring enlargement with four carbon atoms using the oxy-Cope rearrangement transforms 1 into cyclohexadec-5-ene-1-one 127, ${ }^{88,89}$ which is a valuable musky compound known under the trade name Ambretone ${ }^{\circledR}$ and musk TM II ${ }^{\circledR}$ (Scheme 25). ${ }^{90}$

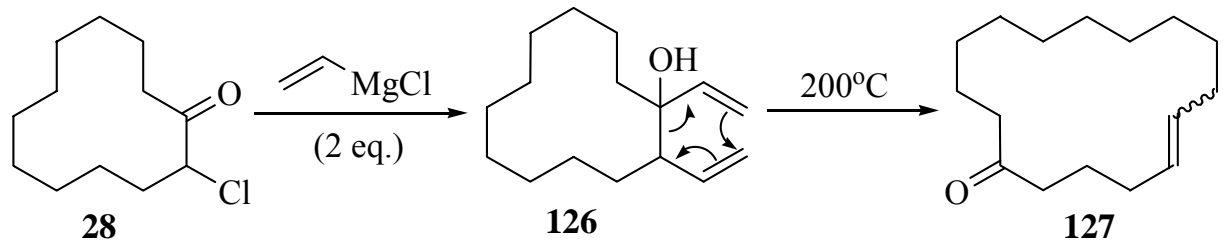

\section{Scheme 25}


The diketone $\mathbf{1 3 0}$ is a key synthetic intermediate for muscone, ${ }^{91}$ it was synthesized from 2hydroxymethelenecyclododecanone 98 via thermal rearrangement of spirocyclicvinylcyclo-propane 128 into 2,3,4,5,6,7,8,9,10,11,12,13-dodecahydro- $H$-cyclopenta[12]annulene 129. Then periodate oxidation of 129 furnished the target dione 130 (Scheme 26). ${ }^{92}$

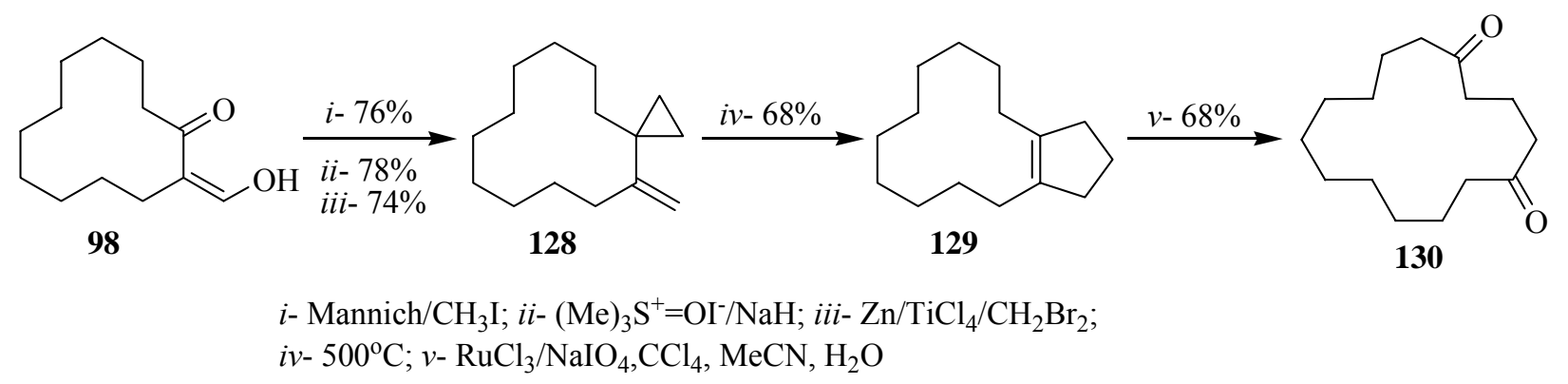

\section{Scheme 26}

The thirteen-membered ring $\gamma$-ketoester 133 was achieved through free radical one carbon ring expansion of the iodomethylene derivative 132 which was prepared by alkylation of $\beta$-ketoester 131 with methylene iodide as illustrated by the following equation (Scheme 27). ${ }^{93}$

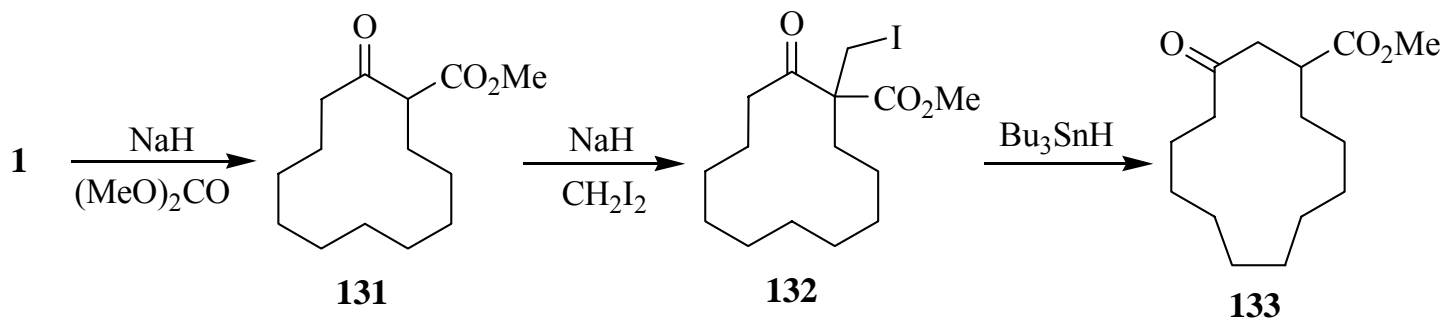

\section{Scheme 27}

The fourteen-membered ring $\beta$-ketoester 136 was prepared by cycloaddition of methyl propiolate 134 to the morpholino enamine of cyclododecanone $123,{ }^{94}$ followed by catalytic hydrogenation of the adduct 135. Alkylation of $\beta$-ketoester 136 with methylene iodide yielded 137. Tri-n-butyltin hydride $\left(\mathrm{Bu}_{3} \mathrm{SnH}\right)$ promoted ring expansion of 137 into the desired fifteen-membered ring $\gamma$-ketoester 138 (Scheme 28). ${ }^{93}$

The three-carbon ring expansion of a twelve to a fifteen-membered ring was used to explore the extension of preceeding method to larger increments. For this purpose, muscone was chosen as a target molecule. First, methyl cyclododecanone-2-carboxylate 131 was alkylated with 3-chloro-2methylpropene 139. The resulting adduct 140 was then hydrobrominated under free radical conditions yielding the terminal bromide 141, which was then converted to the iodide 142 in a Finklestein displacement reaction. The iodide 142 when treated with tri- $n$-butyltin hydride did not yield the desired fifteen-membered ketoester 143. Instead, ring contraction occurred yielding the eleven-membered ketoester 144 together with the product of direct reduction 145 (Scheme 29). ${ }^{93}$ 


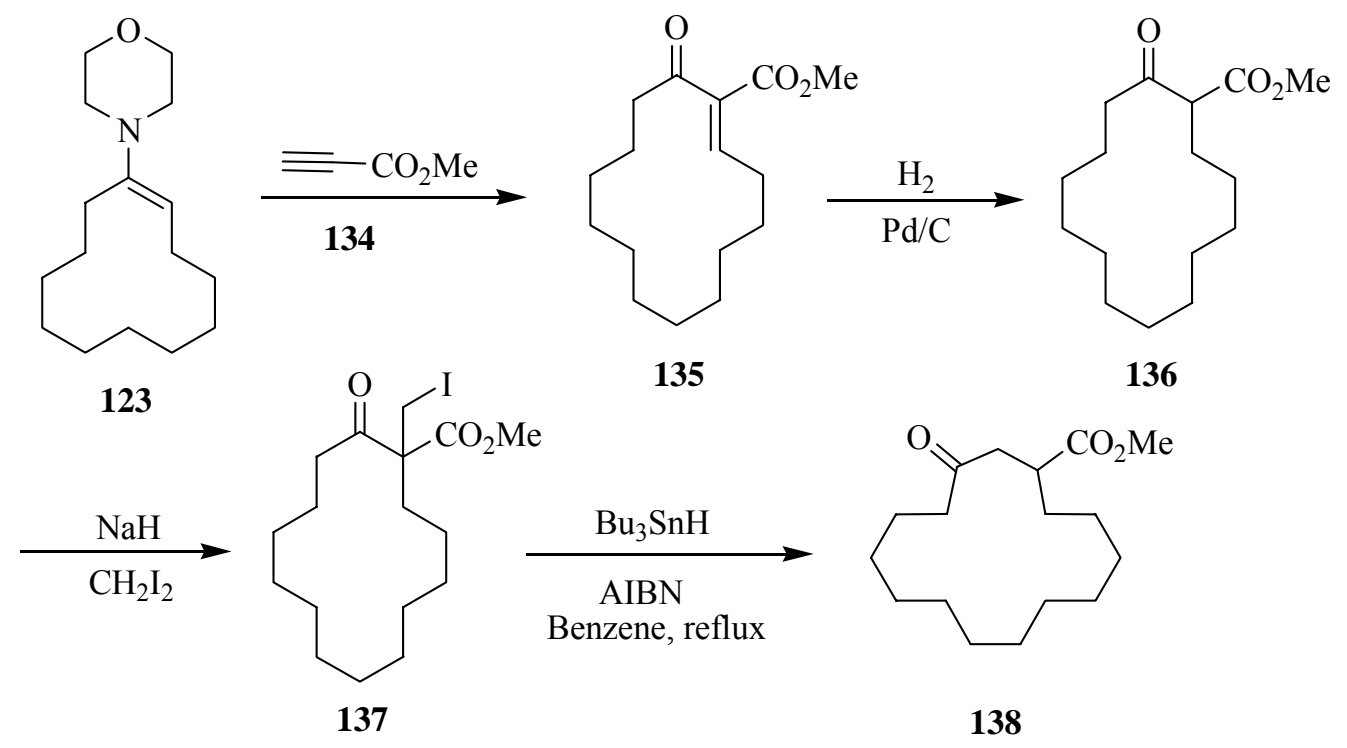

\section{Scheme 28}

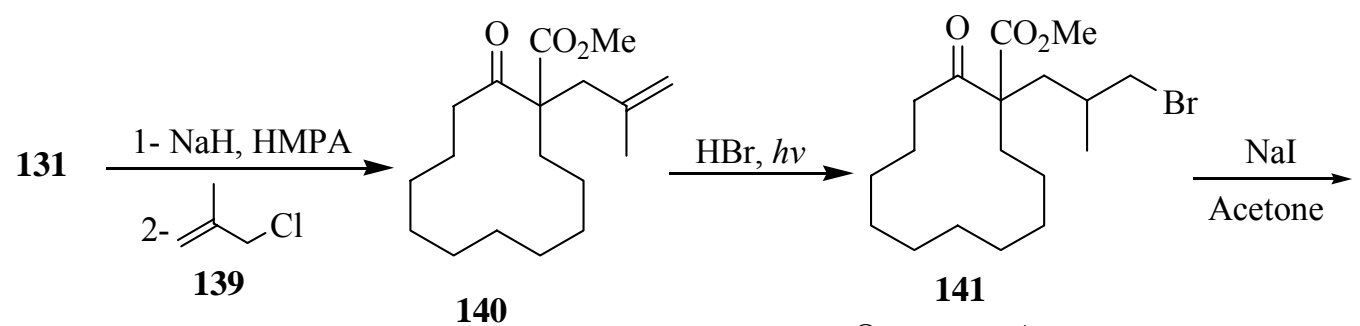

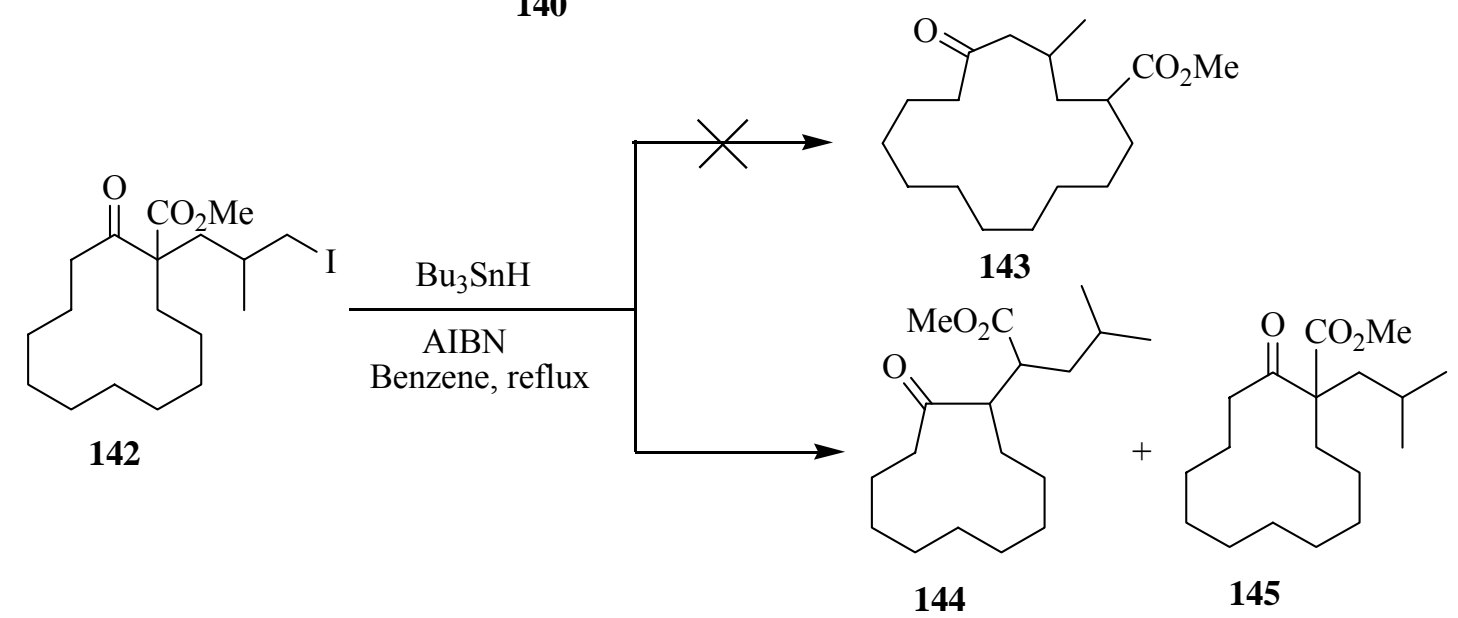

\section{Scheme 29}

A plausible mechanism for formation of $\mathbf{1 4 4}$ is presented in the Scheme $30 .{ }^{93}$ 

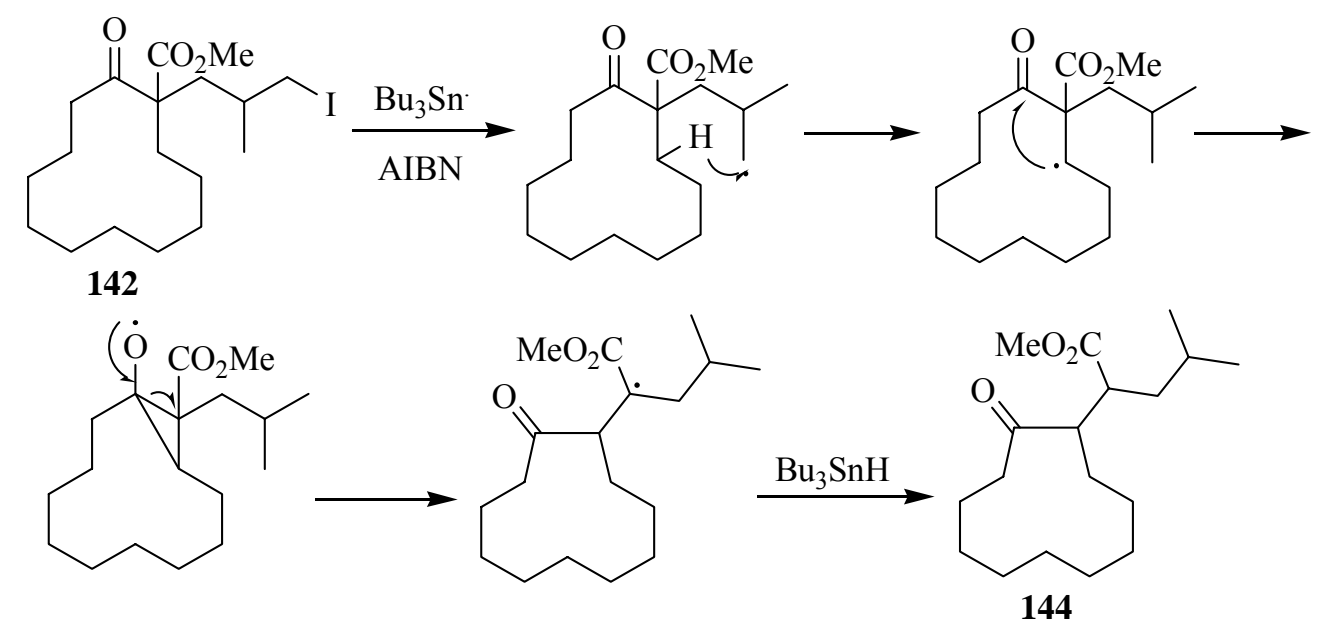

\section{Scheme 30}

So this strategy failed to achieve muscone, and to achieve that target another trial was carried out where the enolate anion of 1 was alkylated with 3-chloro-2-methylpropene 139 in the presence of iodide ion to yield the adduct 146 (54\%). Hydrogen bromide was added to the double bond of 146 under free radical conditions leading to 147 . The primary bromide in 147 was displaced by iodide ion in a Finkelstein reaction. The resulting iodide $\mathbf{1 4 8}$ was treated with tri- $n$-butyltin hydride and rearranged to $( \pm)$-muscone $149(15 \%)$ together with the product of direct reduction 150 (Scheme 31). ${ }^{93}$

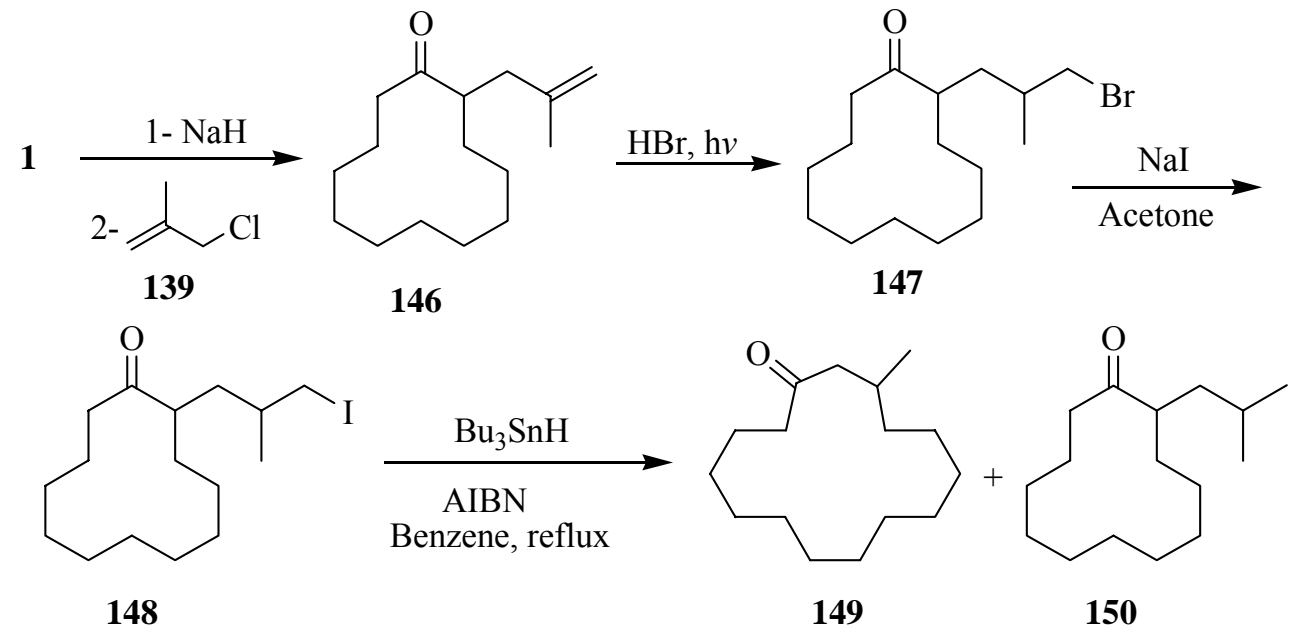

\section{Scheme 31}

Success of the preceeding methodology promoted the synthesis of the naturally occurring levorotatory enantiomer of muscone. Thus, the readily available $(S)-(+)-3$-bromo-2-methylpropanol 151 was protected as its $t$-butyldiphenylsilyl ether 152, and the latter was used to alkylate $\mathbf{1}$ yielding 153. The silyl group was removed with fluoride ion and the resulting alcohol 154 was converted to 
the iodide 155 with chlorodiphenylphospine and iodine. The iodide 155 was treated with triphenyltin hydride under modified conditions, ${ }^{95}$ which yielded, after workup and chromatographic separation, pure (R)-(-)-muscone 156 in addition to 150 (Scheme 32). ${ }^{93}$

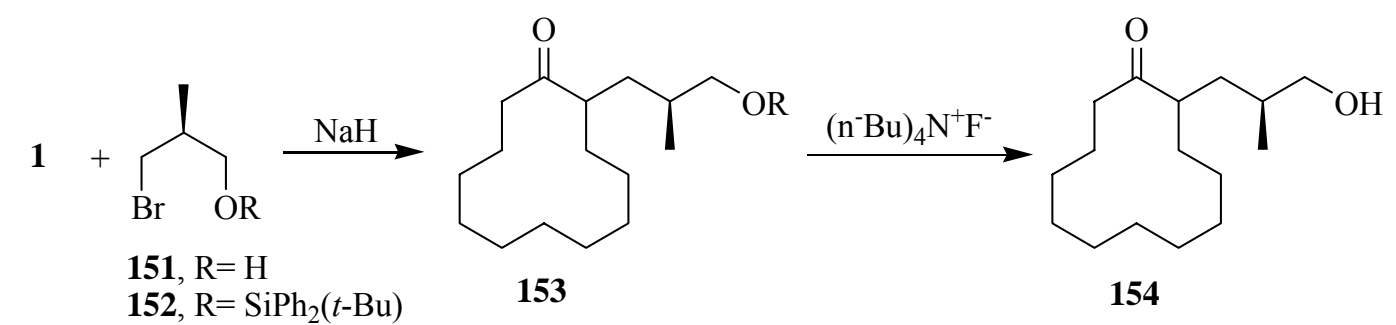

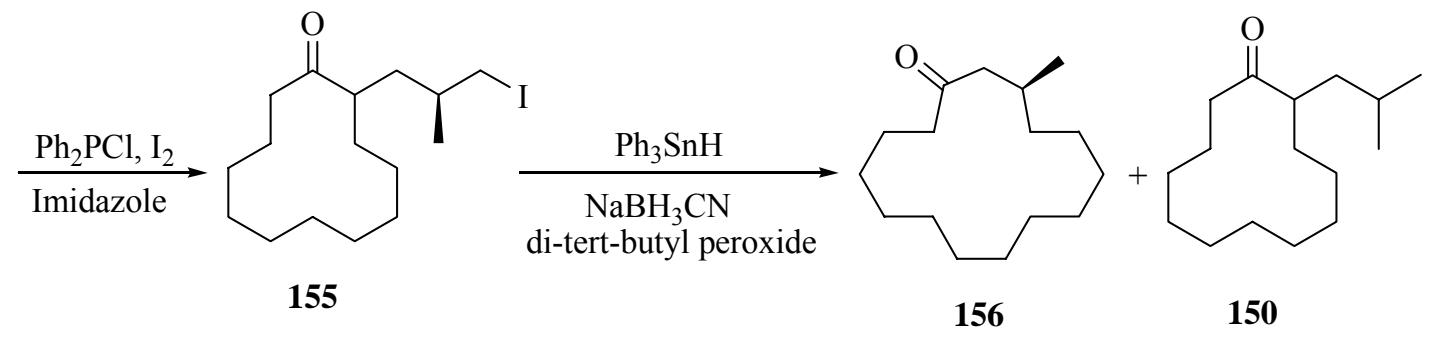

\section{Scheme 32}

Cyclododecanone 1 was enlarged by two carbon atoms into the fourteen-membered ring derivative 160. The ring expansion takes place in water in presence of indium as a metal mediator (Scheme 33). ${ }^{96}$

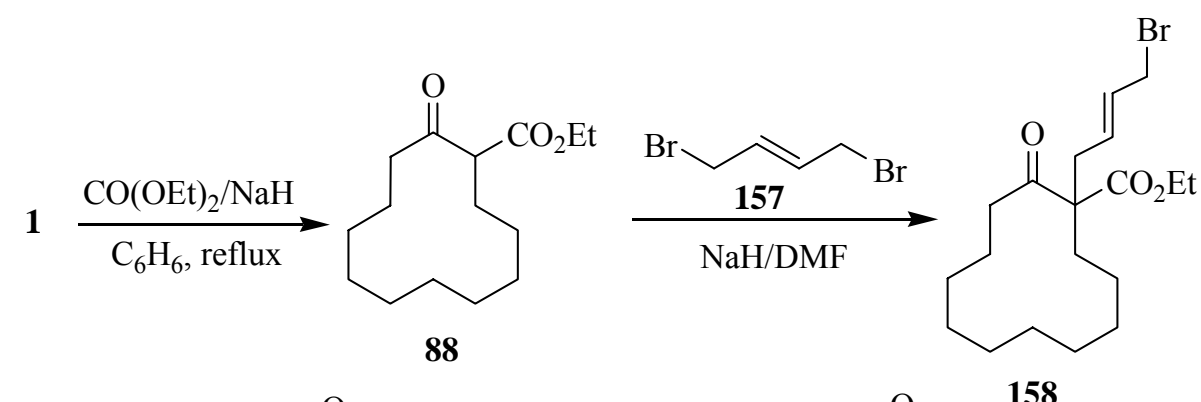<smiles>C=CC(CC(CCCCCCCCCCCCC)C(=O)OCC)C(=O)O</smiles>

159<smiles>C/C=C(\CC(CCCCCCCCCCCCCCCCC)C(=O)OCC)C(=O)O</smiles>

160

\section{Scheme 33}


The reaction of 1-morpholinocyclododecene 122 with either propionyl chloride or butyryl chloride in the presence of triethylamine gives the 1-morpholino-2-alkyl-1-cyclotetradecen-3-one 161a,b in 70-75\% yield. After separating the triethylamine hydrochloride, the crude ketones 161a,b are smoothly reduced by complex aluminium hydrides [ $\mathrm{LiAlH}_{4}, \mathrm{NaAlH}_{4}$, $\left.\mathrm{NaAlH}_{2}\left(\mathrm{OCH}_{2} \mathrm{CH}_{2} \mathrm{OCH}_{3}\right)_{2}\right]$ and forms the 2-alkyl-3-hydroxy-cyclotetradecanone 162a,b on subsequent hydrolysis. Ketols 162a,b easily leaves water when refluxed in toluene in presence of catalytic amounts of $p$-toluenesulfonic acid to give a mixture of the cis- and trans-2-alkyl-2cyclotetradecen-1-one 163a,b in high yield. Hydrogenation of the unsaturated ketones 163a,b over $\mathrm{Pd}$ catalyst gives the 2-methyl- and 2-ethylcyclotetradecanones 164a,b in quantitative yield (Scheme 34). ${ }^{97}$

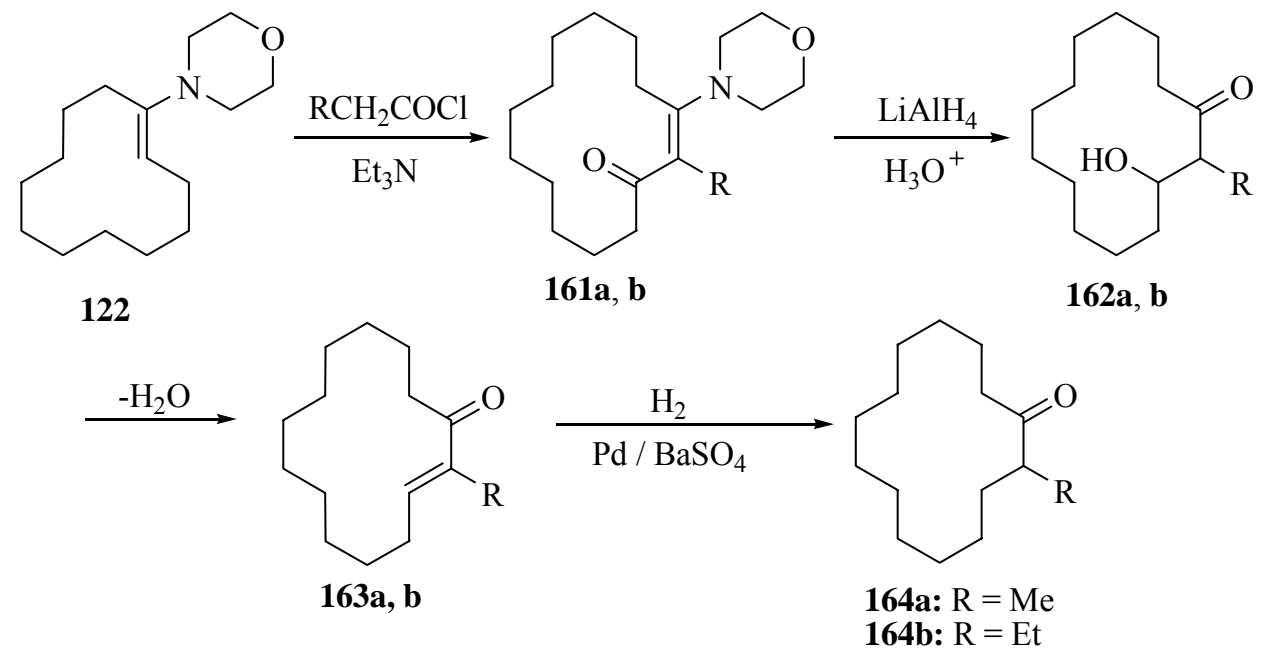

\section{Scheme 34}

3.5.2 Macrocyclic lactams and lactones. Thirteen-membered ring lactam 18 was prepared by Beckmann rearrangement of ketoxime $\mathbf{1 7}$ under the influence of wide variety of catalysts such as mesoporous silicoaluminophosphates, ${ }^{98}$ nanosized and delayer zeolitic catalyst, ${ }^{99}$ and many other catalytic systems. ${ }^{100-106}$ Lactam 18 can be also accessed from cyclododecanone via Schmidt reaction under microwave irradiation using $\mathrm{P}_{2} \mathrm{O}_{5} / \mathrm{SiO}_{2},{ }^{107}$ or silica-sulfuric acid as catalyst, ${ }^{108}$ and $\mathrm{TMSN}_{3}$ in presence of $\mathrm{FeCl}_{3} .{ }^{109}$ While, $N$-methyl azacyclotridecan-2-one 166 was produced simply in $69 \%$ yield in a one-pot reaction of 1, triethylorthoformate and $N-((p-$ nitrobenzene)sulfonyl)oxymethylamine $\left(\mathrm{CH}_{3} \mathrm{NH}-\mathrm{OSO}_{2} \mathrm{C}_{6} \mathrm{H}_{4} \mathrm{NO}_{2}\right) \quad 165$ in presence of sodium iodide. ${ }^{110}$ Baeyer-Villiger oxidation of 1 resulted in formation of oxacyclotridecan-2-one 167. The oxidation process is achieved using chemical and biochemical catalysts (Scheme 35$).{ }^{111-113}$ 


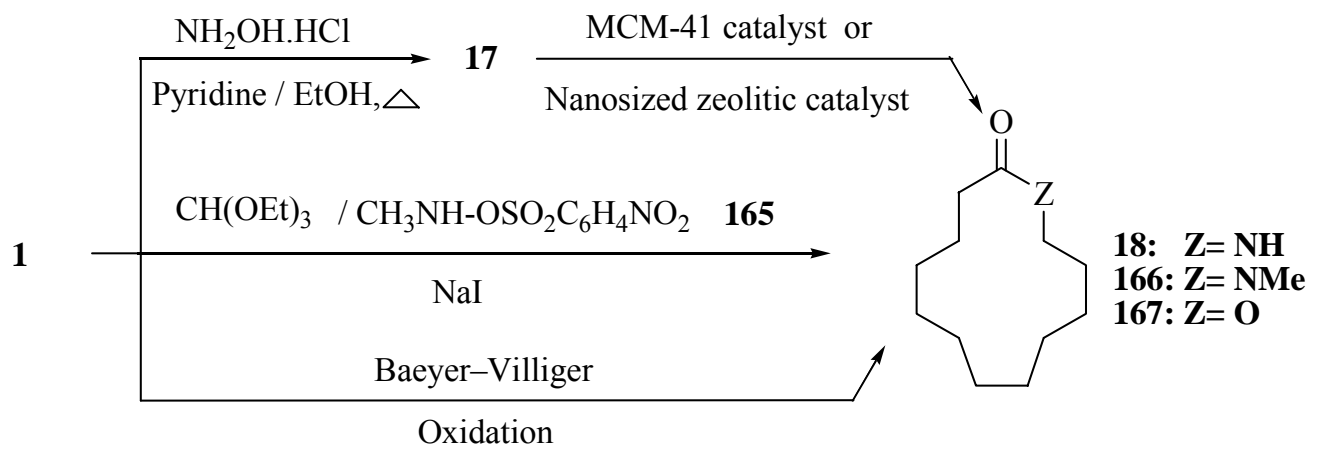

\section{Scheme 35}

$\alpha$-Nitrocyclododecanone 168 reacts with acrolein 169 in water at room temperature giving the expected Michael adduct 170. However, in the case of the more hindered $\alpha, \beta$-unsaturated aldehydes bearing an alkyl group at their $\alpha$ position 171a-c, the reaction did not take place in the absence of catalyst, and addition of base led to an abrupt change in the course of the reaction, since the product was bridged bicyclic lactone 172a-c bearing an unusual 6-hydroxy-1,2-oxazine ring (Scheme 36). ${ }^{114}$

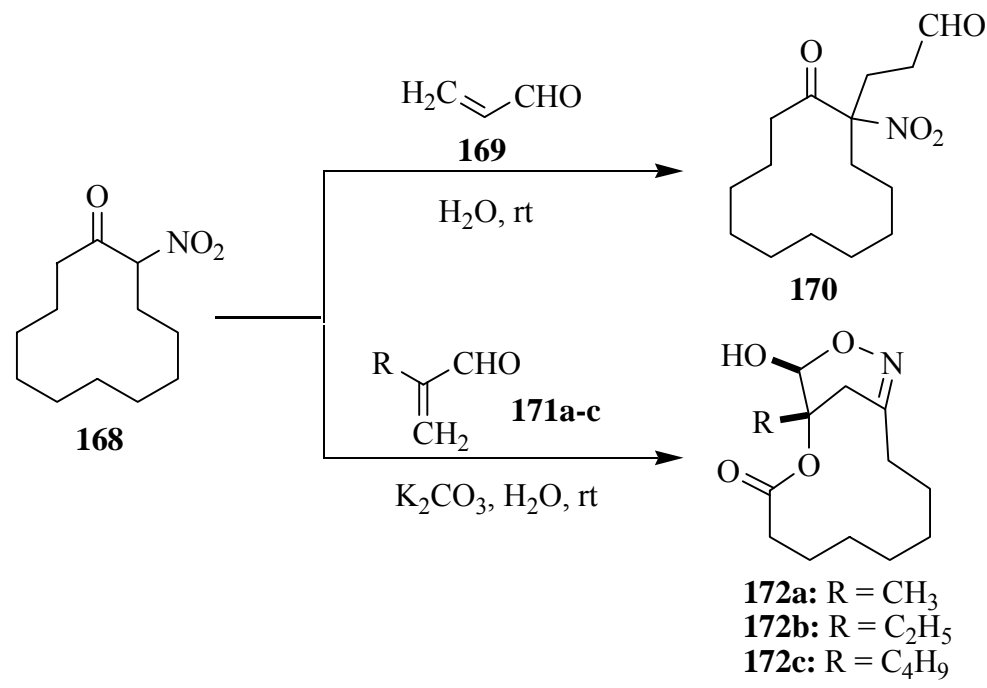

\section{Scheme 36}

A mechanism that accounts for the isolation of compounds 172a-c is summarized in Scheme 36 and involves a unique anionic domino transformation including up to six different reactions in a one-pot process. It was proposed that anion II from the initial Michael addition evolves to III through a retro Claisen-type reaction. Cyclization of III by attack of the nitronate oxygen onto the aldehyde group requires the existence of conformation IIIb, which would be favored by repulsive interactions between the nitronate and ethyl groups in IIIa and would lead to the $\mathrm{N}$-oxide IV. Elimination of water from its tautomer $\mathbf{V}$ would give 1,2-oxazine VI, and a final intramolecular conjugate addition of the carboxylate group in VI onto the $\alpha, \beta$-unsaturated imine system contained in the oxazine ring would lead to the observed products 172a-c (Scheme 37). ${ }^{114}$ 

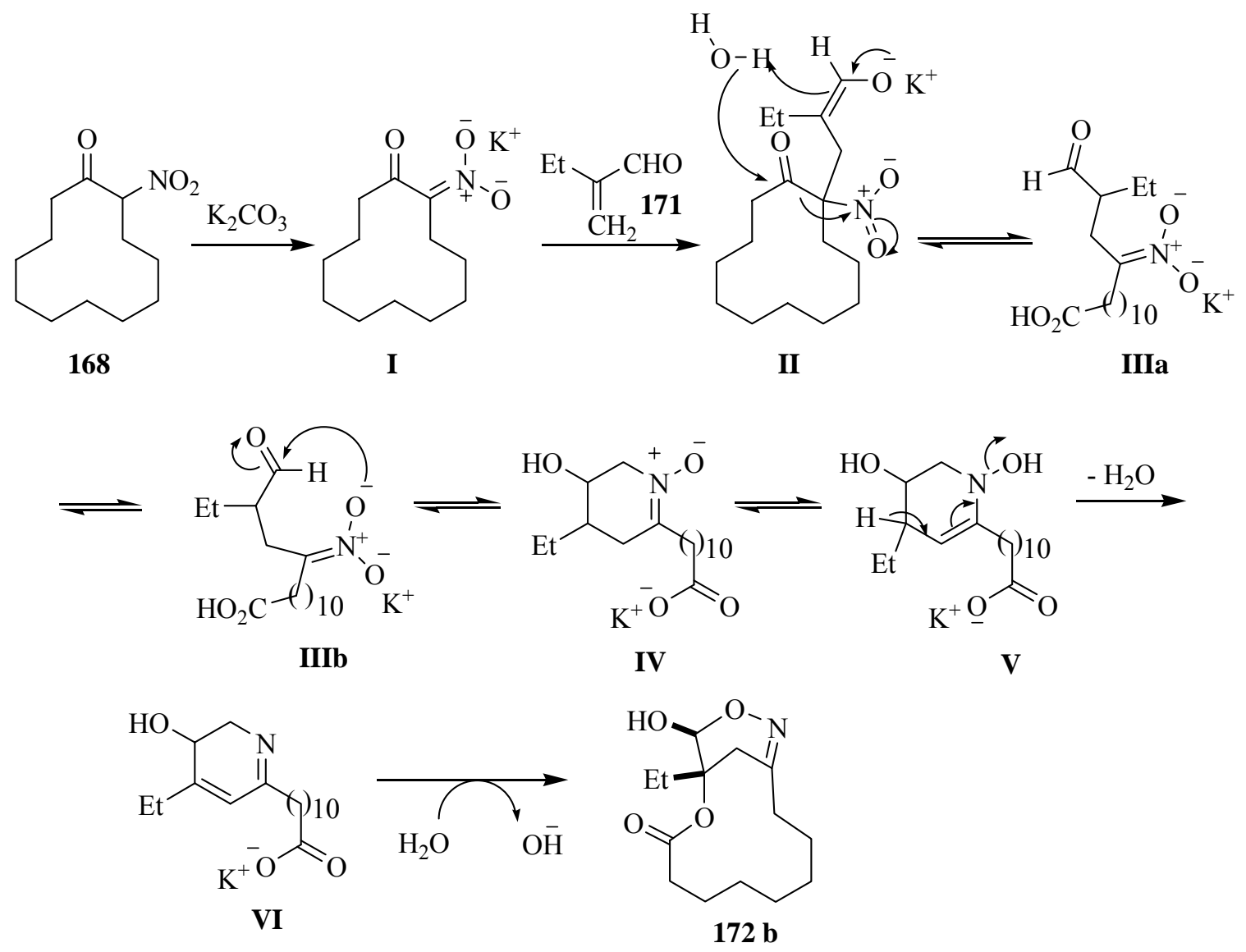

\section{Scheme 37}

Six novel 12-alkoxycarbonylmethylene-1,15-pentadecanolides 174 were synthesized from 2nitrocyclododecanone 168, by the Michael addition with acrolein followed by ring enlargement, Nef and Wittig-Horner reactions (Scheme 38). ${ }^{115}$

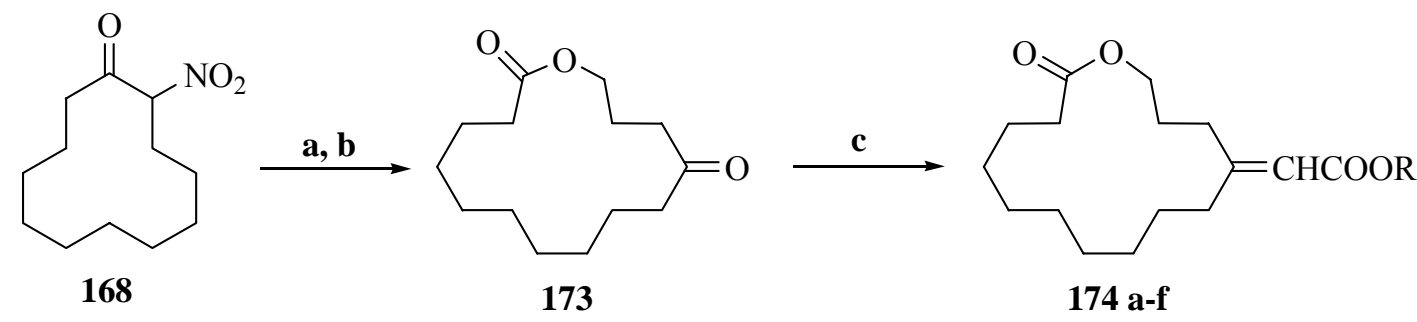
a: acrolein, THF, $\mathrm{Et}_{3} \mathrm{~N}, 0^{\circ} \mathrm{C}$; b: $(i) \mathrm{NaBH}_{4}, \mathrm{NaOH}, \mathrm{CH}_{3} \mathrm{OH}(i i) \mathrm{HCl}$;
c: $(\mathrm{EtO})_{2} \mathrm{P}(\mathrm{O}) \mathrm{CH}_{2} \mathrm{COOR}, \mathrm{KOBu}^{t}, \mathrm{THF}$, reflux
$\mathrm{R} ; \mathbf{a}: \mathrm{CH}_{3}, \mathbf{b}: \mathrm{C}_{2} \mathrm{H}_{5}, \mathbf{c}:\left(\mathrm{CH}_{2}\right)_{4} \mathrm{CH}_{3}, \mathbf{d}:\left(\mathrm{CH}_{2}\right)_{2} \mathrm{CH}\left(\mathrm{CH}_{3}\right)_{2}, \mathbf{e}:\left(\mathrm{CH}_{2}\right)_{7} \mathrm{CH}_{3}$, f:cyclohexyl

\section{Scheme 38}


12-Oxo-1,15-pentadecanlactam 178 was synthesized from 1 with a total yield of $36 \%$ in seven steps. Conversion of the azide 176 to 12-nitro-1,15-pentadecanlactam $\mathbf{1 7 7}$ is the key step featured by direct ring expansion (Scheme 39). ${ }^{116}$

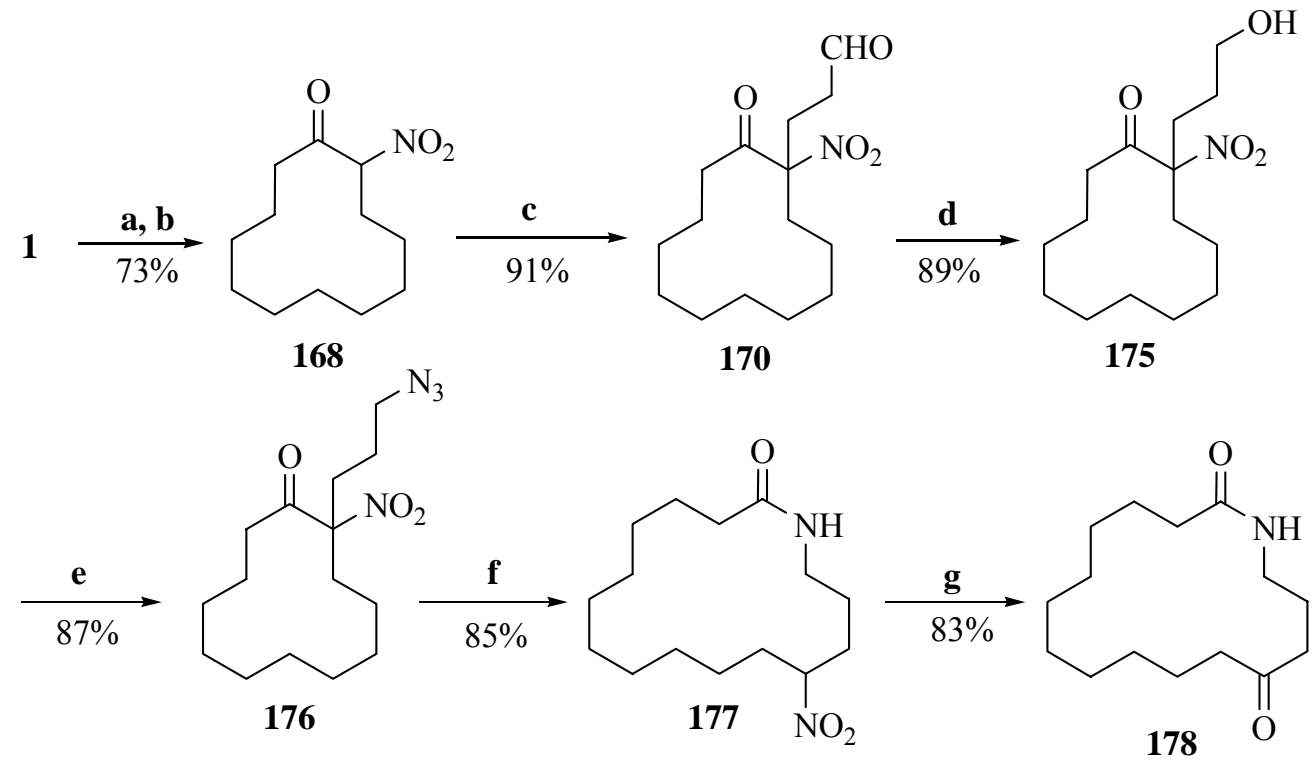

a) $\mathrm{Ac}_{2} \mathrm{O}, \mathrm{TsOH}$, reflux; b) $\mathrm{Ac}_{2} \mathrm{O}, \mathrm{CCl}_{4}$, concentrated $\mathrm{H}_{2} \mathrm{SO}_{4}$, concentrated $\mathrm{HNO}_{3}, \mathrm{AcOH}$;

c) $\mathrm{CH}_{2}=\mathrm{CHCHO}, \mathrm{Et}_{3} \mathrm{~N}$, THF; d) $\mathrm{NaBH}_{4}, \mathrm{MeOH}, 0^{\circ} \mathrm{C}, 40$ min; e) $\mathrm{MeSO}_{2} \mathrm{Cl}_{2} \mathrm{Et}_{3} \mathrm{~N}$, toluene, $0^{\circ} \mathrm{C}, 40$ min then $\mathrm{NaN}_{3}, \mathrm{Bu}_{4} \mathrm{NBr}, \mathrm{H}_{2} \mathrm{O}, 60^{\circ} \mathrm{C}$; f) $\mathrm{H}_{2}$ /Lindlar catalyst, $\mathrm{EtOH}$, r.t; g) $\mathrm{NaOMe}$, $\mathrm{MeOH}$ then $4 \mathrm{~mol} / \mathrm{L} \mathrm{HCl}$.

\section{Scheme 39}

Oxabicycloalkene 179, ${ }^{117}$ was transformed into the 13 -membered ring lactone 181, by gradual addition of excess hydrogen peroxide and 0.1 equiv. $\mathrm{H}_{2} \mathrm{SO}_{4}$ to a solution of $\mathbf{1 8 1}$ in formic or acetic acid (Scheme 40). ${ }^{118,119}$

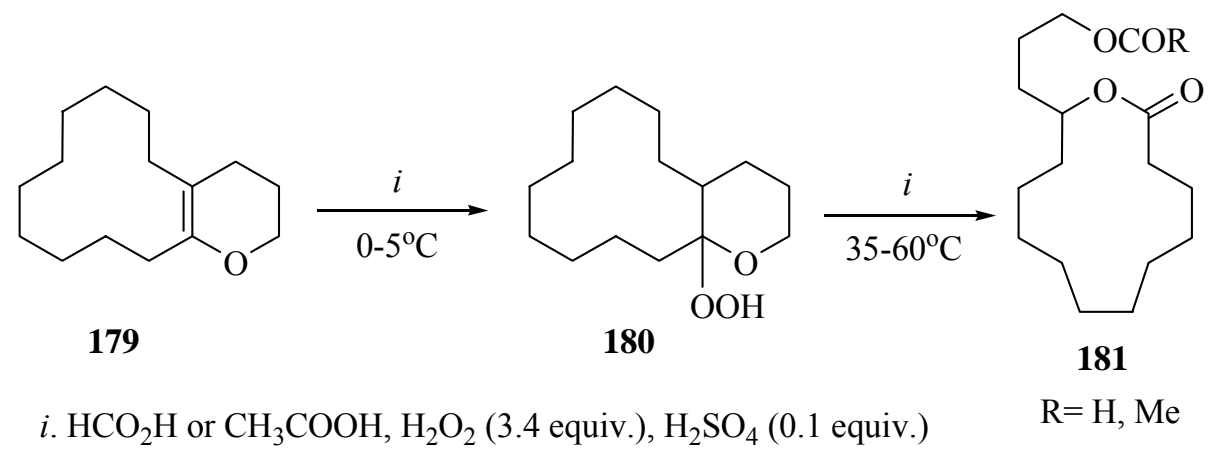

\section{Scheme 40}


The $(R)$-enantiomer of muscolide 186a, related to naturally occurring $(R)$-muscone the principal odorous constituent of the male musk deer (Moschus moschiferus L., Ungulata), was prepared in $23 \%$ overall yield from chiral building block 182a and 1, (Scheme 41). ${ }^{120}$

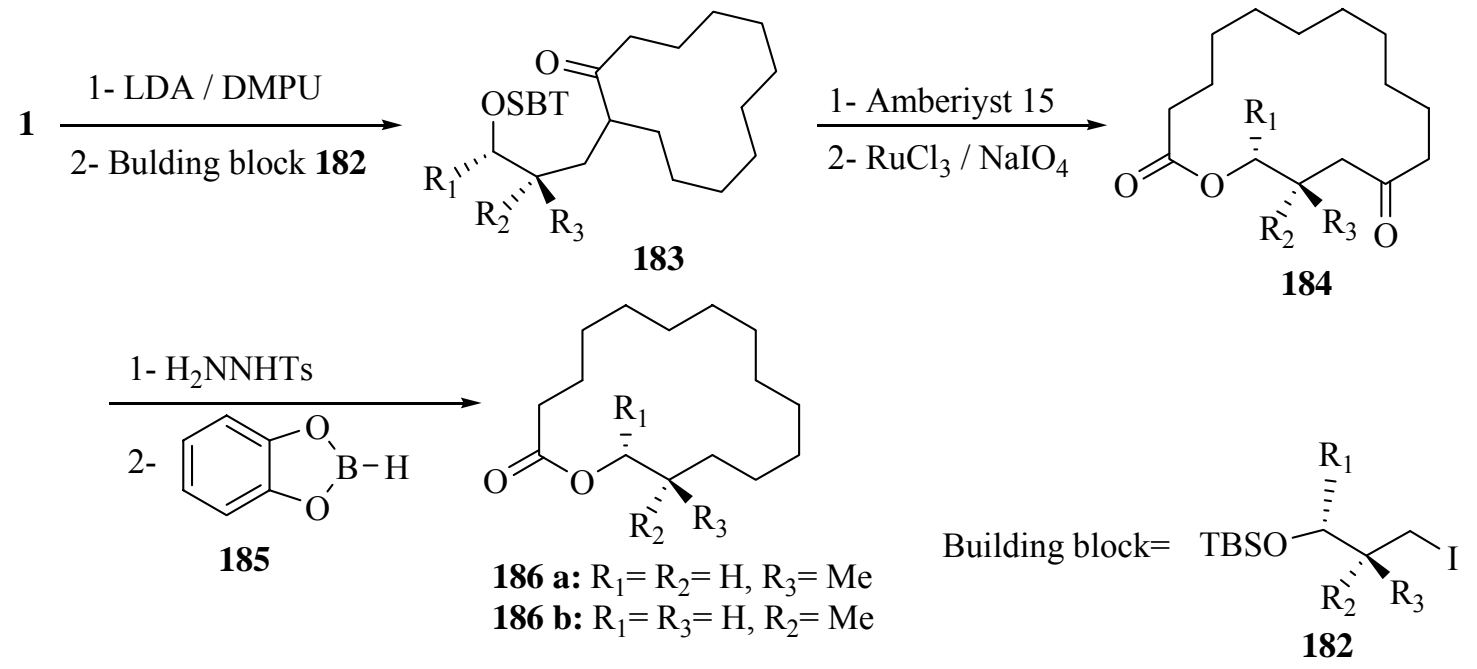

\section{Scheme 41}

Acid catalyzed reaction of 1 with the azido alcohols 187 followed by base catalyzed hydrolysis of iminium ether intermediate produced the macrocyclic lactam 188 and lactone $189 .{ }^{121}$

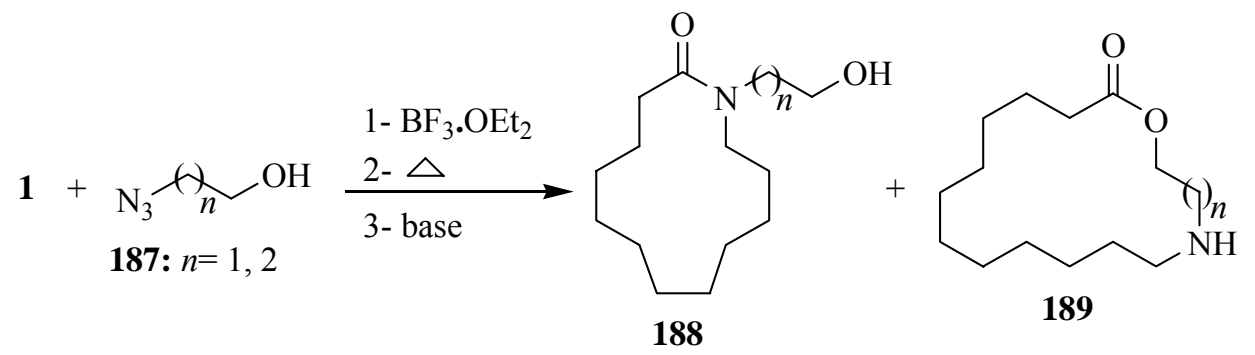

Goulaouic-Dubois et al, reported the retro Aldol type ring enlargement of 2-nitrocycloalkanones in basic medium as a methodology for synthesis of macrocyclic lactams. Reductive amination of the aldehyde $\mathbf{1 7 0}$ allows the nitrogen atom to react with the carbonyl group to give a bicyclic intermediate 190 which give the desired lactam $191 .^{122}$

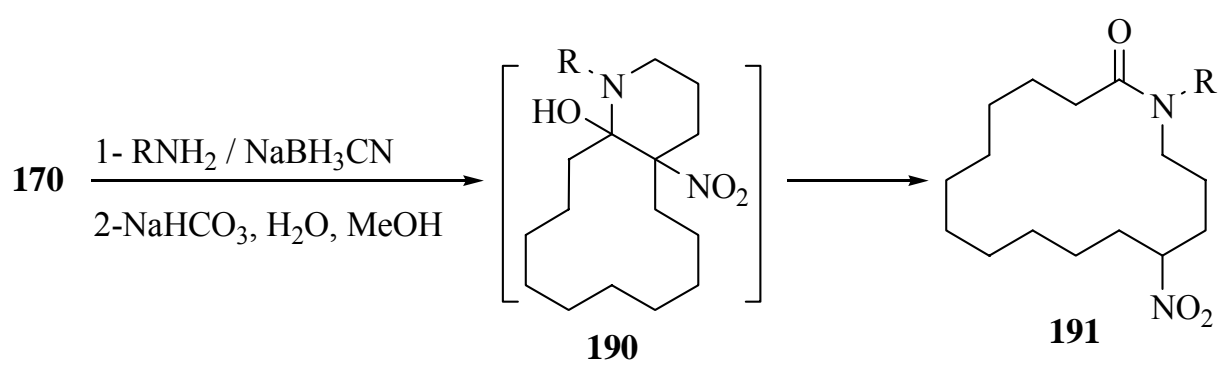


The alcohol 194 was obtained in two steps by Michael addition of 2-cyanocyclododecanone 192, ${ }^{123,124}$ to acrylaldehyde $\mathbf{1 6 9}$ followed by selective reduction of the aldehydic group of the adduct 193 by $\mathrm{NaBH}_{4}$ in methanol. ${ }^{125,126}$ Alcohol 194 was then converted into the azide 195 via reaction of the corresponding mesylate with $\mathrm{NaN}_{3}$ under phase-transfer catalysis. ${ }^{127}$ Treatment of the azide 195 with samarium iodide $\left(\mathrm{SmI}_{2}\right){ }^{128}$ (3.3 equiv.) in THF at room temperature for 2 hours promoted a smooth transformation into the 16-membered ring lactam 196 and the unexpected amidine 197 which was then acetylated to afford 198. ${ }^{122}$ Alternatively, the 16-membered ring lactam 196 was prepared from 195 in two steps by another route for direct comparison. Catalytic hydrogenation of azide 195 with Lindlar catalyst, ${ }^{129}$ afforded the bicyclic imine 199 which was hydrolyzed to the desired lactam 196 (Scheme 42). ${ }^{122}$

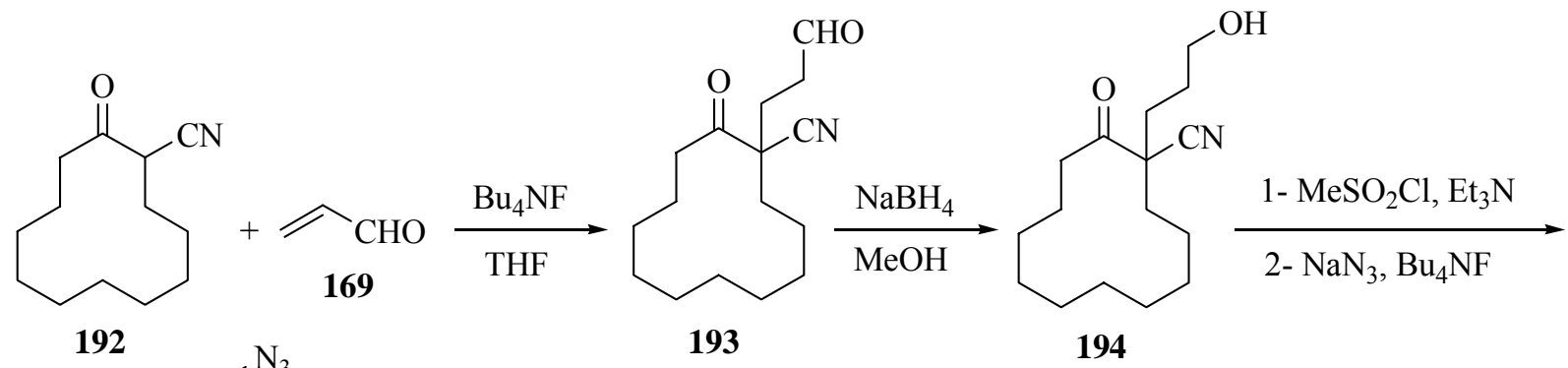

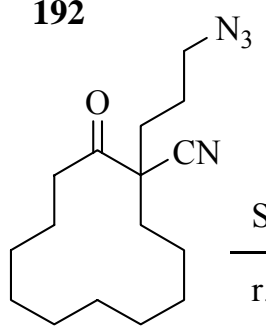

195

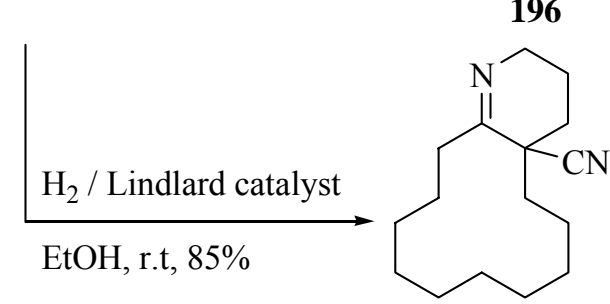

199

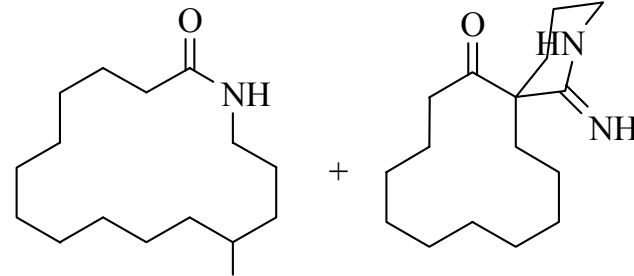

197<smiles>CC(C)C(=O)N1CC1</smiles>

198

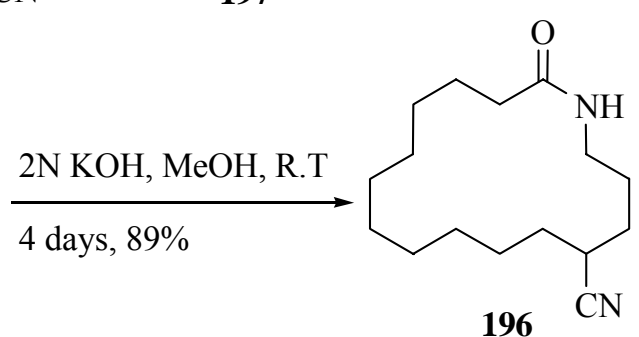

\section{Scheme 42}

Lactonization of keto-alcohol $\mathbf{1 7 5}$ proceeded smoothly in DME in presence of catalytic amount of sodium hydride. Then, the nitro-lactone 200 was converted to the keto-lactone 201 in $75 \%$ (Scheme 43). ${ }^{130}$ 


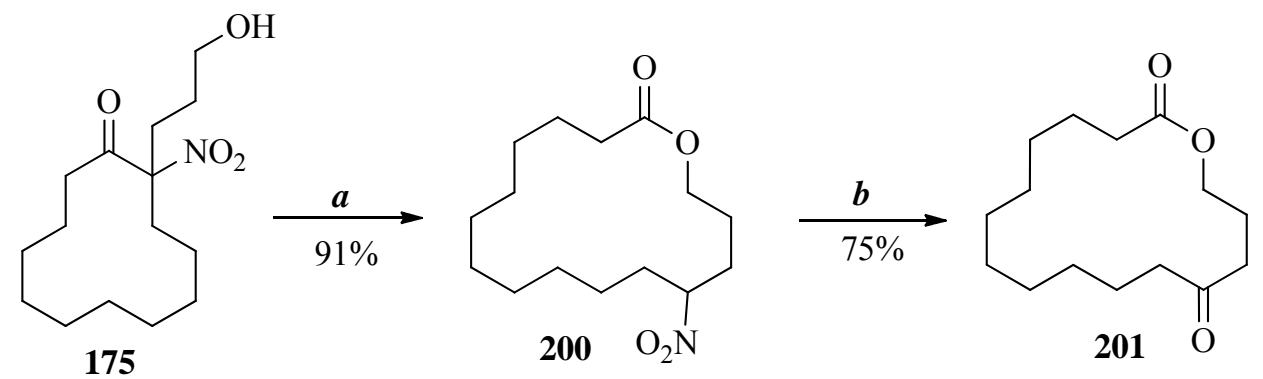

a: $\mathrm{NaH}, \mathrm{DME} ; \boldsymbol{b}$ : $\left(\mathrm{C}_{2} \mathrm{H}_{5}\right)_{3} \mathrm{~N}$ (3 equivs.), $\mathrm{CH}_{3} \mathrm{CN}$, aq. $\left(\mathrm{NH}_{4}\right)_{2}\left[\mathrm{Ce}\left(\mathrm{NO}_{3}\right)_{6}\right]$ (3 equivs.), reflux, 2 days

\section{Scheme 43}

Manfredi et al. reported the synthesis of the furan derivative 206 from 156, and explored its oxidation with two equivalents of $m$-chloroperbenzoic acid (MCPA) in methylene chloride which resulted in formation of 15-membered ring keolactone 207 in 70\% yield as a result of oxidative ring opening (Scheme 44). ${ }^{131}$

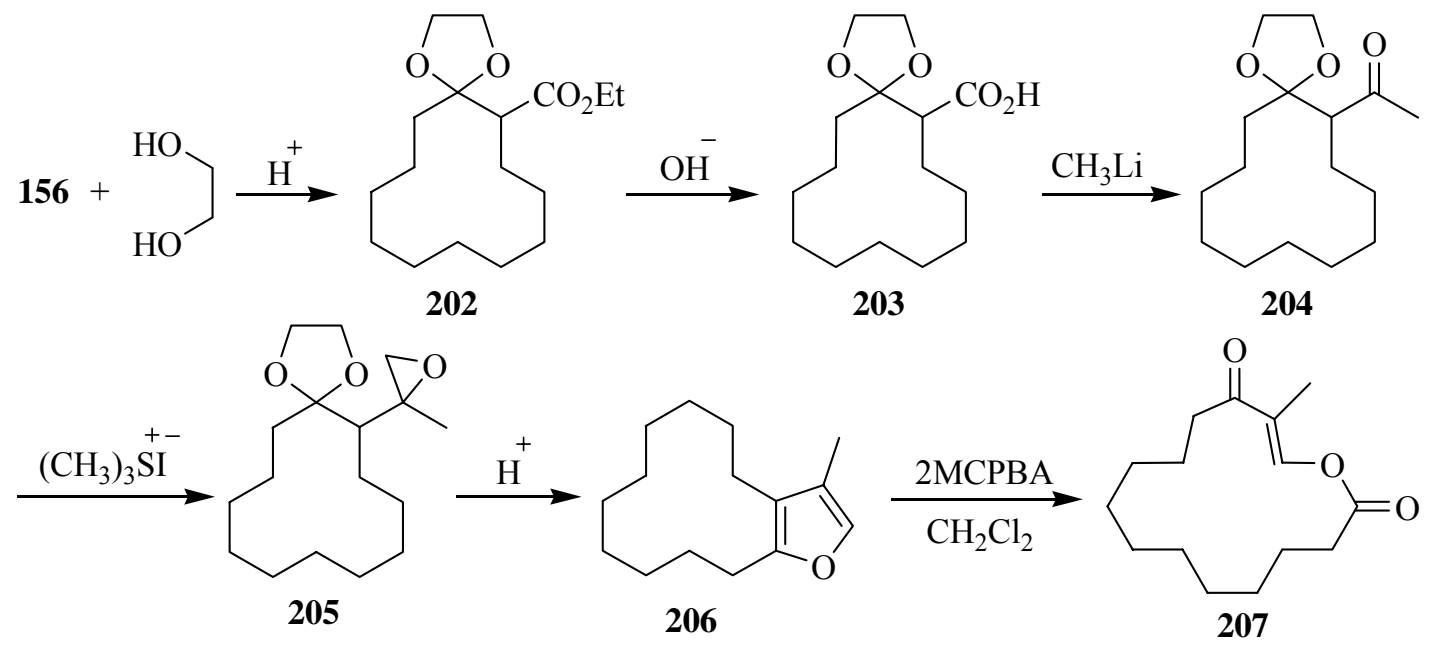

\section{Scheme 44}

Alkylation of the pyrrolidine enamine derivative 208 with 2,5-bis(dimethylaminomethyl)hydroquinone 209 in DMF afforded the benzodipyran derivative 210 as a coarse powder in 57\% yield. Hydrolysis of $\mathbf{2 1 0}$ furnished 211 which recyclized to 212. Dehydration of 212 with $\mathrm{P}_{2} \mathrm{O}_{5}$ afforded the benzodipyran derivative 213, which transformed into the macrocyclic benzodilactone 214 under the influence of $m$-chloroperbenzoic acid (Scheme 45). ${ }^{132}$ 
<smiles>CN(C)Cc1cc(O)c(CNC(C)(C)C)cc1O</smiles>

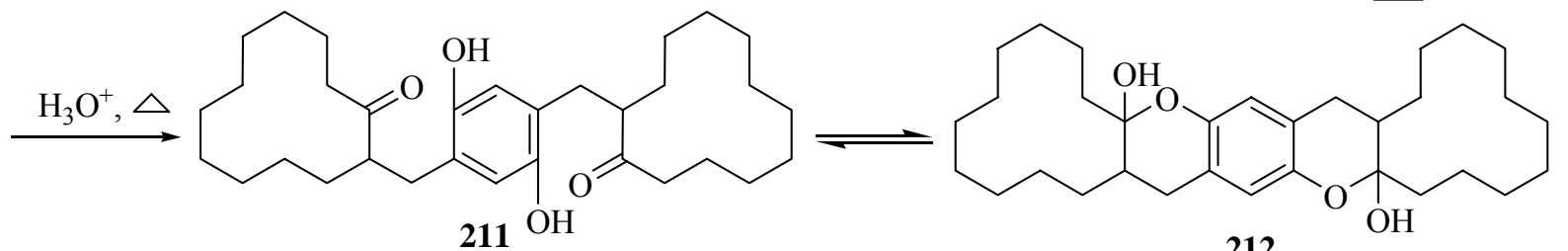

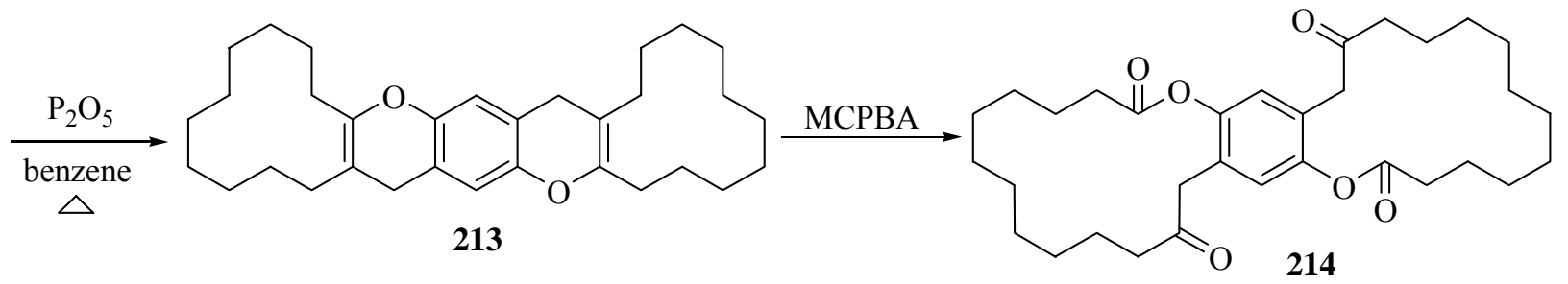

\section{Scheme 45}

3.5.3 Macrocyclic acetylenes. Treatment of cyclododecenyl trifluoromethanesulfonate 215 with LDA resulted in formation of the twelve-membered ring acetylenecyclododecyne $\mathbf{2 1 6}$ in 95\% yield (Scheme 46). ${ }^{133}$

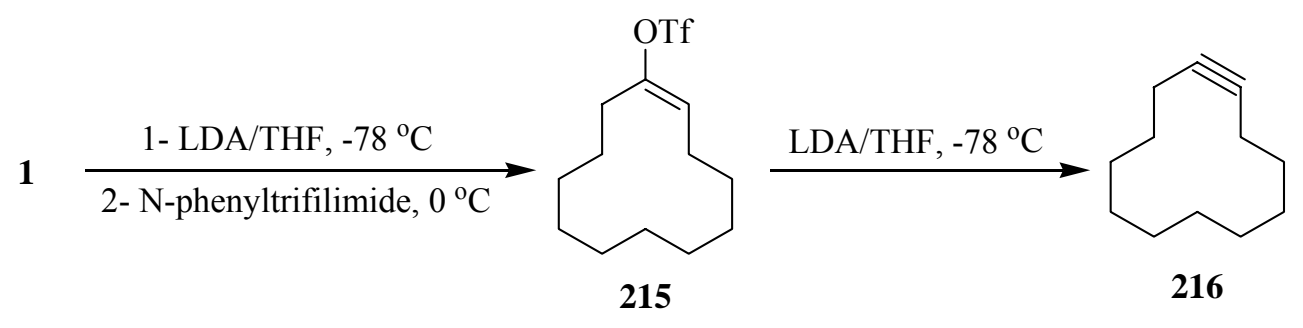

\section{Scheme 46}

Furthermore, thirteen and fourteen membered ring acytelenes $\mathbf{2 1 9}$ and 223 are accessed through nitrosation of isoxazolones 218 and 222, respectively. They are prepared through reaction of macrocyclic $\beta$-ketoesters 217 and 221 with hydroxyl amine hydrochloride (Scheme 47). ${ }^{134}$ 


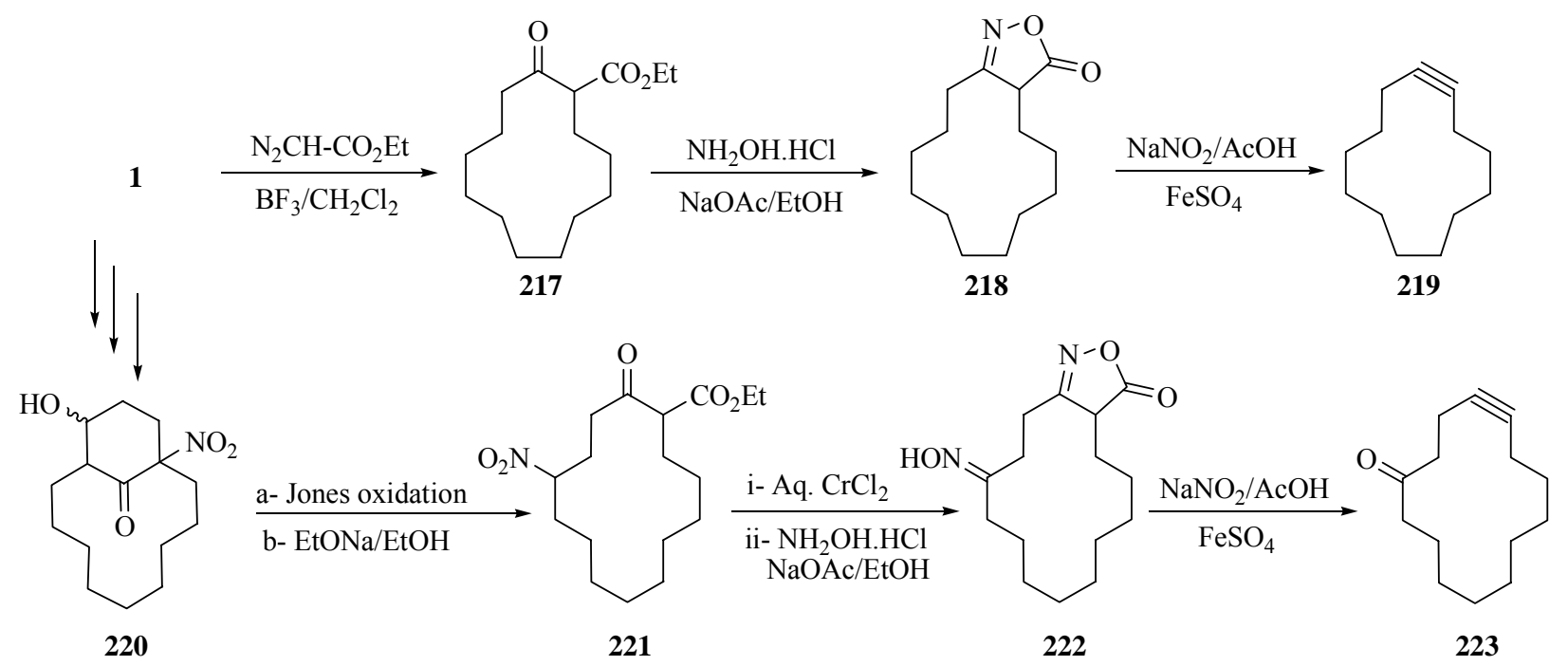

\section{Scheme 47}

In the same manner both regioisomeric $\beta$-ketoesters 226 and 227 gave 4-methylcyclotridecyne 230 in 87\% yield from the corresponding isoxazolones 228 and 229 (Scheme 48). ${ }^{134}$<smiles>CCCCCCCCCCC(=O)C=CCCC(C)C</smiles>

224<smiles></smiles>

225

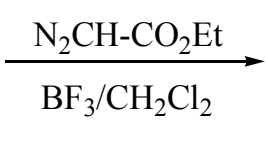

$\mathrm{BF}_{3} / \mathrm{CH}_{2} \mathrm{Cl}_{2}$

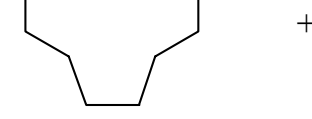

226

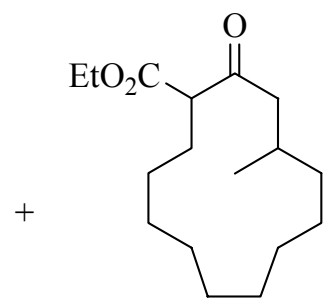

227<smiles>CCCCCCCCCCC#CCC(C)CC</smiles>

230

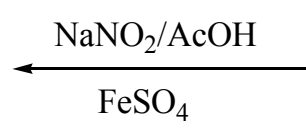

$\mathrm{FeSO}_{4}$

$\mathrm{NH}_{2} \mathrm{OH} . \mathrm{HCl}, \mid \mathrm{NaOAc} / \mathrm{EtOH}$

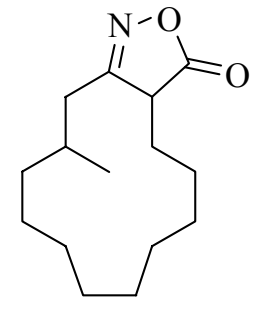

228

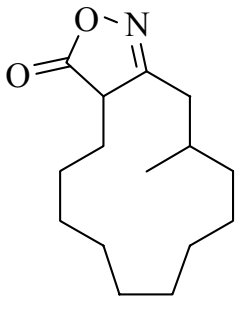

229

\section{Scheme 48}

Also, the macrocyclic lactone 231 was converted to 17-membered ring acetylene 233 following the same methodology (Scheme 49). ${ }^{134}$ 

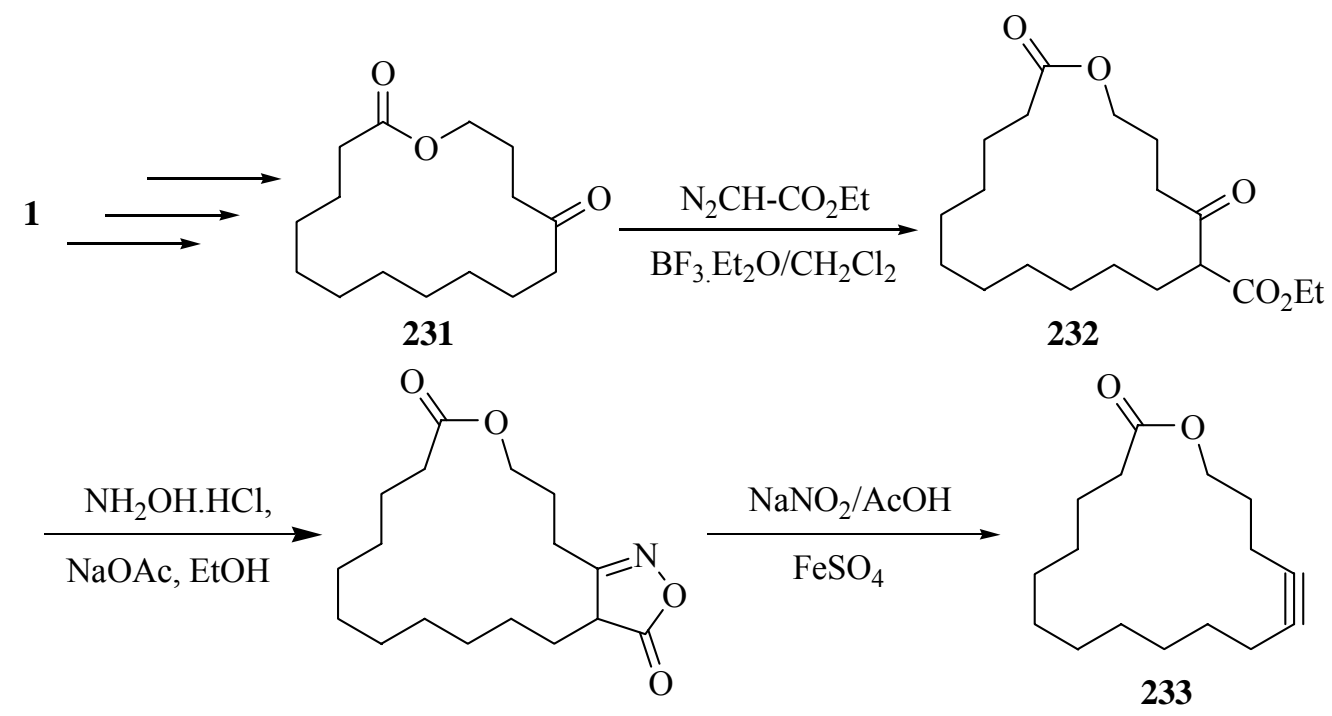

\section{Scheme 49}

\subsection{Ring contraction}

Cyclododecanone 1 and its imine derivative 234 react with $\mathrm{HF} / \mathrm{SbF}_{5}$ in presence of $\mathrm{CCl}_{4}$ whereby ring contraction takes place to produce a mixture of fluoro and hydroxy cycloheptanone derivatives 235 and 236, respectively. The ratio of 235/236 is about 3 when starting from 1 while it is about 0.5 when starting with imine 234 (Scheme 50). ${ }^{135}$

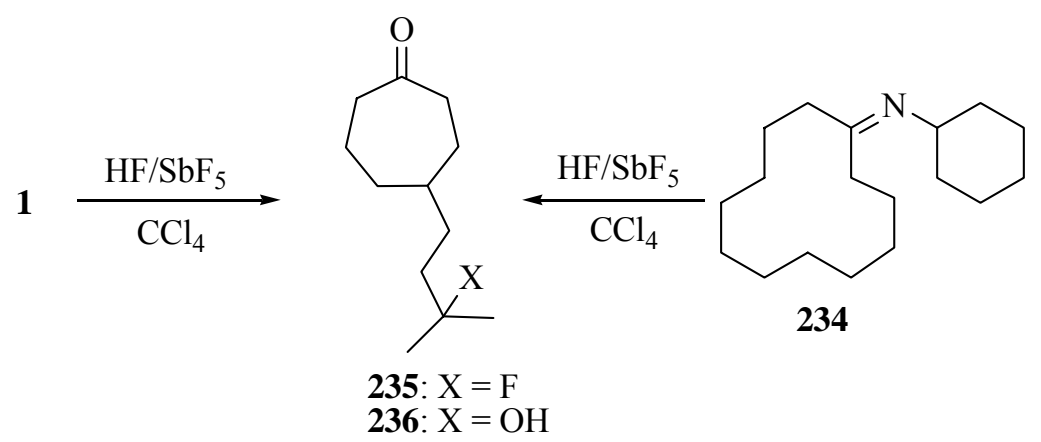

\section{Scheme 50}

Cycloundecanecarboxylic acid 239 has been prepared from 1 in three steps. The first step is the usual procedure for the preparation of enamines. The second step involves 1,3-dipolar cycloaddition of diphenyl phosphorazidate 237 to the pyrrolidine enamine 208 followed by ring contraction with evolution of nitrogen. The third step is hydrolysis of the $N$-phosphorylated amidines 238 to the desired acid (Scheme 51). ${ }^{136}$ 


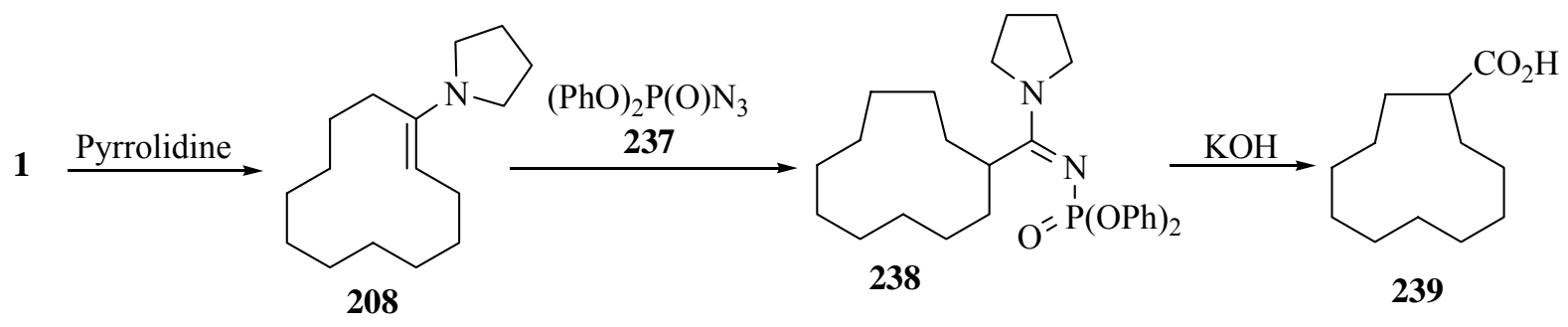

\section{Scheme 51}

Favorskii-type rearrangement of 2,12-dibromocyclododecanone 240 afforded methyl 1cycloundecenecarboxylate $\mathbf{2 4 1}$ which in turn underwent Schmidt degradation yielding cycloundecanone 242 (Scheme 52). ${ }^{137,138}$

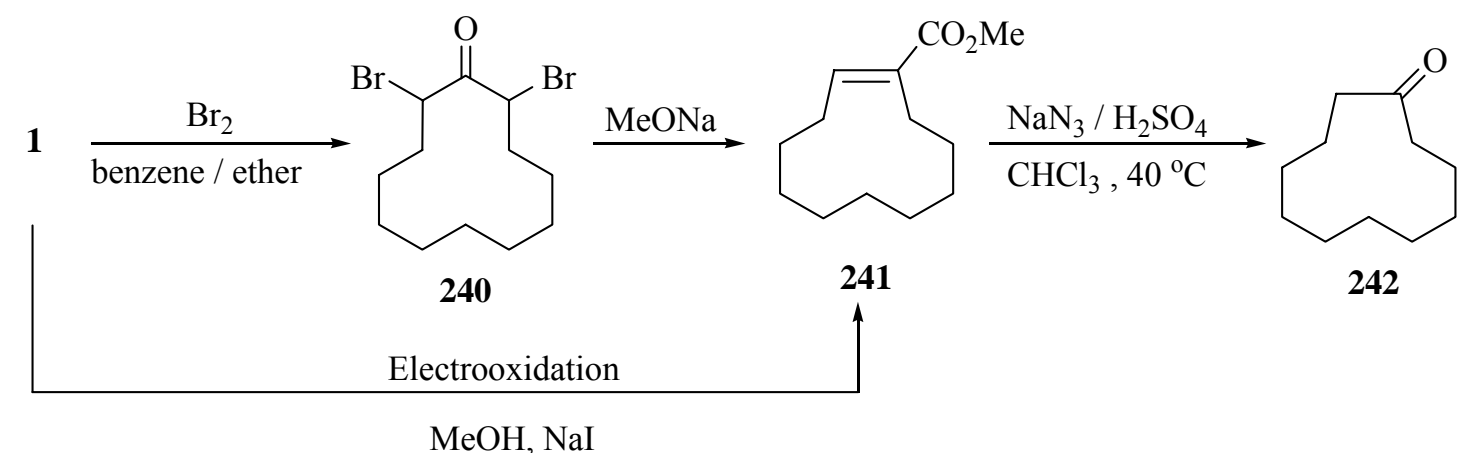

\section{Scheme 52}

\subsection{Construction of spiro and fused heterocyclic systems}

3.7.1 Spiro heterocyclic systems. Titanium tetrafluoride can efficiently be used for the stereoselective synthesis of 4-fluorotetrahydropyrans via Prins cyclization. By applying this methodology 4-fluorotetrahydropyran derivative 244 was achieved via reaction of 1 with but-3-en1 -ol 243 in $50 \%$ yield. $^{139}$

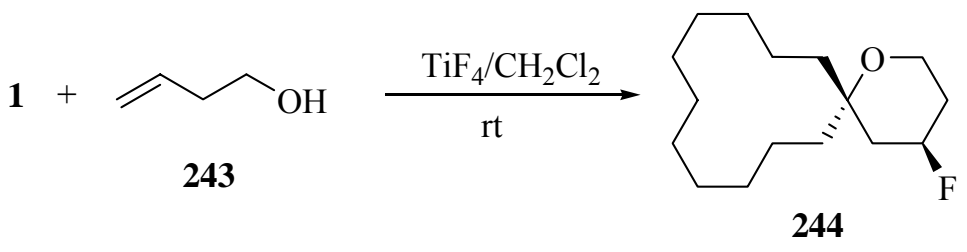

4-Iodo analogue of 244 was synthesized in analogous manner, but using $\mathrm{TMSCl} / \mathrm{NaI}$ in acetonitrile instead of $\mathrm{TiF}_{4}$ in methylene chloride. ${ }^{140}$ A series of novel 2-(1-substituted-1,11undecylidene)-5-arylimino- $\Delta^{3}-1,3,4$-thiadiazolines 247a-f were synthesized and their structures 
were characterized by ${ }^{1} \mathrm{H}$ NMR, ${ }^{13} \mathrm{C}$ NMR and elemental analysis. Their solubility and fungicidal activity was also investigated (Scheme 53 ). ${ }^{141}$

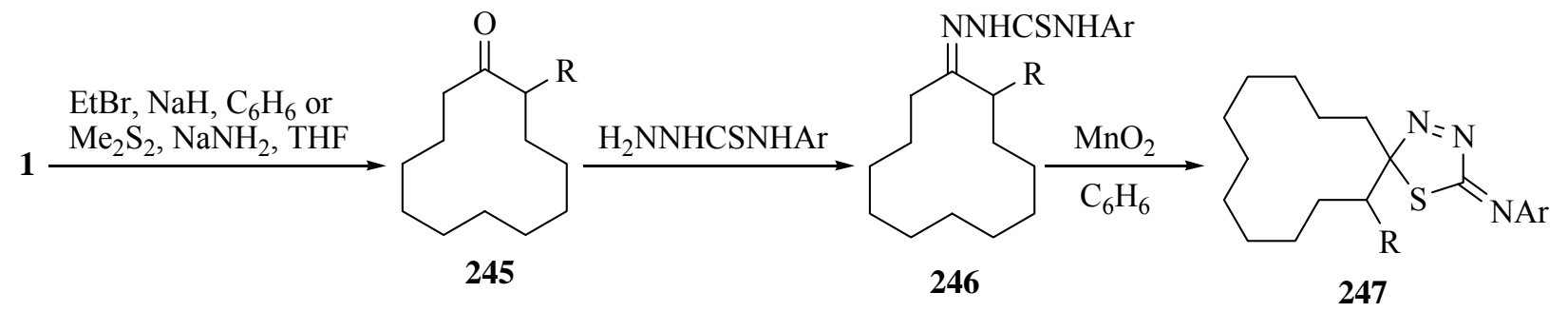
247a: $\mathrm{R}=\mathrm{Et}, \mathrm{Ar}=\mathrm{C}_{6} \mathrm{H}_{5}$;
247b: $\mathrm{R}=\mathrm{Et}, \mathrm{Ar}=4-\mathrm{FC}_{6} \mathrm{H}_{4}$;
247c: $\mathrm{R}=\mathrm{Et}, \mathrm{Ar}=2-\mathrm{ClC}_{6} \mathrm{H}_{4}$;
247d: $\mathrm{R}=\mathrm{Et}, \mathrm{Ar}=4-\mathrm{MeC}_{6} \mathrm{H}_{4}$;
247g: $\mathrm{R}=\mathrm{MeS}, \mathrm{Ar}=4-\mathrm{MeC}_{6} \mathrm{H}_{4}$;
247e: $\mathrm{R}=\mathrm{Et}, \mathrm{Ar}=2,4-\mathrm{Me}_{2} \mathrm{C}_{6} \mathrm{H}_{3} ; \quad$ 247f: $\mathrm{R}=\mathrm{MeS}, \mathrm{Ar}=4-\mathrm{ClC}_{6} \mathrm{H}_{4}$;

\section{Scheme 53}

A facile approach for the synthesis of spirocyclic butenolides through cascade oxidative/cleavage reaction of ( $Z$ )-enynols bearing cyclic substituents at the $\mathrm{C}-1$ position catalyzed by gold under oxygen atmosphere has been developed and applied on transformation of $\mathbf{1}$ into the butenolide 250 through the enynol 249 in a good overall yield (Scheme 54). ${ }^{142}$

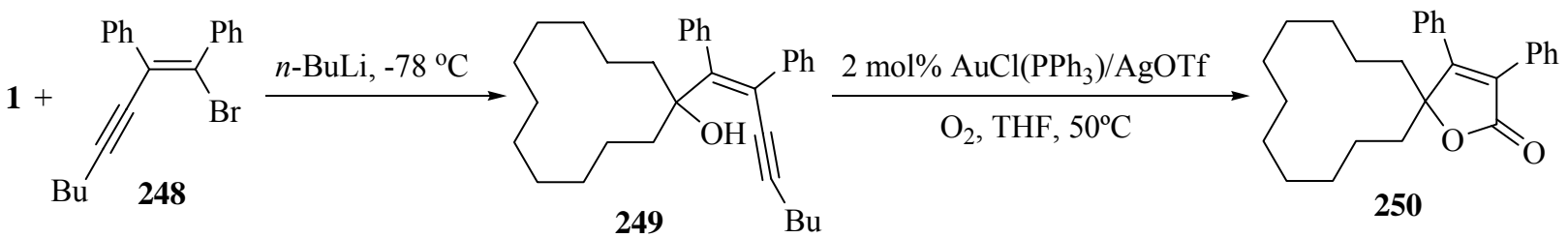

\section{Scheme 54}

Spirocyclic butenolide 253 was also achieved stereoselectively by ring closing metathesis strategy (Scheme 55). ${ }^{143}$

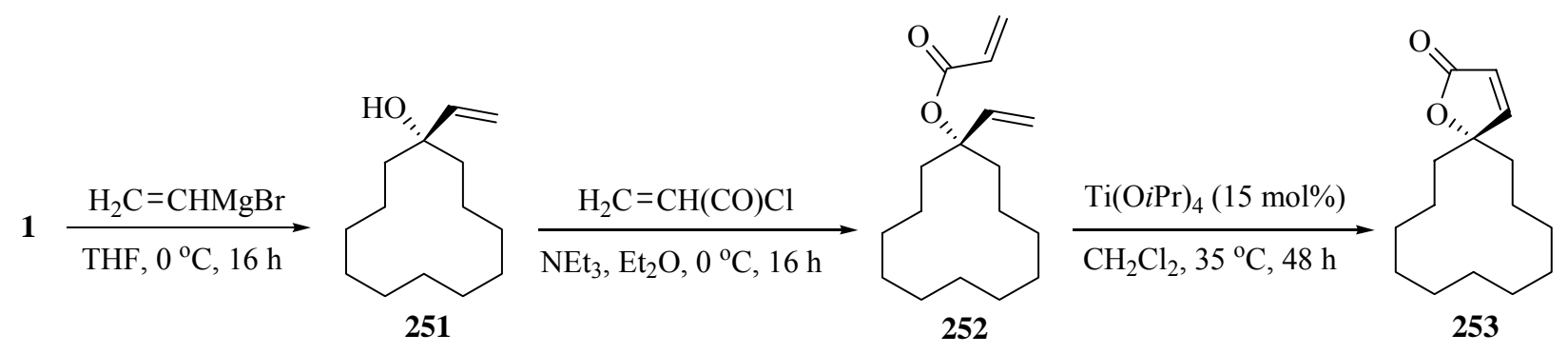

\section{Scheme 55}


While, spirocyclic furanone $\mathbf{2 5 6}$ was achieved in good yield through reaction of $\mathbf{1}$ with the lithium salt of propynal diethyl acetal 254, followed by treatment of the resulting 1-(3,3diethoxyprop-1-ynyl)cyclododecanol 255 with sulfuric acid in methanol (Scheme 56). ${ }^{144}$

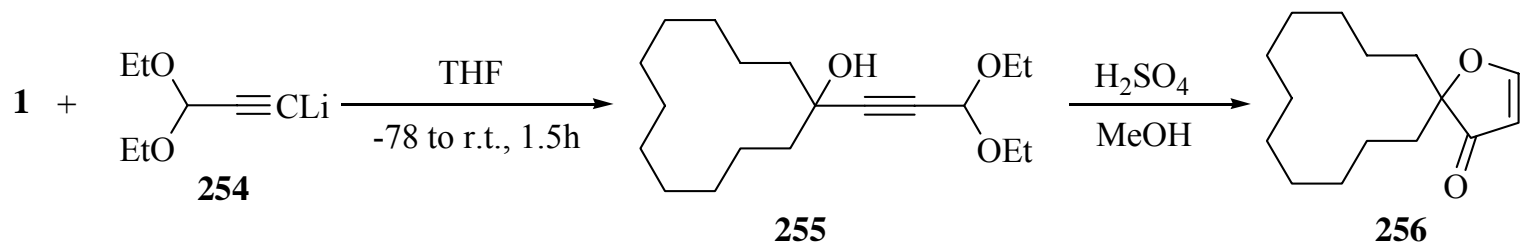

\section{Scheme 56}

A novel application of Al-SBA-15 catalyst in the protection of ketones was reported and applied on transformation of $\mathbf{1}$ into spiro[1,3-benzodioxole-2,1-cyclododecane] 257 through reaction with catechol. ${ }^{145}$ 1,8-Nonamethylene-3,6-diazahomoadamantan-9-one $\mathbf{2 5 9}$ was synthesized by condensation of tetramethylenediethylenetetramine 258 with cyclododecanone $1 .{ }^{146}$ Furthermore, $\mathbf{1}$ reacted with 2-aminoethene-1,1,2-tricarbonitrile $\mathbf{2 6 0}$ in presence of ammonium acetate in dioxane at room temperature to give the spiro derivative $\mathbf{2 6 1}$ (Scheme 57). ${ }^{147,148}$

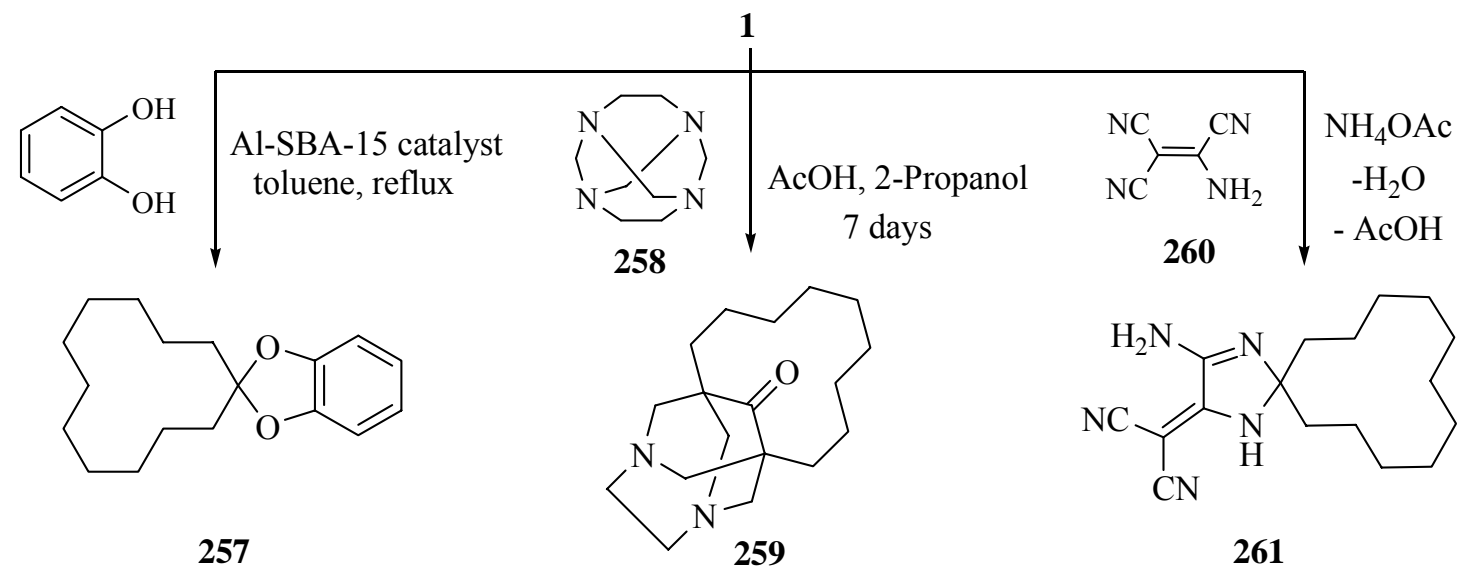

\section{Scheme 57}

3.7.2 Fused heterocyclic systems. Cyclododeca[b]pyrrole derivative 263 was synthesized via modified Knorr-pyrrole condensation between $\mathbf{1}$ and phenyl-hydrazone 262 under reducing conditions $(\mathrm{Zn} / \mathrm{AcOH}) .{ }^{149}$

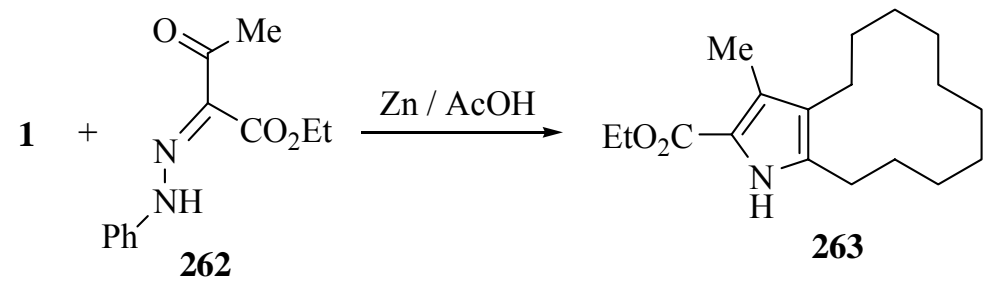


The $\mathrm{SnCl}_{2}$ reduction of 2-nitrocyclododecanone 162 or 2-bromo-12-nitrocyclododecanone 264 gave a colorless compound 2,3,5,6-bis-(ortho-1,10-decylidene)dihydropyrazine $\mathbf{2 6 6},{ }^{150,151} \mathrm{X}$-ray studies showed that the product exists in the 1,4-dihydropyrazine form $\mathbf{2 6 6}$ and not in diimino form 265. Compound 265 can be transformed to the pyrazine form 267 by the effect of oxygen (Scheme $58)$.

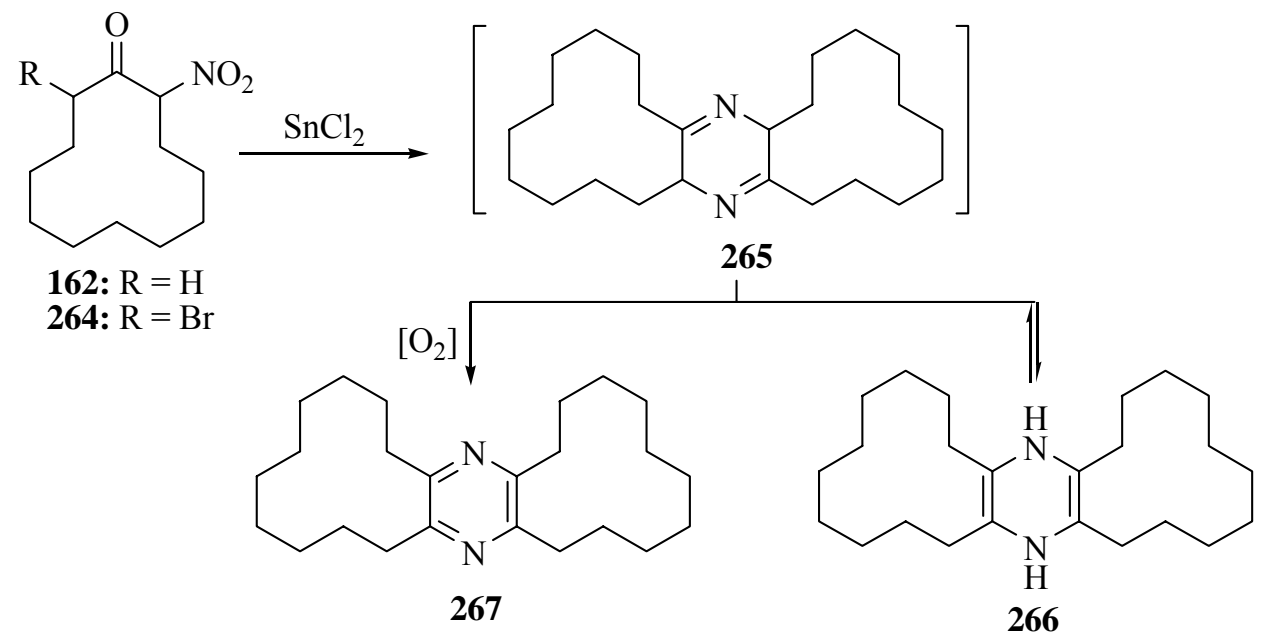

\section{Scheme 58}

Reaction of 2-(dimethoxymethyl)cyclododecanone $\mathbf{2 6 8}$ with hydroxylamine hydrochloride in toluene under reflux for $\mathbf{2 4}$ hours then treating the solution with polyphosphoric acid in toluene under reflux gave oxazole 269 in $46 \%$ yield. ${ }^{152}$

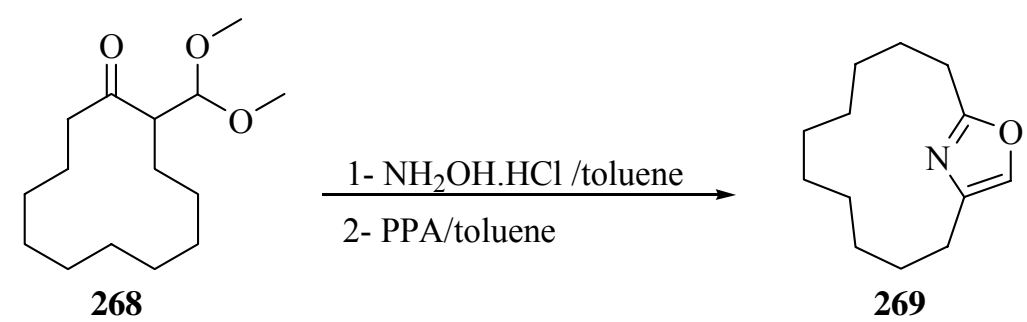

While, [9](3,5)pyrazolophane 271 and 11-methyl[9](2,4)furanophane 274 were prepared from 2-cyclododecenone 218, ${ }^{153}$ and their spectral properties were discussed (Scheme 59). ${ }^{154}$ 


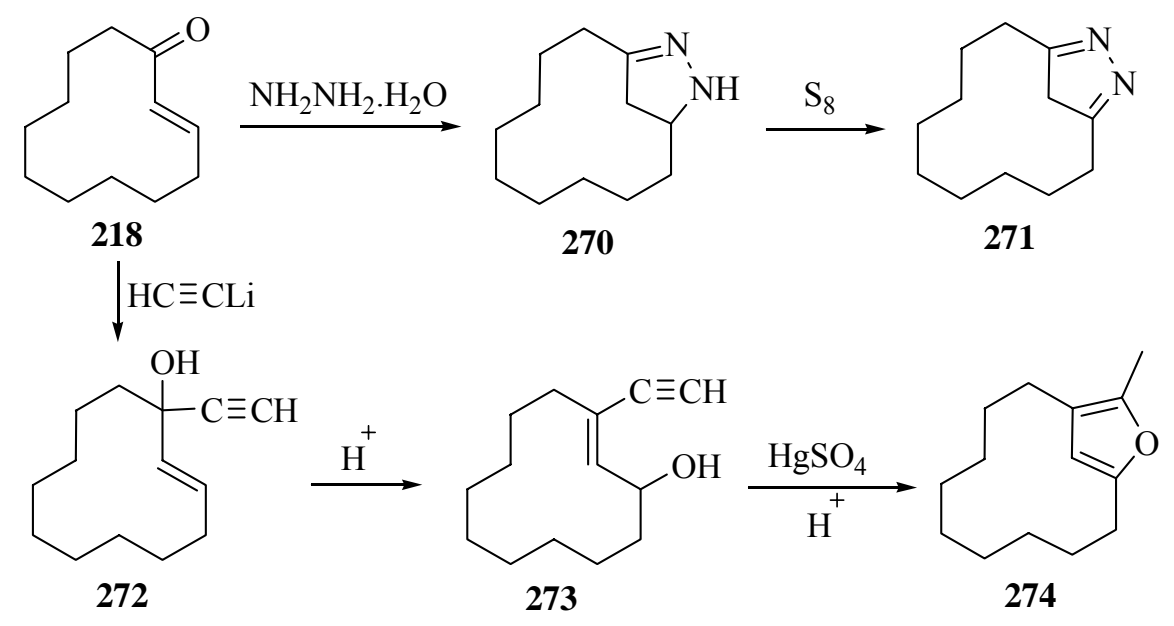

\section{Scheme 59}

Utilization of trimethylsilyl chloride (TMSCl) as a Lewis acid allowed one-pot chemoselective multicomponent Biginelli reaction between 1, urea or thiourea and aldehydes to afford fused heterobicyclic compounds 276a-g. ${ }^{155}$

\section{Table 1}

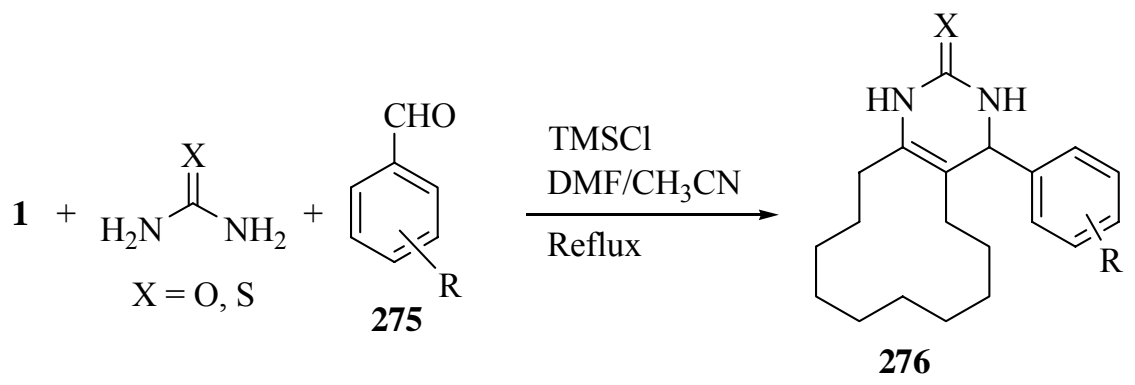

\begin{tabular}{cccccccc}
\hline Product & $\mathbf{X}$ & $\mathbf{R}$ & Yield\% & Product & $\mathbf{X}$ & $\mathbf{R}$ & Yield\% \\
\hline $\mathbf{2 7 6 a}$ & $\mathrm{O}$ & $4-\mathrm{Cl}$ & 87 & $\mathbf{2 7 6 e}$ & $\mathrm{O}$ & $2-\mathrm{Br}$ & 85 \\
$\mathbf{2 7 6 b}$ & $\mathrm{O}$ & $2-\mathrm{OCH}_{3}$ & 96 & $\mathbf{2 7 6 f}$ & $\mathrm{S}$ & $4-\mathrm{OCH}$ & 89 \\
$\mathbf{2 7 6 c}$ & $\mathrm{O}$ & $2-\mathrm{F}$ & 93 & $\mathbf{2 7 6 g}$ & $\mathrm{S}$ & $2-\mathrm{F}$ & 83 \\
276d & $\mathrm{O}$ & $2-\mathrm{Cl}$ & 90 & & & & \\
\hline
\end{tabular}

The aminothiazolium salt 277 was obtained in $72 \%$ yield by heating $\mathbf{1}$, thiourea and iodine in a one pot reaction. ${ }^{156}$

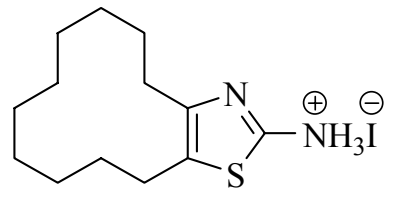


Spirohydantoin 278 and its amino derivative 279 were synthesized and their biological activity was studied. The synthesis of $\mathbf{2 7 8}$ was achieved by refluxing a mixture of $\mathbf{1}$, potassium cyanide and ammonium carbonate in aqueous ethanol. Treatment of the resulting spirohydantoine with hydrazine hydrate furnished the 3-amino derivative 279 (Scheme 60). ${ }^{157}$

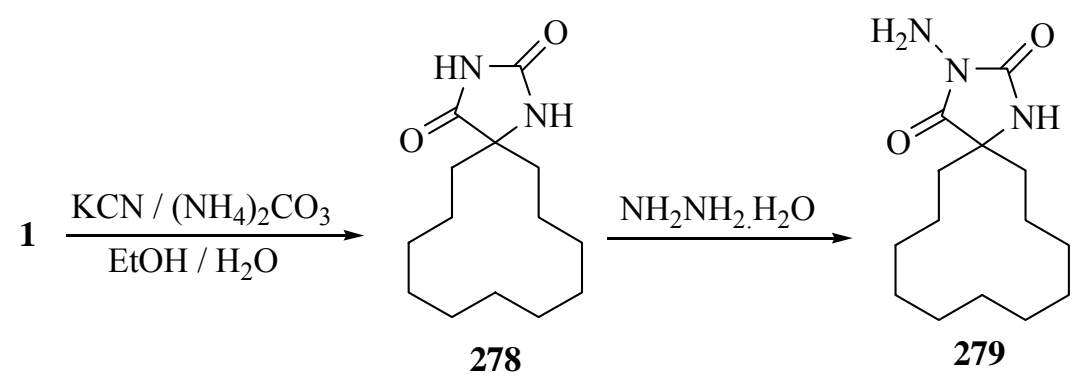

\section{Scheme 60}

The Stobbe condensation of cyclododecanone 1 with diethyl succinate gave the exocyclic carboxylic acid $\mathbf{2 8 0}$ which then underwent cyclization with zinc chloride in polyphosphoric acid to the $\delta$-keto $\beta, \gamma$-unsaturated ester 281. Acid hydrolysis of 281 with simultaneous decarboxylation gave the $\alpha, \beta$-unsaturated ketone 282. Wolff-Kizhner reduction of the obtained bicyclo[10.3.0]-1(12)pentadecen-13-one $\mathbf{2 8 2}$ gave the two isomeric olefins $\mathbf{2 8 3}$ and 284, from which the trisubstituted olefin $\mathbf{2 8 4}$ is formed with a 70\% yield. The Schmidt reaction for compound 284 and dehydrogenation over $\mathrm{Pd} / \mathrm{C}$ gave 2,6-pyridinophane $\mathbf{2 8 8}$ and its 2,3 isomer $\mathbf{2 8 9}$ (Scheme 61). ${ }^{158}$

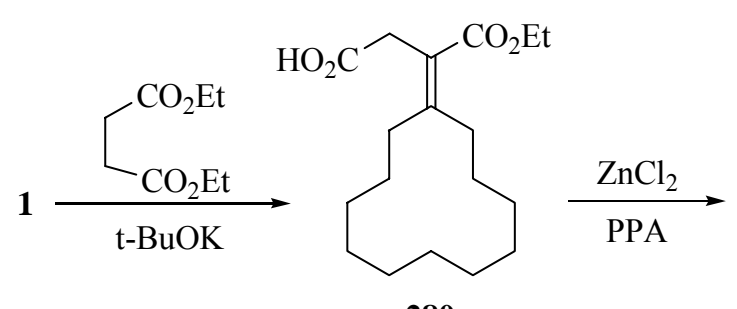

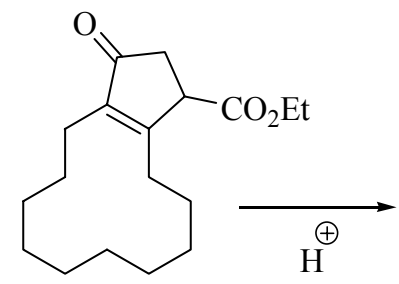

281

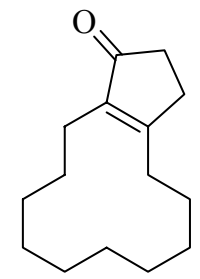

282

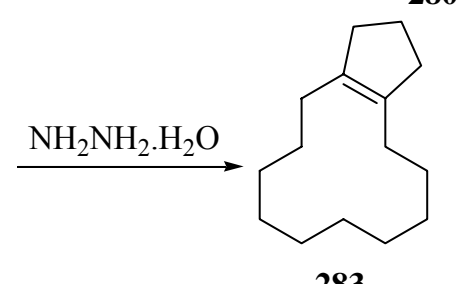

283

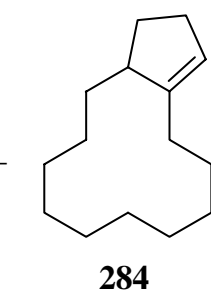<smiles>C=NC1CCCCCCCCCC2CCCC(=N2)CCC1</smiles>

286

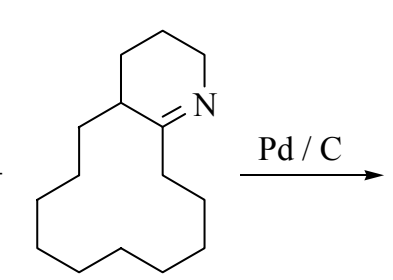

287

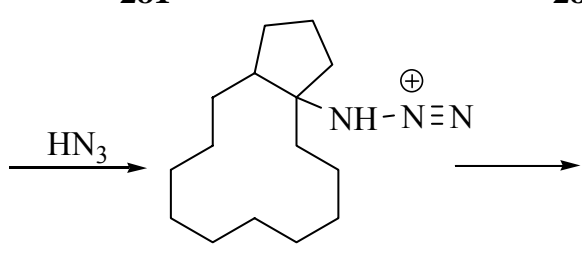

285

\section{Scheme 61}

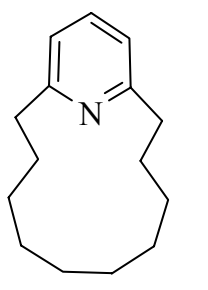

288<smiles>c1cnc2c(c1)CCCCCCCCCC2</smiles>

289 
Cyclododeca[b]pyridine 289 was also synthesized from 1 via hydrogenation of the oxonitrile 290 into 291 which on dehydrogenation over Pd/C furnished $289 .{ }^{158}$ The oxonitrile 290 proved to be a valuable intermediate where it was also used as a key precursor in the synthesis of dihydropyridone 293 and pyridone 294 (Scheme 62). ${ }^{158}$

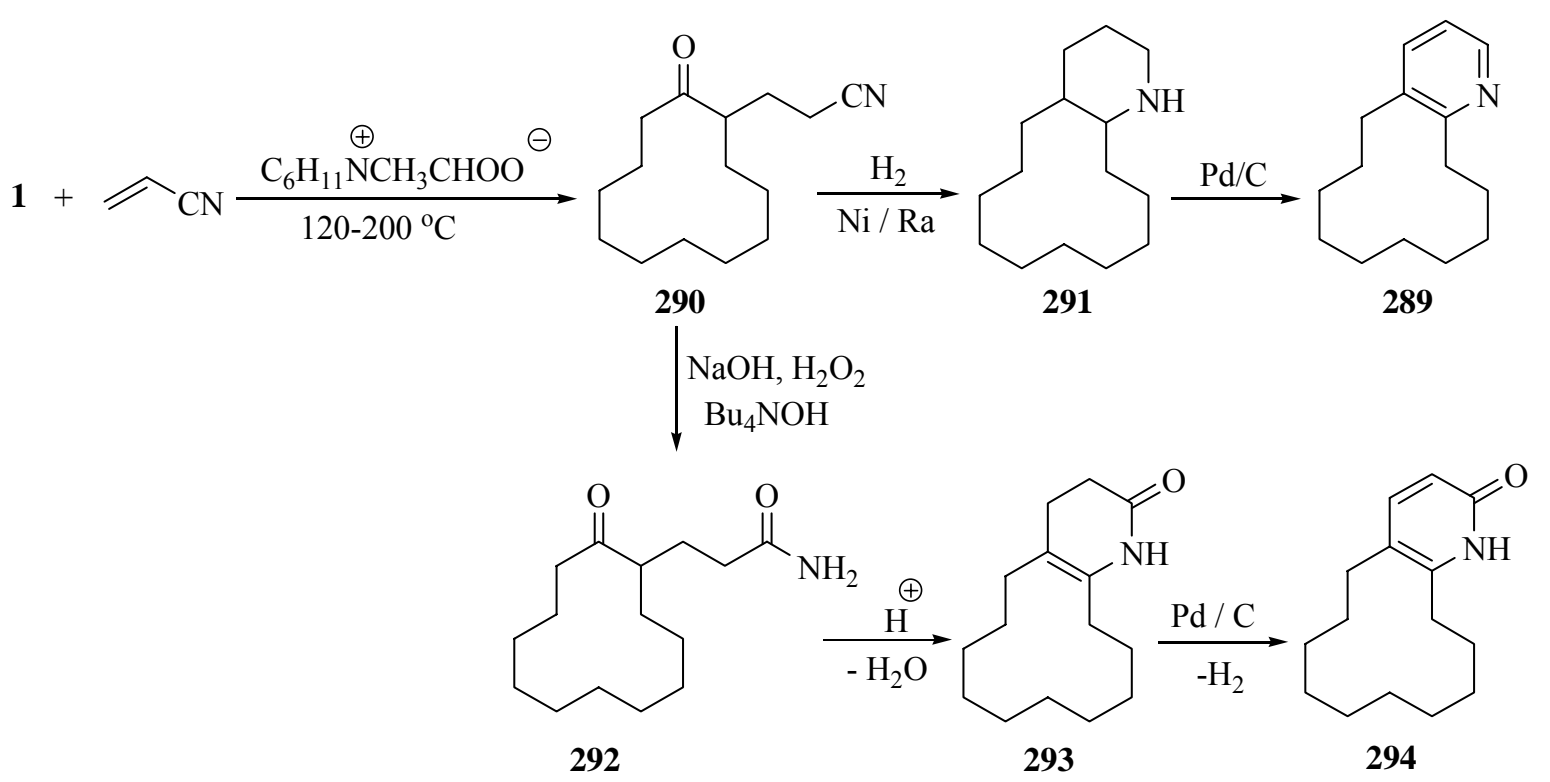

\section{Scheme 62}

A second approach to the synthesis of the pyridone 294 involves the reaction of $\mathbf{1}$ with 1,1,1,3tetrachloro-3-acetoxypropane 295 with the formation of the $\alpha$-pyrone 296. Its transformation by the action of ammonium acetate gave the (2,3)pyridinophane 294 (Scheme 63). ${ }^{158}$<smiles>CCC(=O)OC(Cl)CC(Cl)(Cl)OC(C)=O</smiles>

\section{Scheme 63}

Significant successes by Japanese chemists in the use of new reagents for the Beckmann rearrangement made it possible to realize an original and effective approach to the synthesis of muscopyridines. So, muscopyridine $\mathbf{3 0 0}$ was synthesized from $\mathbf{1}$ in five steps as presented in Scheme $64 .{ }^{158}$ 


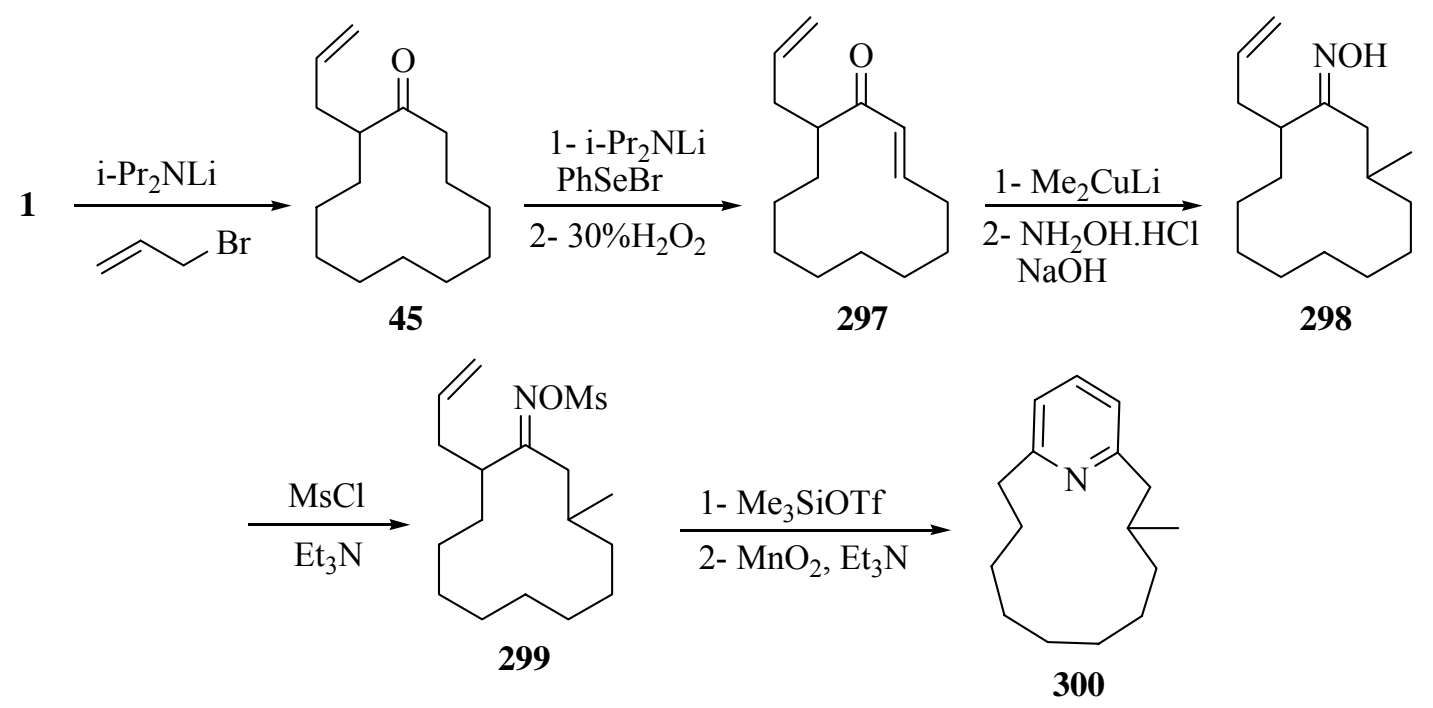

\section{Scheme 64}

Tetrahydrocarbazole derivatives 303 have been prepared in one flask from indols 301, 1 and maleic acid with acid catalysis. The reaction involves a condensation of the indol with the ketone followed by an in situ trapping of the vinylindol $\mathbf{3 0 2}$ in a Diels-Alder reaction with maleic acid. ${ }^{159}$ Also, hydrolysis of 303 followed by dehydrogenation afforded the anhydrides 305 and 306, respectively (Scheme 65).

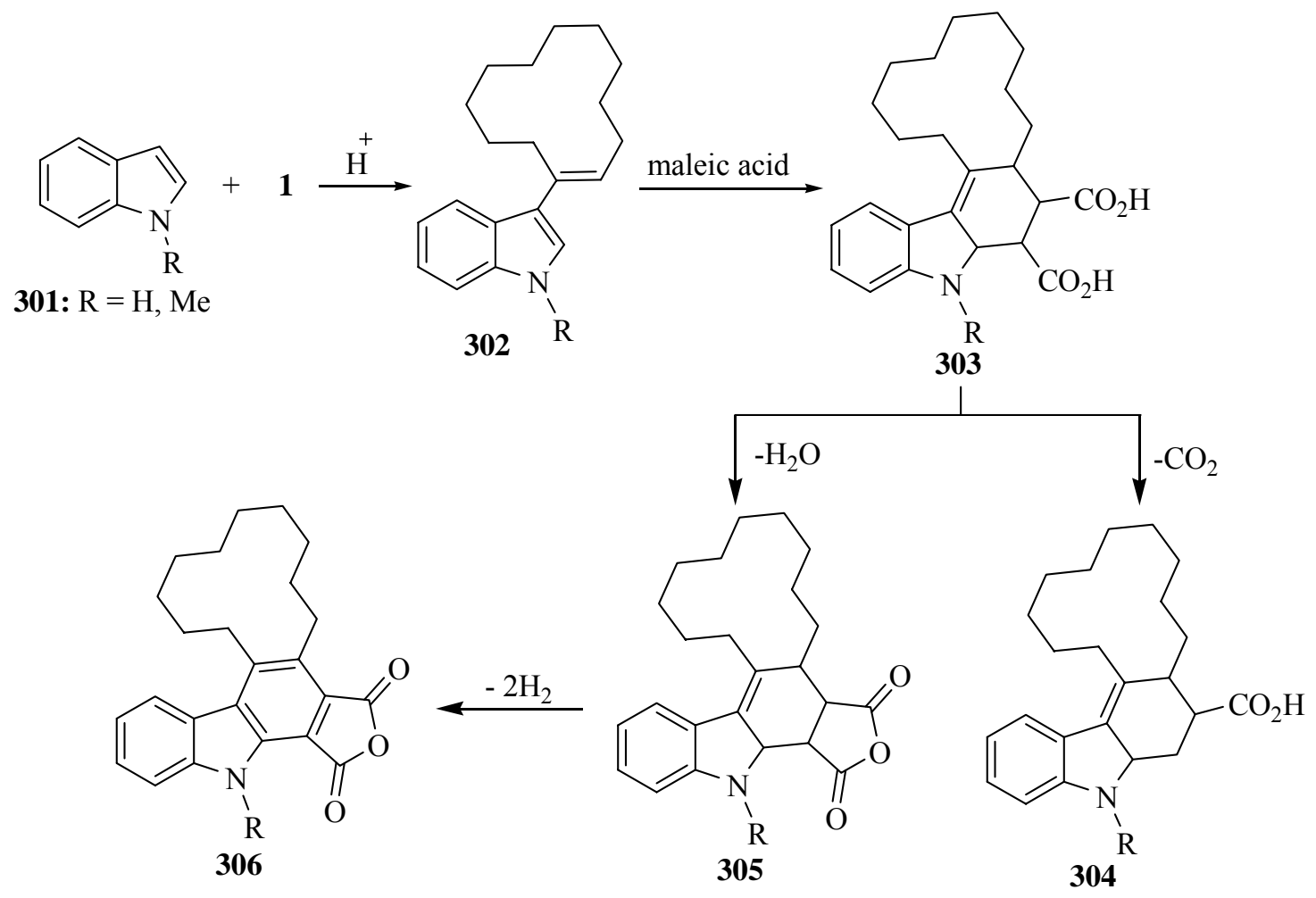

\section{Scheme 65}


The complex base $\mathrm{NaNH}_{2}-t$-BuONa allowed expeditious syntheses of indoles 309a, b by arynic cyclization of cyclododecanone imine derivative $\mathbf{3 0 8}$ which prepared from chloroaniline derivative 307 and 1. ${ }^{160}$ Furthermore, the indol derivatives 311 are obtained via the reaction of $\mathbf{1}$ with pyrazolone derivatives $\mathbf{3 1 0}$ in refluxing glacial acetic acid (Scheme 66). ${ }^{161}$

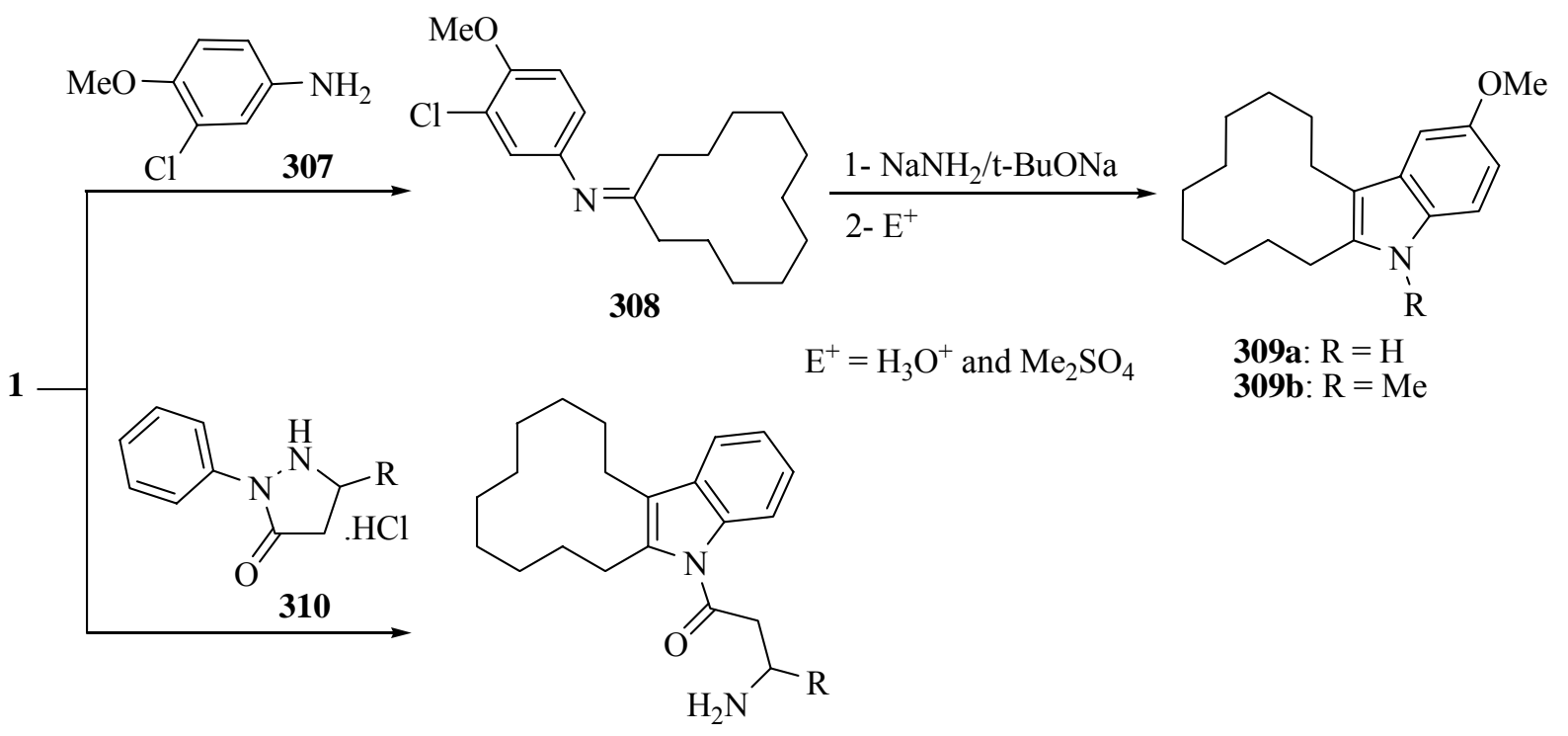

311: $\mathrm{R}=\mathrm{H}, \mathrm{Me}$

\section{Scheme 66}

The synthesis of 2-oxabicyclo[4.10.0]hexadec-1(6)-ene 179, which is the key material in the production of pentadecanolide (tibetolide), a valuable fragrant macrocycliclactone with a fine musk odor was achieved by alkylation of 1 with 3-tert-butoxy- and 3-benzyloxy-propyl bromides 312a, b under phase-transfer catalysis conditions in the presence of an alkali, to obtain 2-(3alkoxypropyl)cyclododecanones 313a, b which then transformed into 179 according to Scheme $67 .^{162}$

4,5-Decamethyleneimidazole 317, 4,5-decamethyleneoxazole 318, and 4,5-decamethyleneimidazolone 319 were synthesized by reactions of 2-bromocyclododecanone 25 with formamide and urea, respectively (Scheme 68). ${ }^{163}$ 


$$
\mathbf{1}+\mathrm{BrCH}_{2} \mathrm{CH}_{2} \mathrm{CH}_{2}(\mathrm{OR})_{2} \underset{\mathrm{DB}-18-\mathrm{C}-6}{\stackrel{\mathrm{KOH} / \text { Toluene }}{\longrightarrow}}
$$

312a, b<smiles>[R]CCCC1CCCCCCCCCCC1=O</smiles>

313a: $\mathrm{R}=\mathrm{Bz}$

313b: $\mathrm{R}=\mathrm{Bu}^{t}$<smiles>C=CCOCCCC1CCCCCCCCCCC(=O)C1CCCOC(C)(C)C</smiles>

313b

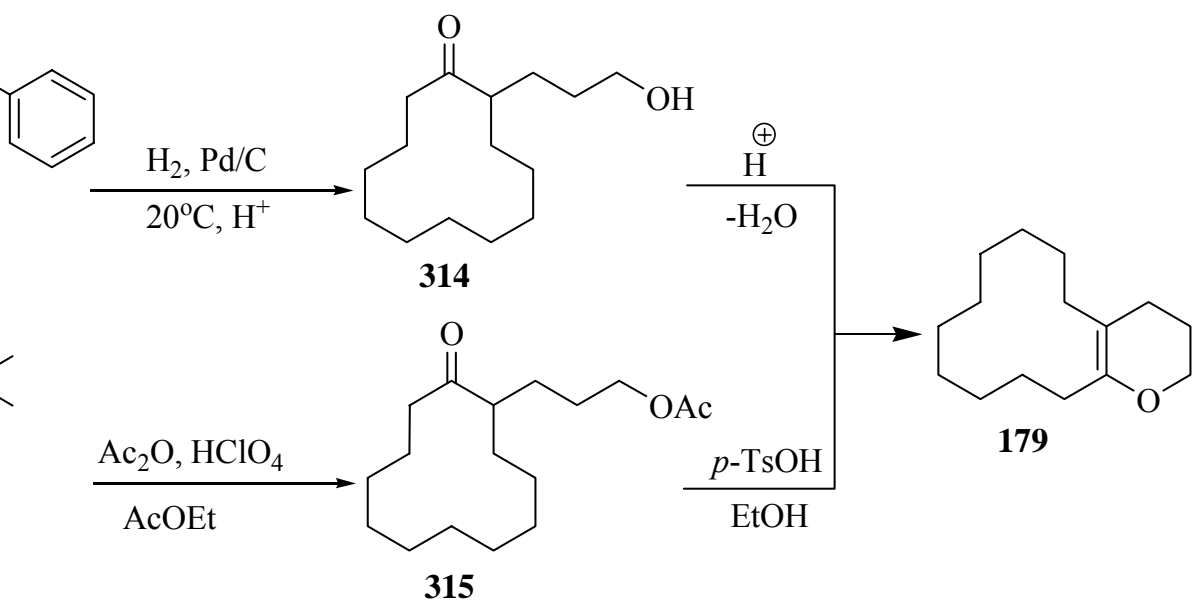

\section{Scheme 67}

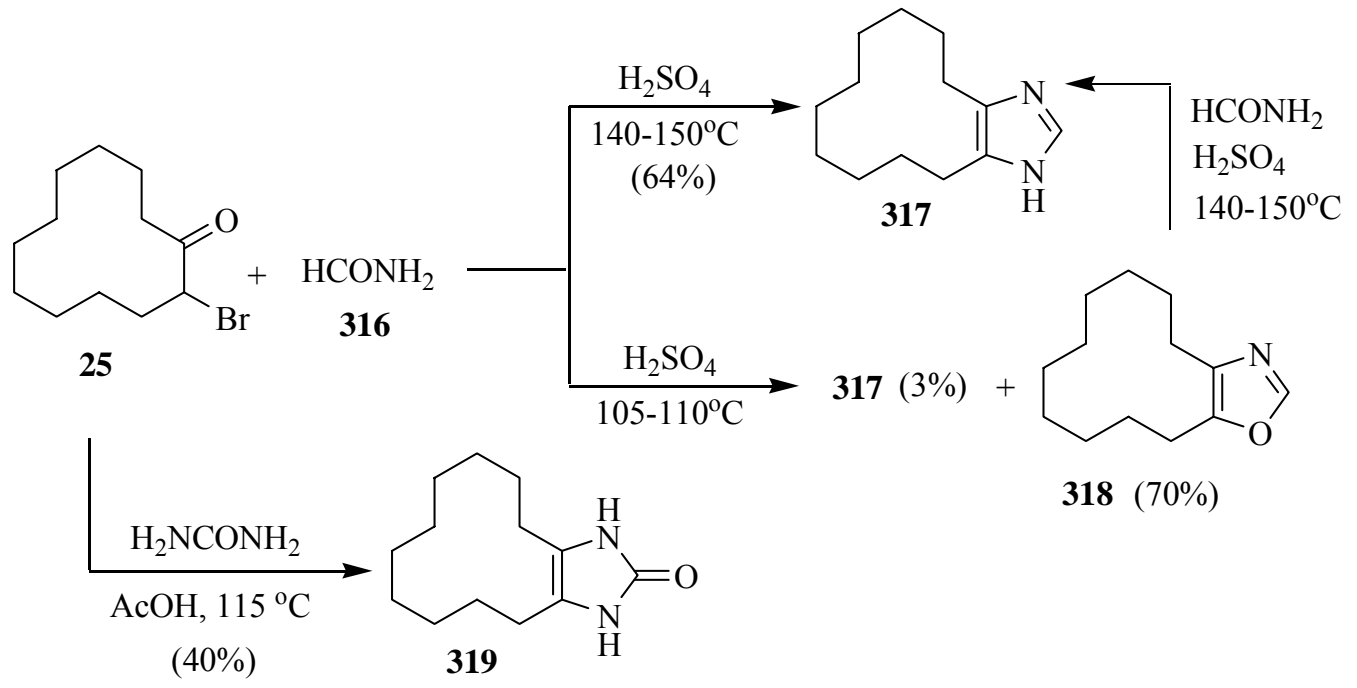

\section{Scheme 68}

While, condensation of 2-hydroxymethylenecyclododecanone 98 with hydroxylamine hydrochloride and hydrazine hydrate resulted in formation of 4,5-decamethyleneisoxazole $\mathbf{3 2 0}$ and 4,5-decamethylene-pyrazole 321, respectively (Scheme 69). ${ }^{163}$ 


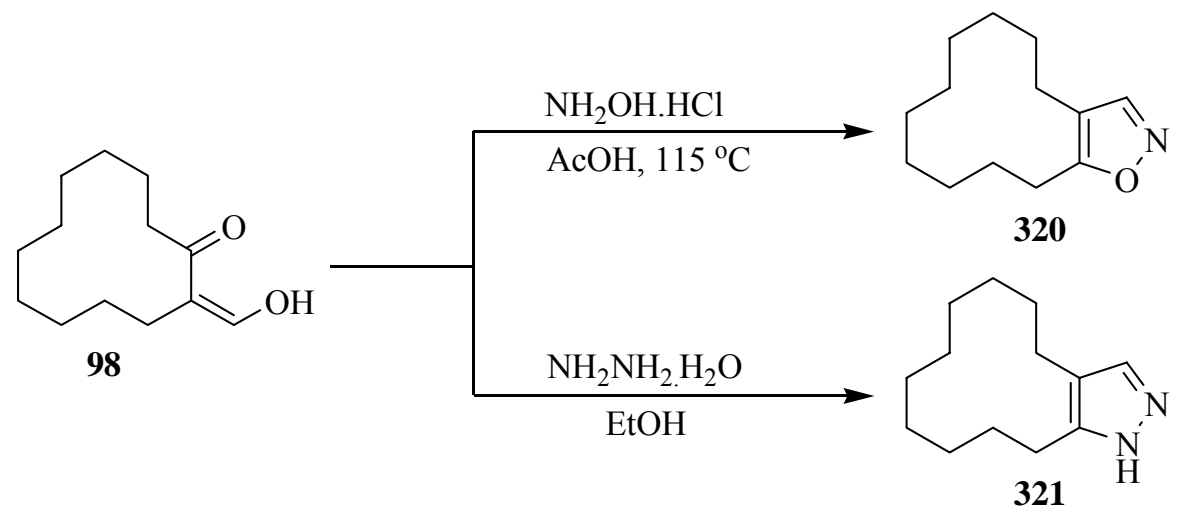

\section{Scheme 69}

The triazolothiadiazine derivatives 323 were obtained in low yield via direct condensation of 2bromocyclododecanone 25 with the aminotriazole derivatives $322 .{ }^{164}$

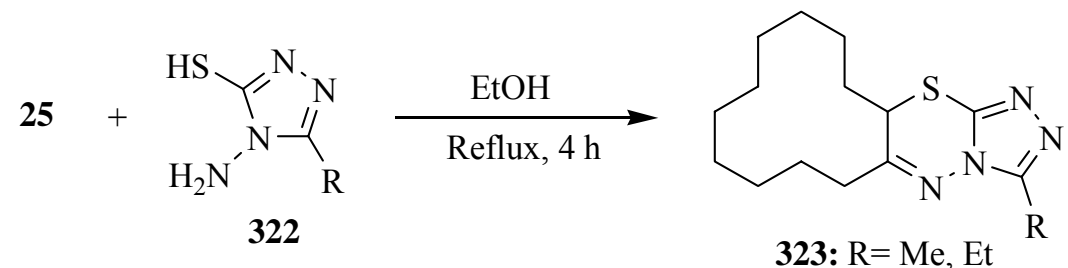

Brassylic acid 325 is used in the perfume industry for the preparation of the valuable fragrance, ethylenebrassylate, which has a musk odor. A simple method is proposed for the preparation of brassylic acid by the alkaline hydrolysis of 5,6,7,8,9,10,11,12,13,14-decahydrocyclododeca-[1,2d]pyrimidine-2,4(1H,3H)dione 324, which is the product of the condensation of 1 with urea or biuret. On the other hand, condensation of the cyclododecanone with thiourea proceeds differently, leading to $5,6,7,8,9,10,11,12,13,14$-decahydrocyclododeca[1,2- $d]$ pyrimidine $(1 H, 3 H)$-spirocyclododecane-2-thione 326 (Scheme 70). ${ }^{165}$

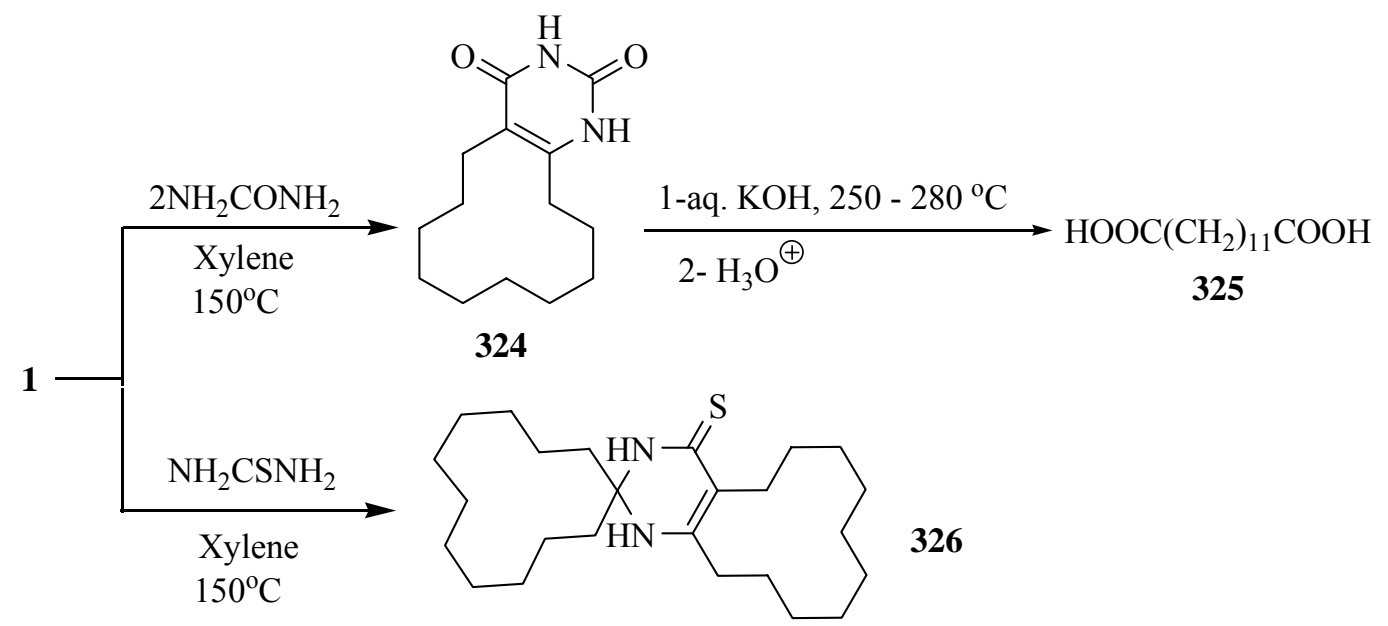

\section{Scheme 70}


The condensation reaction of 1-benzyl-1H-1,2,3-triazole-4,5-dicarboxaldehyde 327 with 1 under aldol condensation conditions resulted in formation of the hydroxyl cycloheptatriazolone derivative 328. $^{166}$

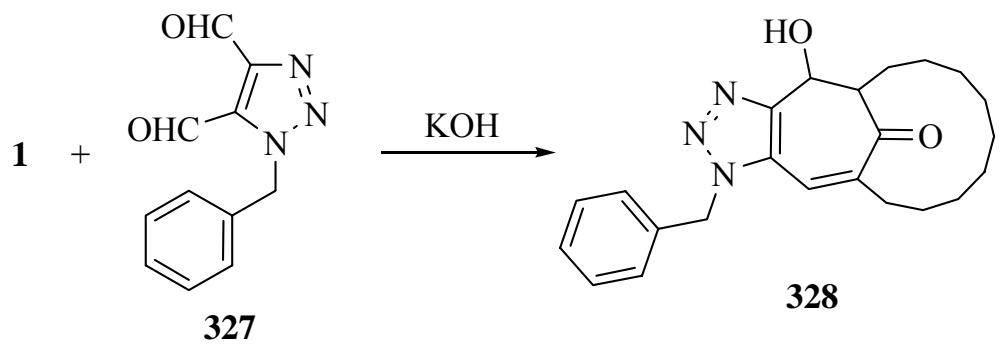

Cyclododecanone 1 was converted conventionally to the dithioketals 329a, b and then to monosulfoxides 330a, b. ${ }^{167}$ Action of $p$-toluenesulfonic acid mono hydrate converted 330a to the corresponding 1,4-dithiine 331. Compound 331 was also obtained by a different route, through the action of 1,2-ethanedithiol on 2-bromocyclododecanone 25 in $67 \%$ yield. However this condensation reaction was modeled on an analogous behavior of acyclic $\alpha$-haloketones reported by Rubinstein and Wuerthele. ${ }^{168}$ Also, treatment of 2-bromocyclododecanone 25 with the monoanion from 2-mercaptoethanol gave the sulfide 332 as illustrated by $\mathrm{IR}$ and ${ }^{1} \mathrm{H}$ NMR. $p$ Toluenesulfonylchloride in dry pyridine converted sulfoxide 330b almost quantitatively to the liquid trisubstituted alkene 333 which isomerized to the crystalline tetra-substituted alkene 334 by action of dry hydrogen chloride (Scheme 71). ${ }^{169}$

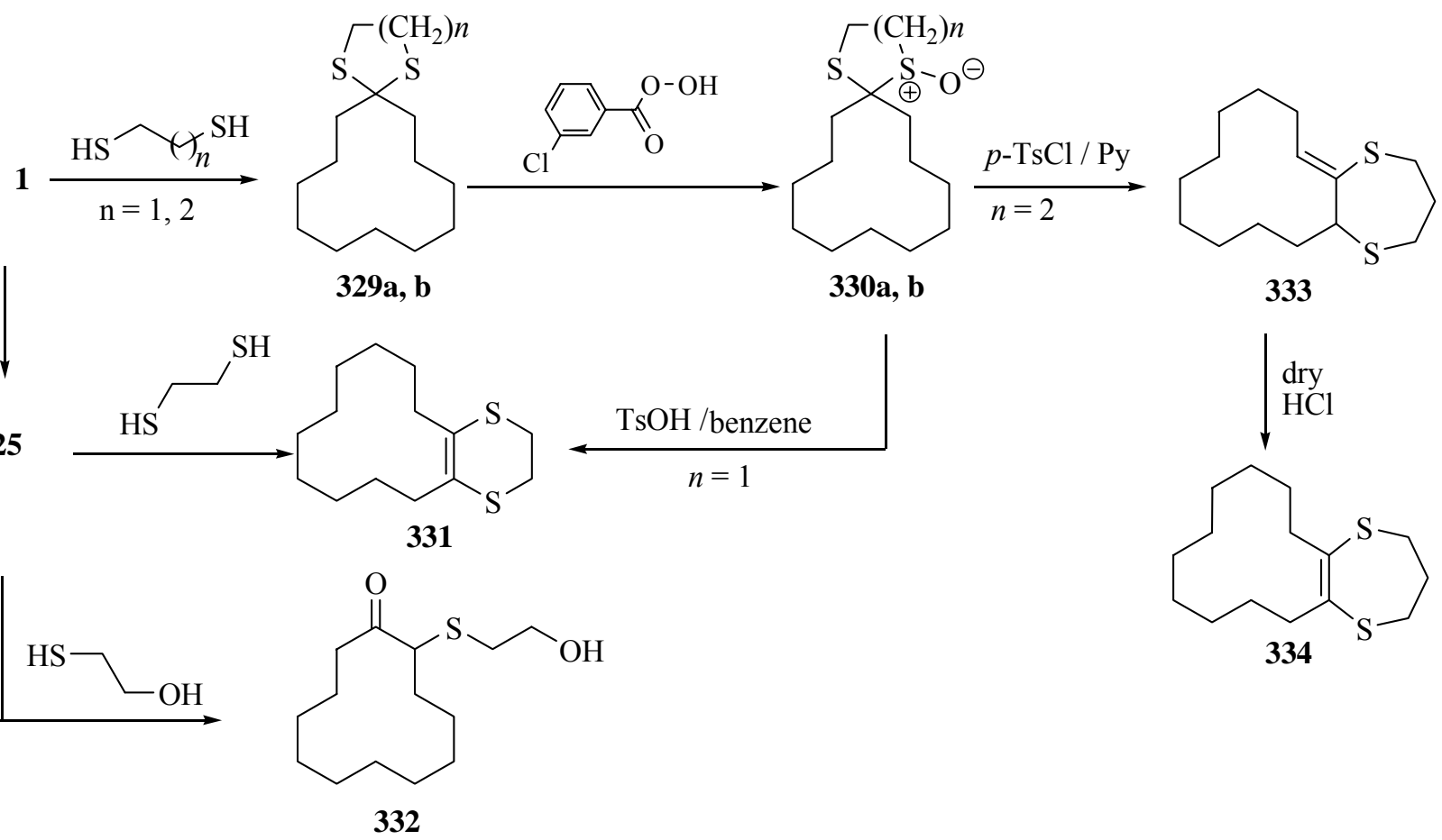

\section{Scheme 71}


This effective route for preparation of compound 334 as fused bicyclic 12/7 ring system, encourage Ong, ${ }^{170}$ to apply the same methodology whereby fused bicyclic $12 / 8$ ring system represented by 338 was synthesized. Accordingly, attempted preparation of dithioketal of cyclododecanone 336 by reaction of 1 with 1,4-butanedithiol and $\mathrm{BF}_{3} . \mathrm{Et}_{2} \mathrm{O}$ resulted in formation of the dimmer 335. However, repeating the reaction, but using $\mathrm{AlCl}_{3} / \mathrm{CH}_{2} \mathrm{Cl}_{2}$, in lieu of $\mathrm{BF}_{3}$. $\mathrm{Et}_{2} \mathrm{O}$ converted 1 to the desired dithioketal 336 in good yield (67\%) which then converted to the monosulfoxide 337 which in turn gave the desired compound 338 under the influence of TsCl/Py system. ${ }^{169}$ The secondary mercaptan cyclododecanethiol 339 was synthesized in $90 \%$ yield by butyl lithium reduction of thioketal 329a (Scheme 72). ${ }^{171}$

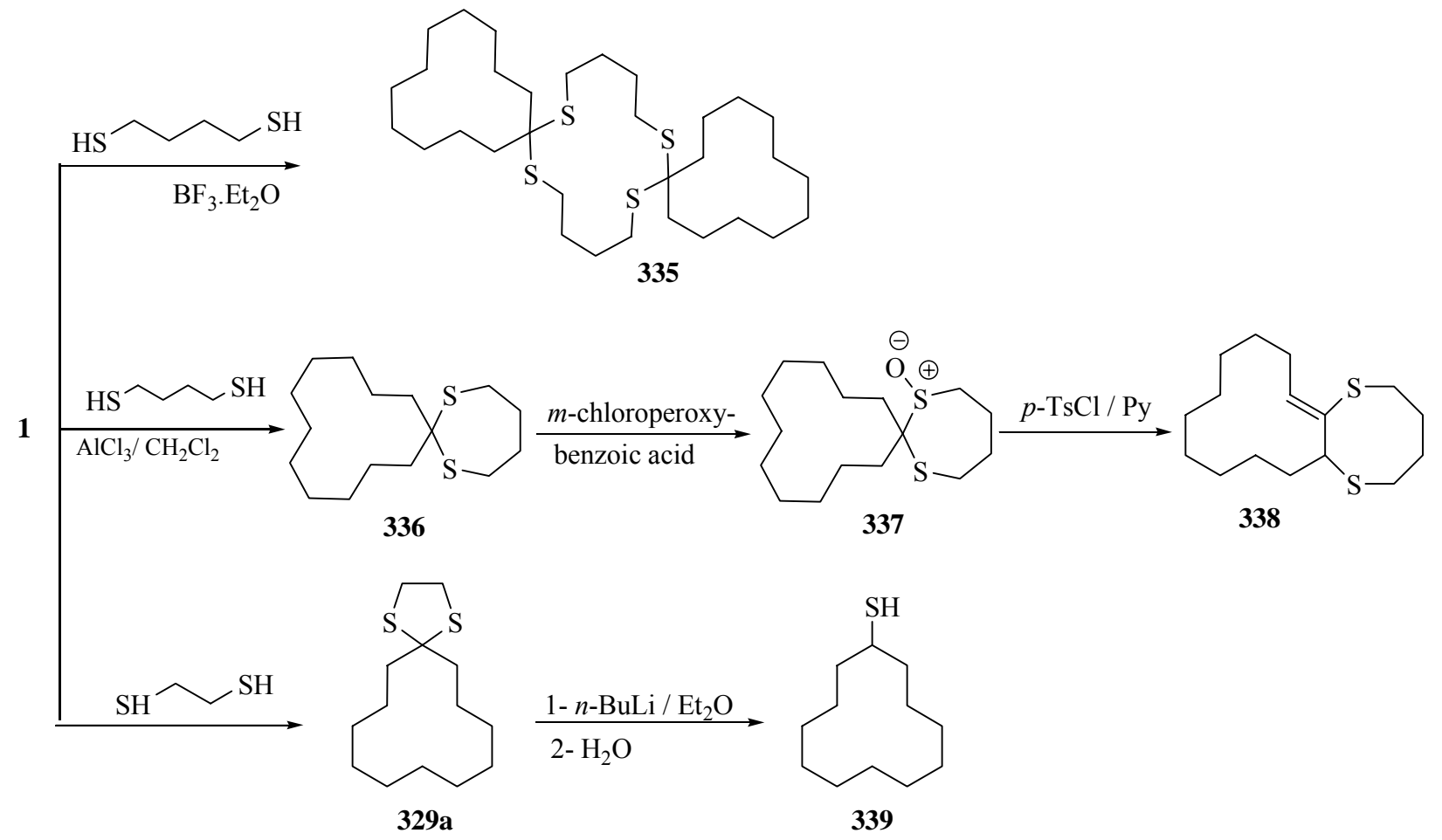

\section{Scheme 72}

Base catalyzed condensation of 1,2-cyclododecanedione $\mathbf{3 8}$ and 2-aminonicotinaldehyde $\mathbf{3 4 0}$ afforded 3,3'-octamethylene-2,2'-bi-1,8-naphthyridin 341 in $70 \%$ yield. ${ }^{172}$<smiles>O=C1CCCCCCCCCC1=O</smiles>

38<smiles>Nc1ncccc1C=O</smiles>
340<smiles>c1cnc2nc3c(cc2c1)CCCCCCCCc1cc2cccnc2nc1-3</smiles>

341 


\subsection{Photochemistry}

Irradiation of 2-iodocyclododecanone 27 under high pressure mercury lamp gave 2hydroxycyclododecanone 35 in a good yield. ${ }^{173}$ Also, the reaction of 2-iodocyclododecanone 27 in hexane containing triethylamine (molar equivalent) at room temperature under nitrogen atmosphere with a $400 \mathrm{~W}$ mercury lamp for 2 hours gave cyclododec-2-enone 224 (70\%) and 1 (30\%) (Scheme 73). ${ }^{174}$

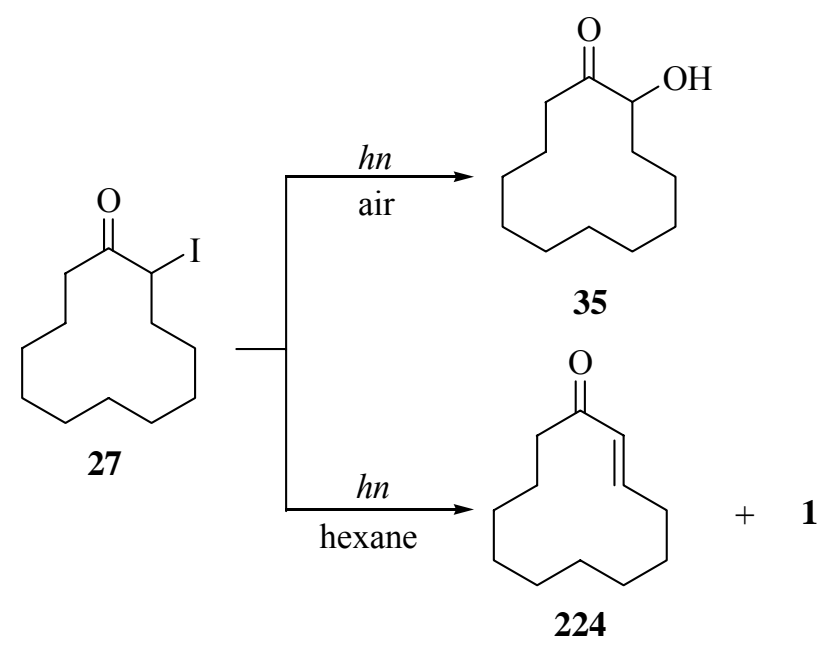

\section{Scheme 73}

While irradiation of $\mathbf{1}$ in methanol at room temperature under a nitrogen atmosphere with a 400 W mercury lamp for 4 hours gave 1,1-bicyclododecanol 342 and cyclododecanol $24 .{ }^{175}$ On the other hand, irradiation of $\mathbf{1}$ in $n$-hexane with high-pressure mercury lamp in atmosphere of nitrogen for 2.5 hours afforded bicyclo[8.2.0]dodecan-1-ol 343 which on dehydration with thionyl chloride afforded bicyclo[8.2.0]dodec-1(10)-ene 344. Oxidation of the bicyclic olefin 344 resulted in formation of cyclododecane-1,4-dione 345 (Scheme 74). ${ }^{176,177}$

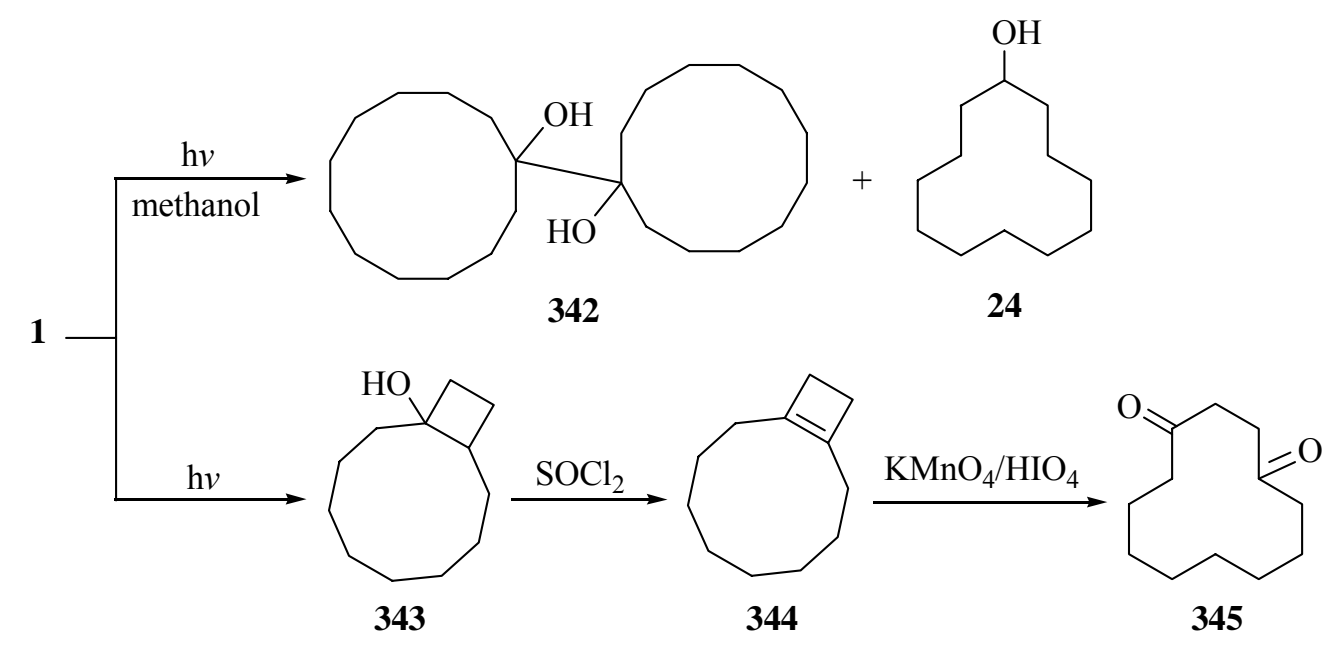

\section{Scheme 74}


A solution of bicyclo[9.4.1]-hexadecan-16-one $\mathbf{6 1}$ in $\mathrm{CCl}_{4}$ was irradiated with a high pressure mercury arc lamp under oxygen stream to afford 20-30\% yields of cyclopentadecanone 348 (Scheme 75). ${ }^{178}$

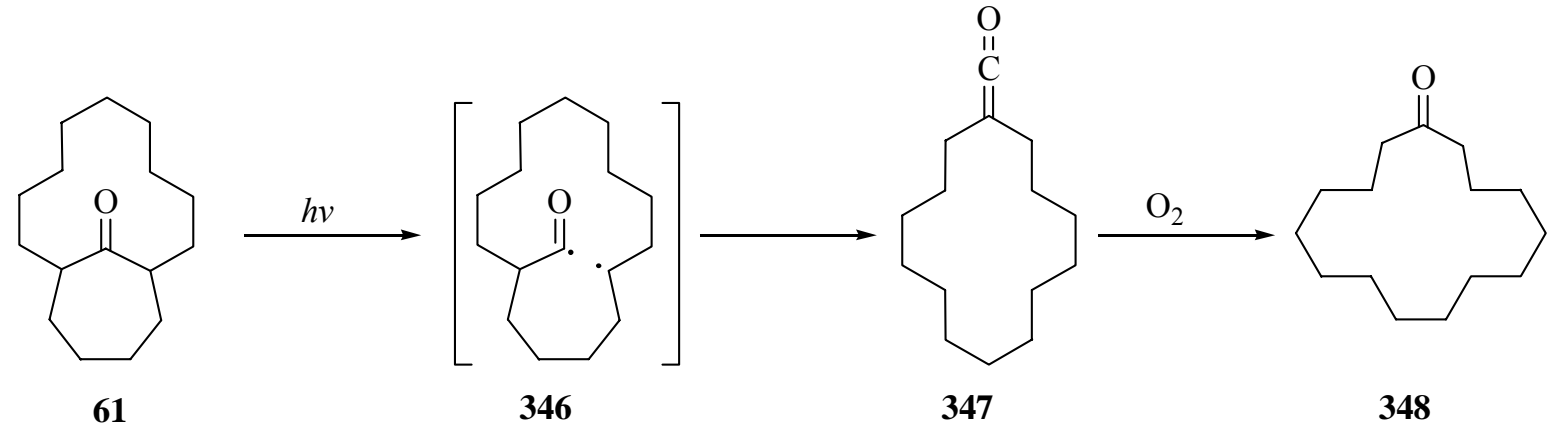

\section{Scheme 75}

\subsection{Miscellaneous reactions}

The reaction of 1-chlorovinyl $p$-tolylsulfoxide derivative 350 , which is derived from cyclododecanone 1 and chloromethyl $p$-tolyl sulfoxide 349, with lithium acetylide 351 gave the adduct 352 in moderate yield. Treatment of 352 with Grignard reagent $(i$-PrMgCl) resulted in the formation of magnesium carbenoid 353 by the sulfoxide-magnesium exchange reaction. 1,2Carbon-carbon insertion (1,2 CC insertion) reaction of the generated magnesium carbenoid 353 took place to afford the conjugated enyne 354 in high yield (Scheme 76$).{ }^{179}$

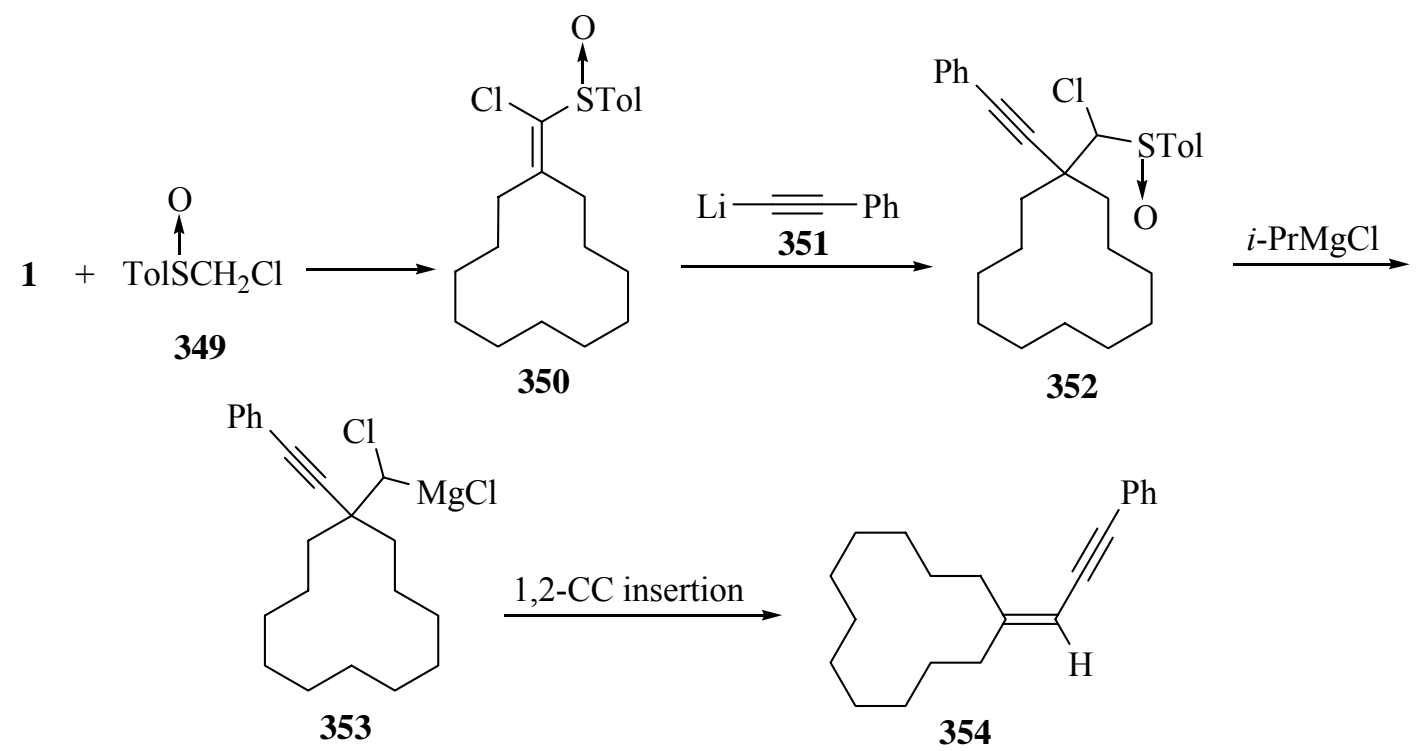

\section{Scheme 76}


Also, treatment of $\mathbf{3 5 0}$ with $t$ - $\mathrm{BuMgCl}$ and $i$-PrMgCl in THF afforded magnesium alkylidene carbenoid 355 which then treated with lithium ester enolate 356 to give the $\beta, \gamma$-unsaturated carboxylic acid ester 357 in a good yield. When this reaction was conducted with lithium enolate of $\alpha$-chlorocarboxylic ester 358, allenic ester 359 was obtained (Scheme 77). ${ }^{180}$

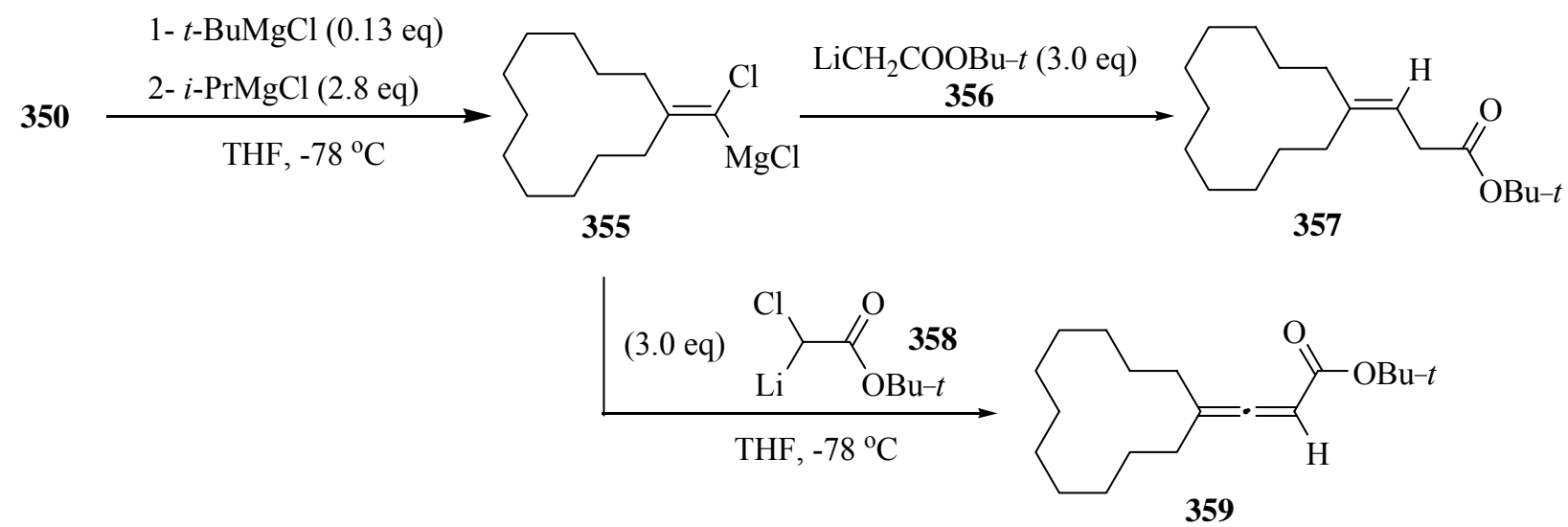

\section{Scheme 77}

The sulfenylation of $\mathbf{1}$ has been achieved using $N$-chlorosuccinimide (NCS) under mild conditions to afford 361 in good yield. ${ }^{181}$ Cyclododecanone 1 undergoes smooth thiocyanation with ammonium thiocyanate in the presence of molecular iodine in refluxing methanol to produce the corresponding $\alpha$-ketothiocyanate 362 in a very good yield. ${ }^{182}$ Treatment of $\mathbf{1}$ with two equivalents of $t$-butyl isonitrile 363 in presence of $\mathrm{BF}_{3}$. $\mathrm{OEt}_{2}$ in nonpolar solvent afforded the $\beta$, $\gamma$-unsaturated $\alpha$ oxocarboxylic amide 364. One equivalent of the isocyanide is the source of the $\alpha$-carbon atom in this reaction (Scheme 78). ${ }^{183}$

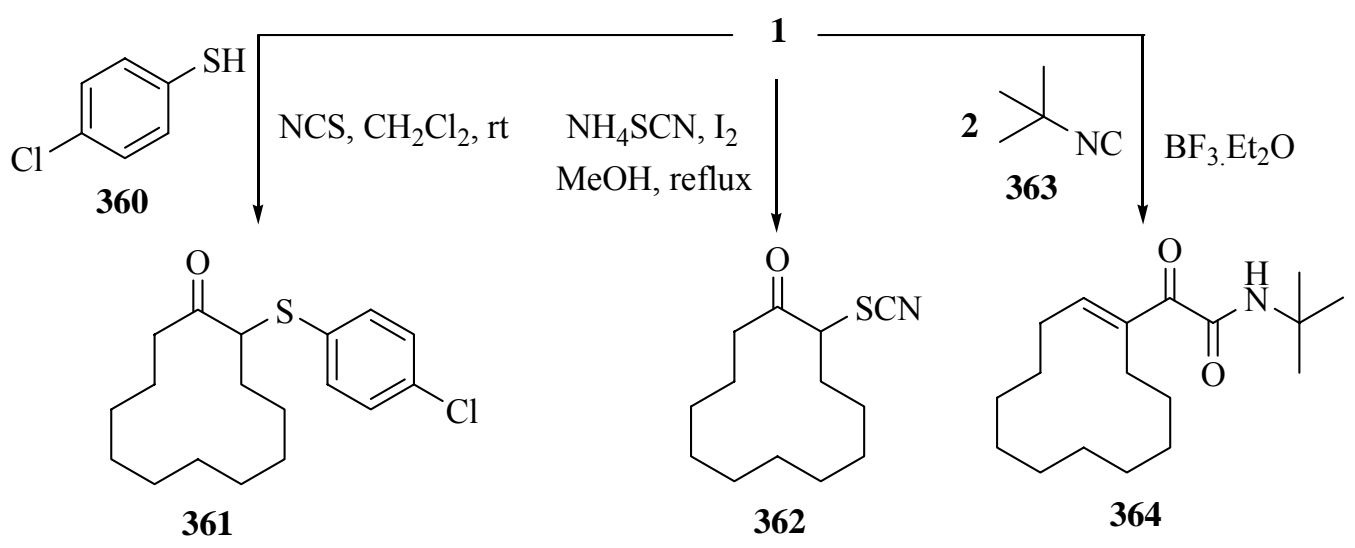

\section{Scheme 78}

Reaction of the 2,4,6-triisopropylbenzenesulfonylhydrazone of cyclododecanone 366 with $\alpha$ magnesio methyl phenyl sulfone afforded the methylidene derivative 367 contaminated with the 
Shapiro product 368. ${ }^{184}$ The spiroenone 372 was synthesized from $\mathbf{1}$ in four steps sequence in a good yield (Scheme 79$).{ }^{185}$

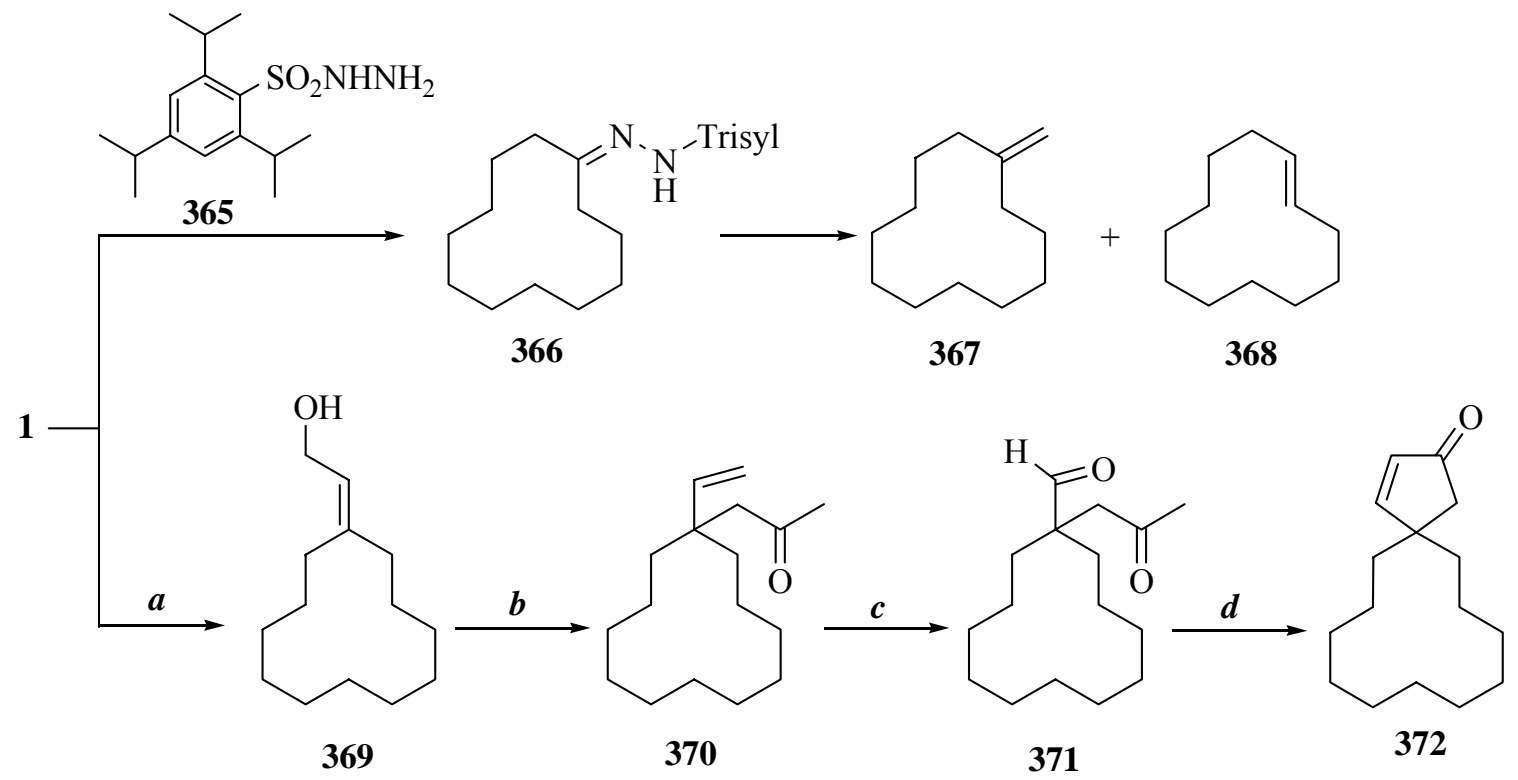

Reagents: (a) (i) NaH, (EtO) ${ }_{2} \mathrm{POCH}_{2} \mathrm{COOEt}$; (ii) $\mathrm{LiAlH}_{4}$; (b) $\mathrm{CH}_{2} \mathrm{vC}(\mathrm{Me}) \mathrm{OMe}, \mathrm{Hg}(\mathrm{OAc})_{2}$;

(c) (i) $\mathrm{O}_{3} / \mathrm{O}_{2}$; (ii) $\mathrm{PPh}_{3}$;(d) $\mathrm{KOH}$.

\section{Scheme 79}

The diene 375 was prepared from 1 in a two steps procedure involving organolithium-induced Shapiro reaction to produce the corresponding vinyl lithium species $374{ }^{186}$ Treatment of 1 with 2,2diethoxyethanamine $\mathbf{3 7 6}$ under reductive amination conditions affords the secondary amine $\mathbf{3 7 7}$ in $88 \%$ yield (Scheme 80 ). ${ }^{187}$

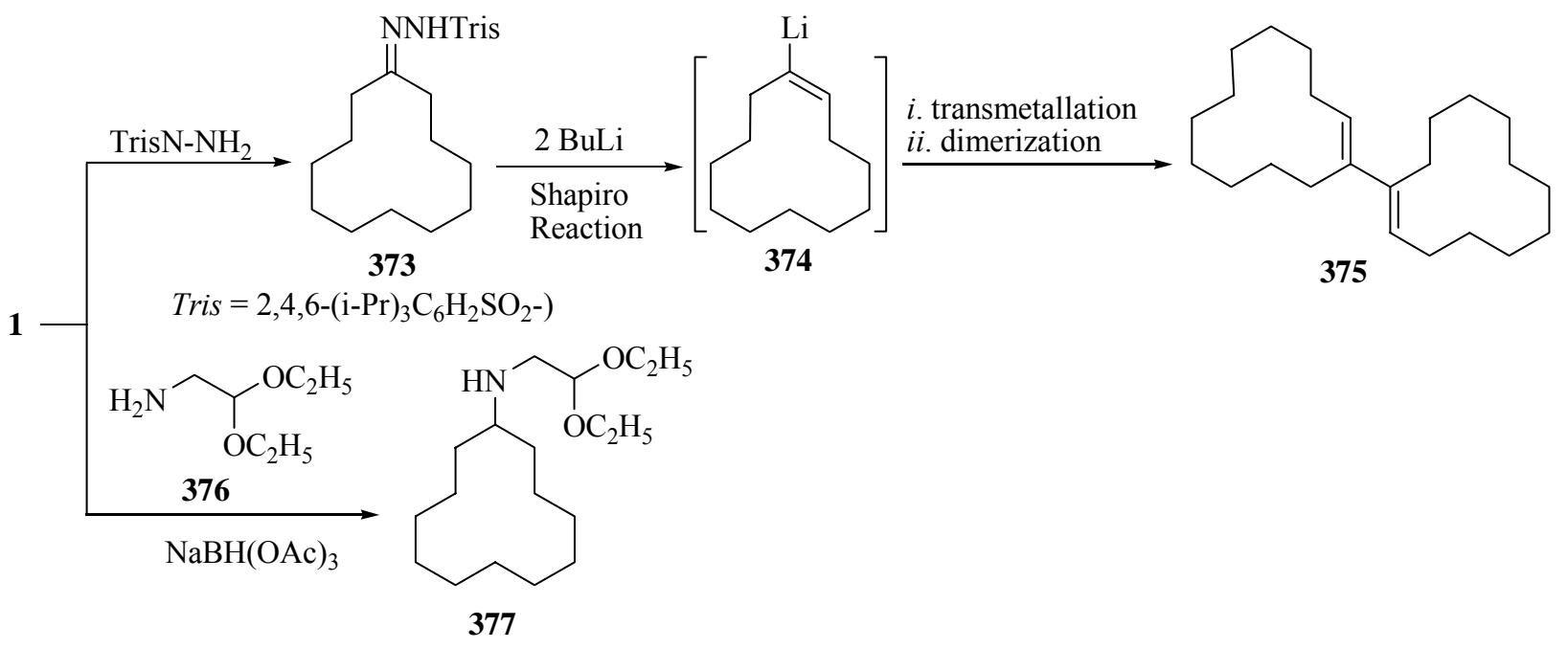

\section{Scheme 80}


Cyclopropylidenecyclododecane $\mathbf{3 8 1}$ was obtained by reaction of biscyclopropyltitanocene $\mathbf{3 8 0}$ with cyclododecanone. ${ }^{188}$ Alternatively, cyclopropylidenecyclododecane $\mathbf{3 8 1}$ was also obtained via Wittig reaction between 1 and cyclopropylidenetriphenyl-phosphorane 382 in 54\% yield (Scheme $81)^{189}$

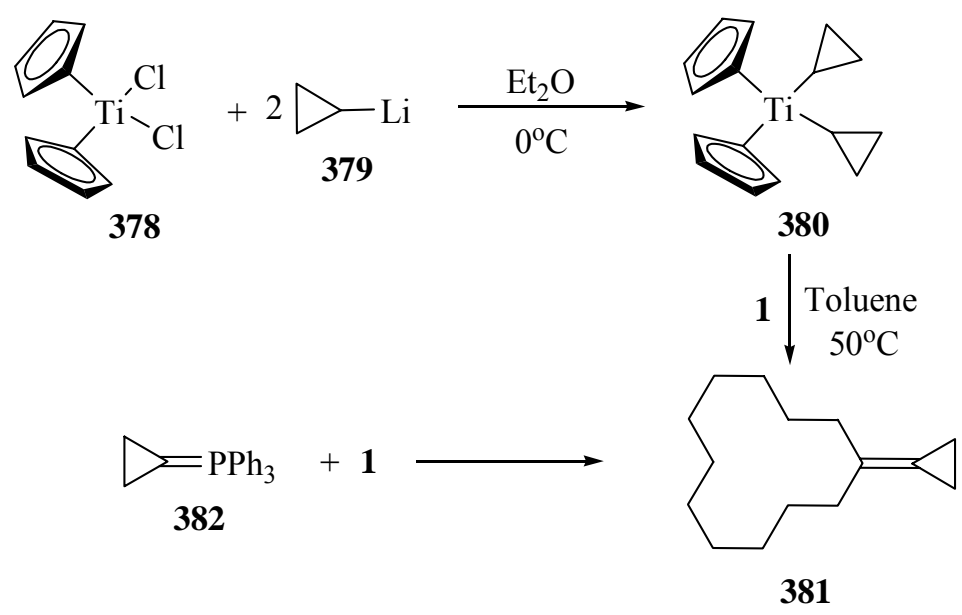

\section{Scheme 81}

Reaction of lithium enolate of cyclododecanone $\mathbf{3 8 3}$ with aryl vinyl selenoxide $\mathbf{3 8 4}$ afforded the corresponding cyclopropyl ketone derivative $\mathbf{3 8 5} .{ }^{190}$ Besides, 5,6,7,8,9,10,11,12,13,14-Decahydro2-methylbenzo[12] annulene $\mathbf{3 8 7}$ was synthesized from 2-hydroxymethylene-cyclododecanone $\mathbf{9 8}$ in two steps in $86 \%$ overall yield (Scheme 82 ). ${ }^{191}$<smiles>C1CCCCCCCCCCC1</smiles>

383<smiles>O=C1CCCCCCCCCCC1=CO</smiles>

98

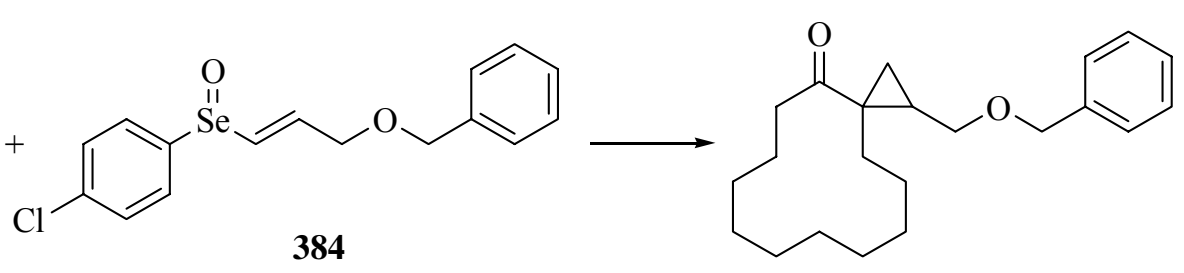

384

\section{5}<smiles>C=C(CCl)C(C)(C)CNCCC(C)CCl</smiles>

ii-<smiles>[GeH2]=C[GeH3]</smiles><smiles>C=C(C)CC1(C)CCCCCCCCCCC1=COCC</smiles>

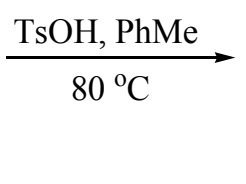

$\underset{80{ }^{\circ} \mathrm{C}}{\stackrel{\mathrm{sOH}, \mathrm{PhMe}}{\longrightarrow}}$<smiles>C1CCCCCCCCCCCCCCC1</smiles>

387

\section{Scheme 82}

Hydroxymethylation of aldehydes or ketones, leading to terminal 1,2-diols, represents a potentially useful strategy for the one carbon extension of carbonyls. Cyclododecanone $\mathbf{1}$ was 
hydroxymethylated by a simple and direct approach which involve the pinacole cross coupling with formaldehyde catalyzed by vanadium(III)chloride in presence of $\mathrm{Zn}$ to produce 1(hydroxylmethyl)cyclododecanol $3 \mathbf{3 8 8} .{ }^{192}$ Cyclododecanone $\mathbf{1}$ was converted to 2methylenecyclododecanol 392 under the influence of KOH-DMSO system in a poor yield (11\%) (Scheme 83). ${ }^{193}$

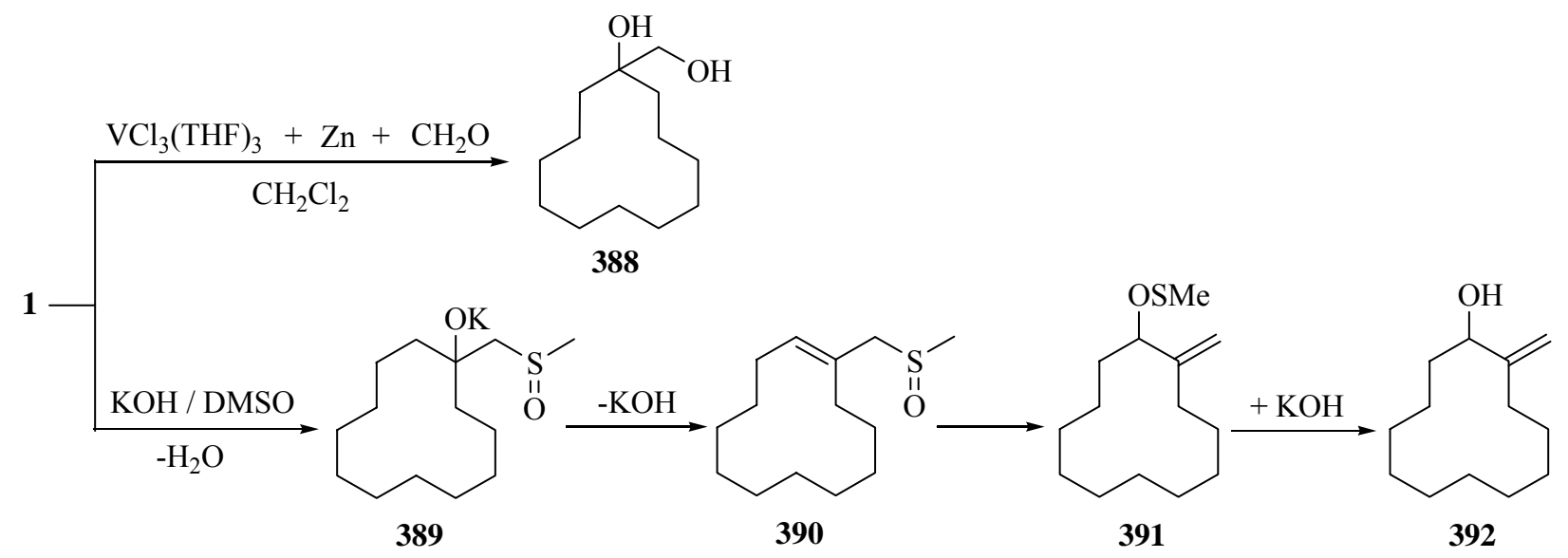

\section{Scheme 83}

$\alpha$-Substituted-cyclododecanones 393a-c react with $\mathrm{KCN}$ in DMF to afford 13oxabicyclo[10.1.0]tridecane-1-carbonitrile 394 and 12-hydroxybicyclo[9.1.0]dodecane-12carbonitrile 395 the products ratio depends on the nature of $\alpha$-substituent. ${ }^{194}$

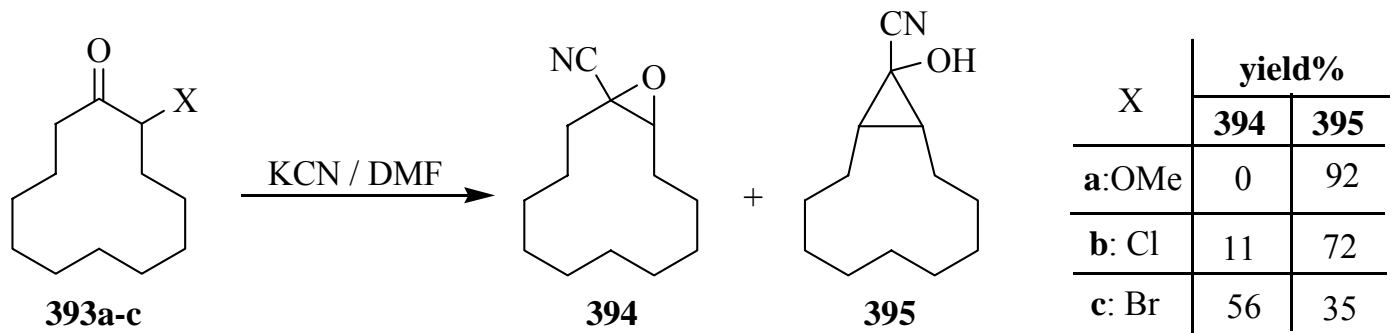

The Aldol 396 was obtained from the reaction 2-iodocyclododecan-one 27 and benzaldehyde under the influence of $\mathrm{TiCl}_{4}-n$ - $\mathrm{Bu}_{4} \mathrm{NI}$ system. ${ }^{195}$ Moreover, trimethylsilyl cyanide (TMSCN) is used for the direct formation of trimethylsilyl cyanohydrine ether of cyclododecanone 397 in excellent yield which on reduction with $\mathrm{LiAlH}_{4}$ afforded 1-(aminomethyl)cyclododecanol 398 in 59.4\% yield (Scheme 84). ${ }^{196}$

The base catalyzed self condensation of cyclododecane-1,2-dione $\mathbf{3 8}$ afforded the tricyclic macrolide 399 as a highly insoluble, high melting colorless crystalline material. The dehydration of 399 failed to produce the benzoquinone derivative $\mathbf{4 0 0}$ and only 399 was recovered unchanged (Scheme 85). ${ }^{197}$ 
<smiles>O=C1CCCCCCCCCCC1I</smiles>

27

$$
\begin{aligned}
& \text { 1- } \begin{array}{l}
\mathrm{TiCl}_{4} / \mathrm{n}-\mathrm{Bu} 4 \mathrm{NI} \\
\mathrm{CH}_{2} \mathrm{Cl}_{2},-78{ }^{\circ} \mathrm{C}, 30 \mathrm{~min} .
\end{array} \\
& \text { 2- } \mathrm{PhCHO}
\end{aligned}
$$<smiles>O=C1CCCCCCCCCCC1C(O)c1ccccc1</smiles>

396

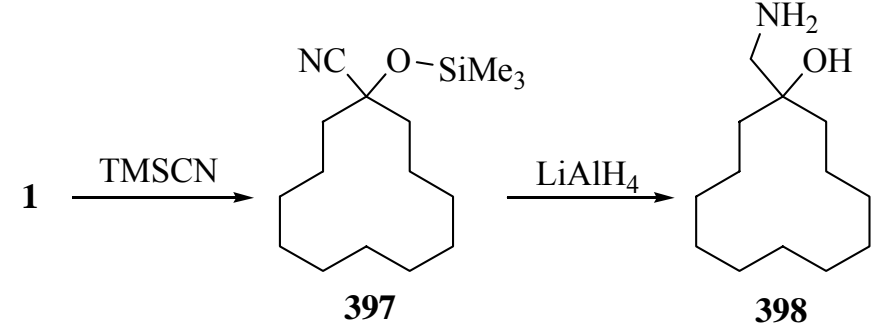

\section{Scheme 84}

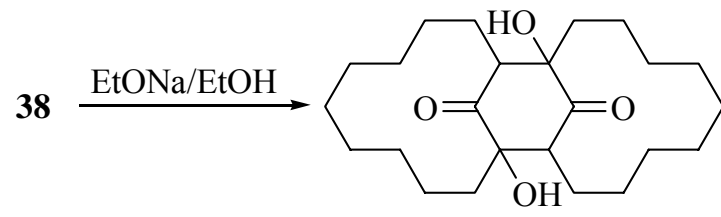

399

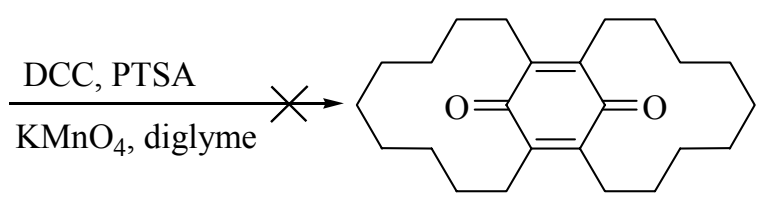

400

\section{Scheme 85}

Finally, dodec-11-ynoic acid $\mathbf{4 0 3}$ may serve as a basic intermediate in the synthesis of $Z$-11- and E-11-alkenals, alken-l-ols and their acetates which are insect pheromones. ${ }^{198}$ This acid 403 can be obtained from 1 through the macrocyclic lactone 167 (Scheme 86). ${ }^{199}$

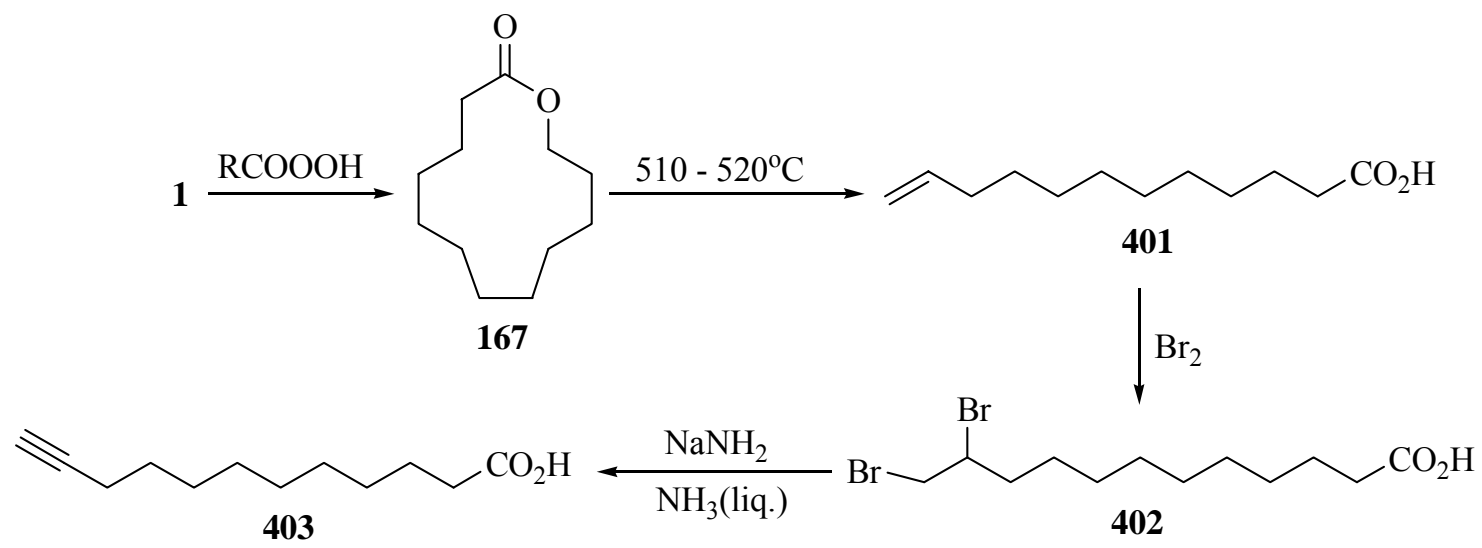

\section{Scheme 86}


Trost $e t a l,{ }^{200}$ were the first group achieved the construction of Roseophilin tricyclic core $\mathbf{4 0 6}$ without using macrocyclization reactions. They go through a ring contraction of $\mathbf{1}$ followed by elaboration of a fused bicycle using enyne metathesis, to obtain the tricyclic core in 20 steps and less than $2 \%$ overall yield (Scheme 87 ).

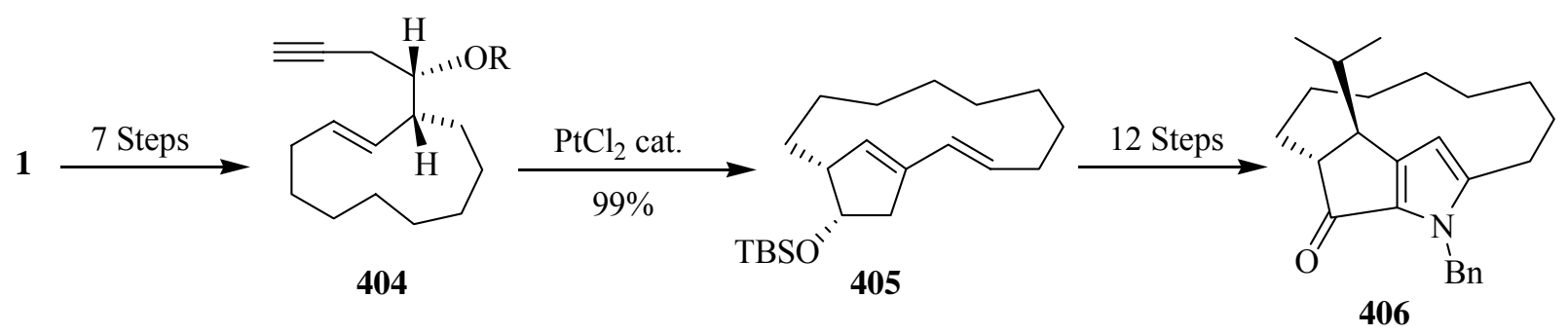

\section{Scheme 87}

Furthermore, compound $\mathbf{4 1 3}$ which serve as a model for the tricyclic core of roseophilin $\mathbf{2}$ is described in Scheme 88. The synthetic scheme features a palladium-catalyzed annulation and oxidative cleavage sequence to provide a macrocyclic ketoester 411. Modified Paal-Knorr pyrrole synthesis and Friedel-Crafts acylation complete the pyrrolophane model system $\mathbf{4 1 3}$ (Scheme $88) .{ }^{201}$
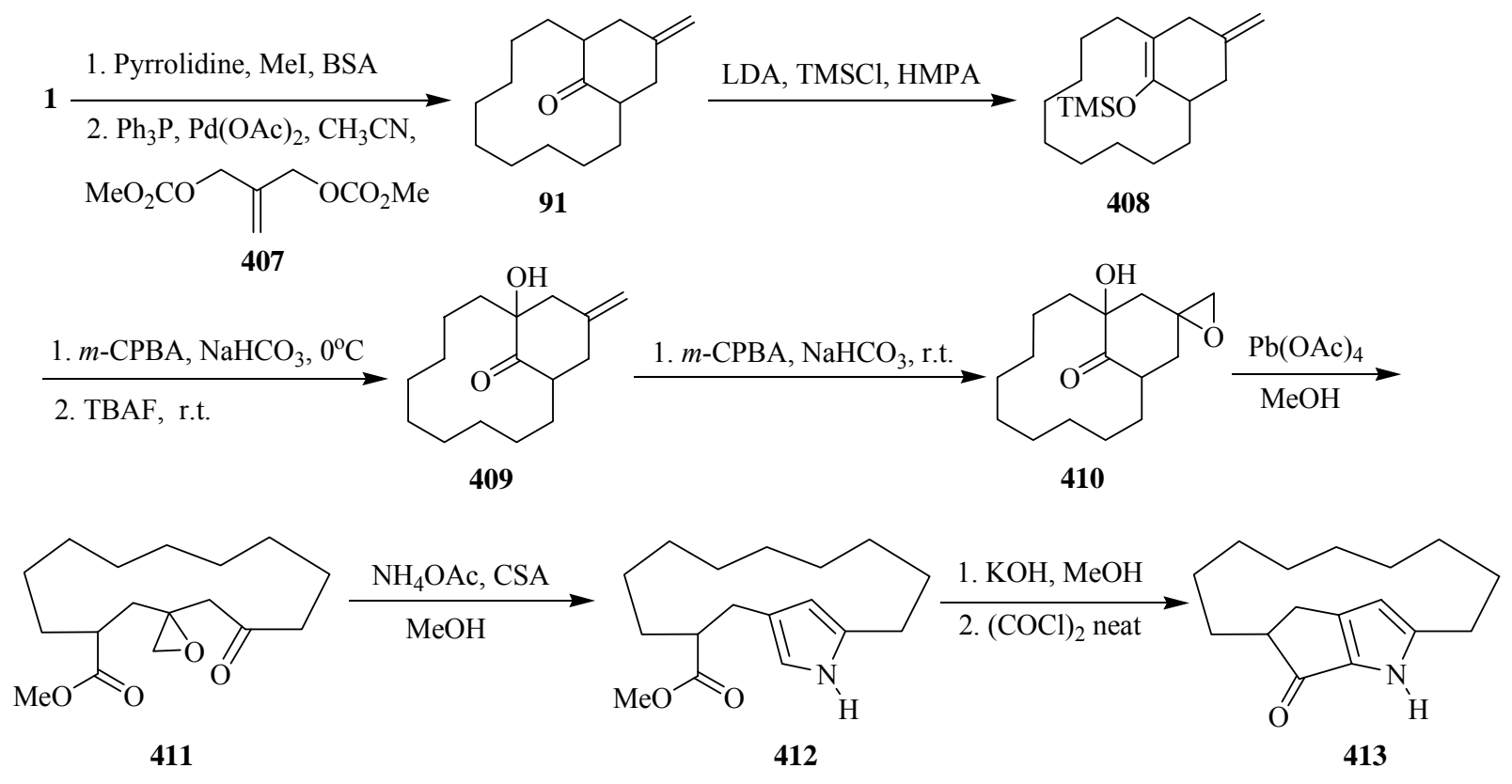

\section{Scheme 88}

Tocopherol fatty alcohols (TFAs) 3 were first synthesized through $C$-alkylation of trimethylhydroquinone $\mathbf{4 1 7}$ (THQ) using $\omega$-benzyloxy allylic alcohols. Cyclododecanone 1 serves 
as a source of the $\omega$-benzyloxy allylic alcohol $\mathbf{4 1 6}$ which was used in the synthesis of TFAs member $3 \mathbf{a},{ }^{2}$ as outlined in Scheme 89.
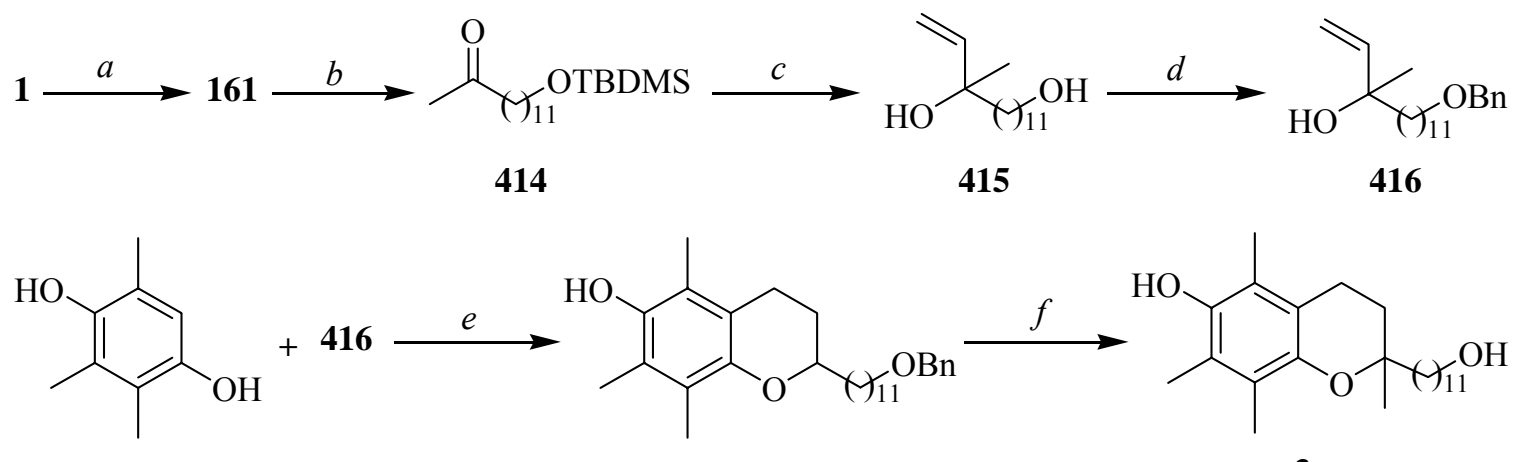

417

418

3a

Scheme 89. Reagents and conditions: (a) $m$-CPBA, $\mathrm{CF}_{3} \mathrm{CO}_{2} \mathrm{H}, \mathrm{CH}_{2} \mathrm{Cl}_{2}$, reflux (80-85\%), (b) (i) NHMeOMe.HCl, MeLi, (ii) MeLi, (iii) TBDMSCl, imidazole, THF, $0{ }^{\circ} \mathrm{C}$ to rt $(68-76 \%)$, (c) (i) $\mathrm{CH}_{2} \mathrm{CHMgBr}$, THF, $0{ }^{\circ} \mathrm{C}$ to rt, (ii) TBAF (66-88\%), (d) NaH, BnBr, THF, reflux (73-81\%). (e) $\mathrm{ZnCl}_{2}, \mathrm{HCl}, \mathrm{EtOAc}$, rt (68-76\%), (f) $\mathrm{H}_{2}, \mathrm{Pd} / \mathrm{C} 5 \%$, EtOH, rt (82-96\%).

The sponge alkaloids motuporamine A 4 was synthesized starting from the commercially available laurolactam 18 which upon reduction with $\mathrm{LiAlH}_{4}$ afforded azacyclotridecane 419. Reductive amination of $\mathbf{4 1 9}$ with aldehyde $\mathbf{4 2 0}$ using sodium triacetoxyborohydride in 1,2dichloroethane gave protected triamine 421 in quantitative yield. Deprotection of 421 by hydrogenolysis gave 4 in $85 \%$ yield (Scheme 90 ). ${ }^{3}$

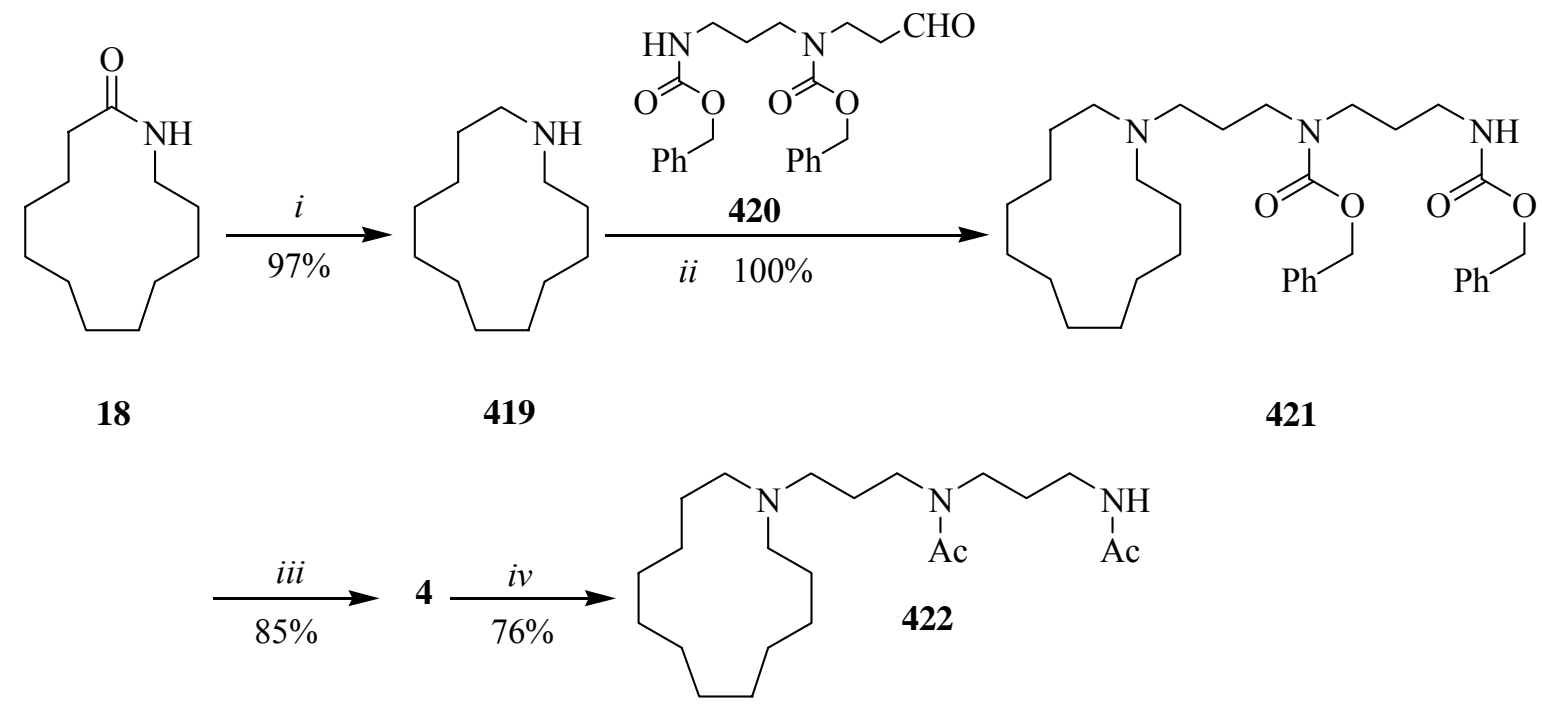

Scheme 90. Reagents and conditions: (i) $\mathrm{LiAlH}_{4}$, THF, reflux, (ii) $\mathrm{NaBH}(\mathrm{OAc})_{3}, 1,2-$ dichloroethane, (iii) $\mathrm{H}_{2}, \mathrm{Pd} / \mathrm{C}, \mathrm{MeOH},\left(\right.$ iv) $\mathrm{Ac}_{2} \mathrm{O}, \mathrm{Et}_{3} \mathrm{~N}$. 
In the same context, synthesis of motuporamine B 5 begin with ring expansion of 1 with trimethylsilyldiazomethane to give cyclotridecanone 423, which then smoothly transformed into the macrocyclic lactam 425 via Beckmann rearrangement of keto-oxime 424. The target molecule 5 was then obtained by applying reduction/ reductive amination/ deprotection protocol cited above (Scheme 91). ${ }^{3}$
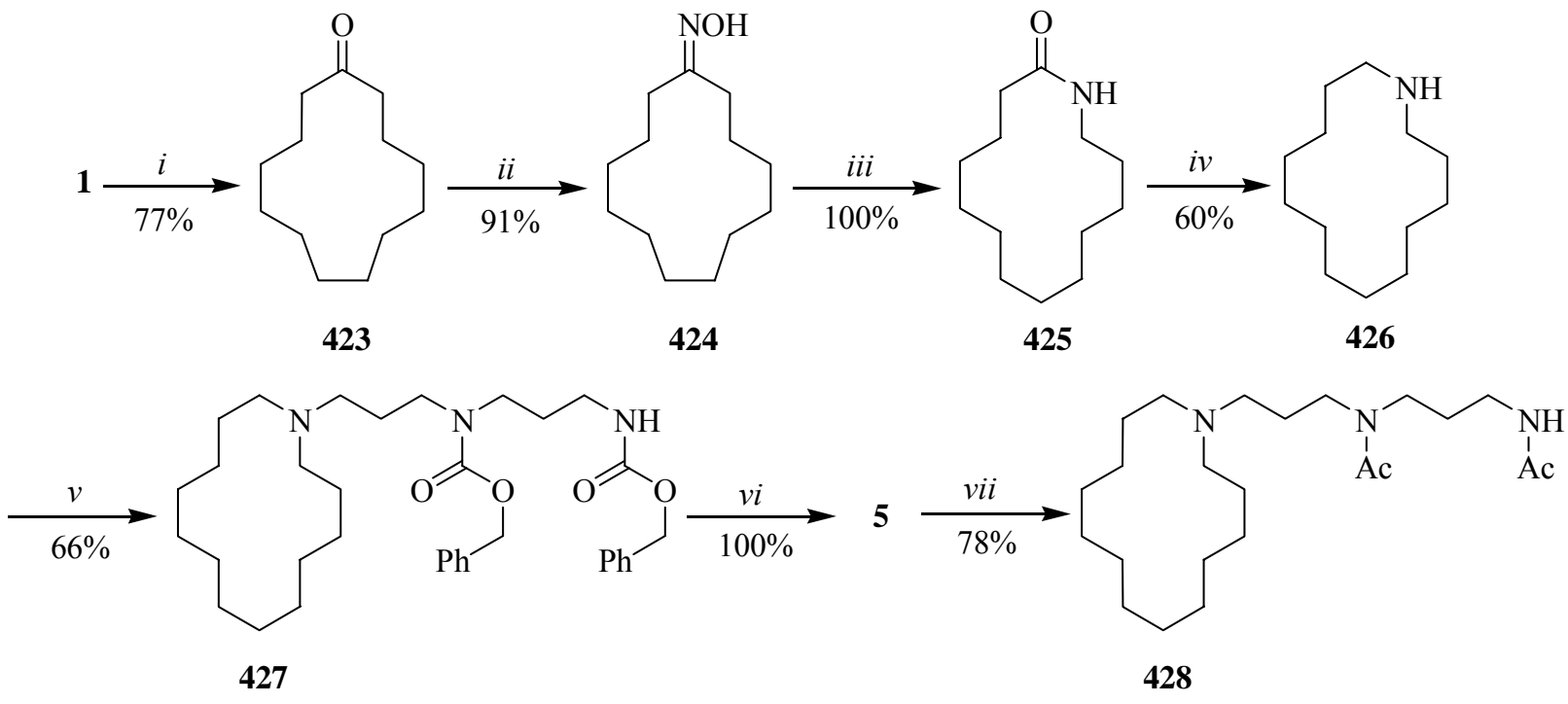

Scheme 91. Reagents and conditions: (i) $\mathrm{Me}_{3} \mathrm{SiCHN}_{2}, \mathrm{BF}_{3} . \mathrm{Et}_{2} \mathrm{O}, \mathrm{CH}_{2} \mathrm{Cl}_{2}$; (ii) $\mathrm{NH}_{2} \mathrm{OH} . \mathrm{HCl}$, $\mathrm{NaHCO}_{3}, \mathrm{MeOH}$; (iii) $\mathrm{P}_{2} \mathrm{O}_{5}, \mathrm{CH}_{3} \mathrm{SO}_{3} \mathrm{H}$; (iv) $\mathrm{LiAlH}_{4}$, THF, reflux; (v) 420, $\mathrm{NaBH}(\mathrm{OAc})_{3}$, 1,2dichloroethane; (vi) $\mathrm{H}_{2}, \mathrm{Pd} / \mathrm{C}, \mathrm{MeOH}$; (vii) $\mathrm{Ac}_{2} \mathrm{O}, \mathrm{Et}_{3} \mathrm{~N}$, Pyridine.

The isomeric cyclo adducts 6 and 7 were obtained in 71\% yield from ketone 429 through enolate formation and chlorination followed immediately by cyclization under Fohlish conditions. Cyclododecanone derivative 429 underwent smooth cycloaddition to give $\mathbf{6 a}, \mathbf{6 b}$ and 7 in $72 \%$ overall yield in a ratio of 7.3:1:1, respectively. The reaction course includes enolate formation and chlorination followed immediately by cyclization (Scheme 92). ${ }^{3,}$

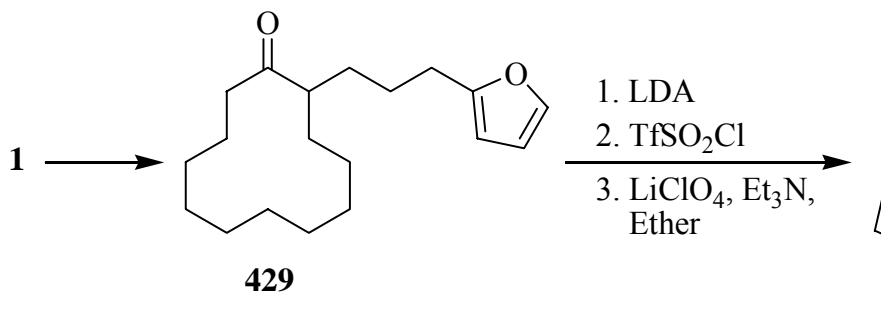

\section{Scheme 92}

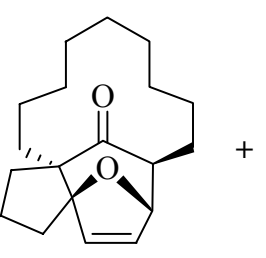

6a

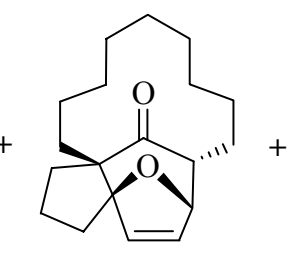

6b

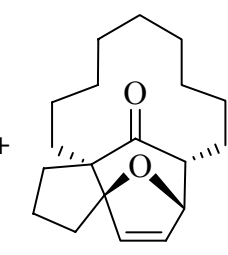

7

(R)-12-Methyltridecanolide 11 was efficiently prepared by a sequence of reactions consisting of a catalytic asymmetric conjugated addition of dimethylzinc to cyclotridec-2-enone $\mathbf{4 3 2}$ followed by a Baeyer-Villiger oxidation (Scheme 93). ${ }^{6}$ 


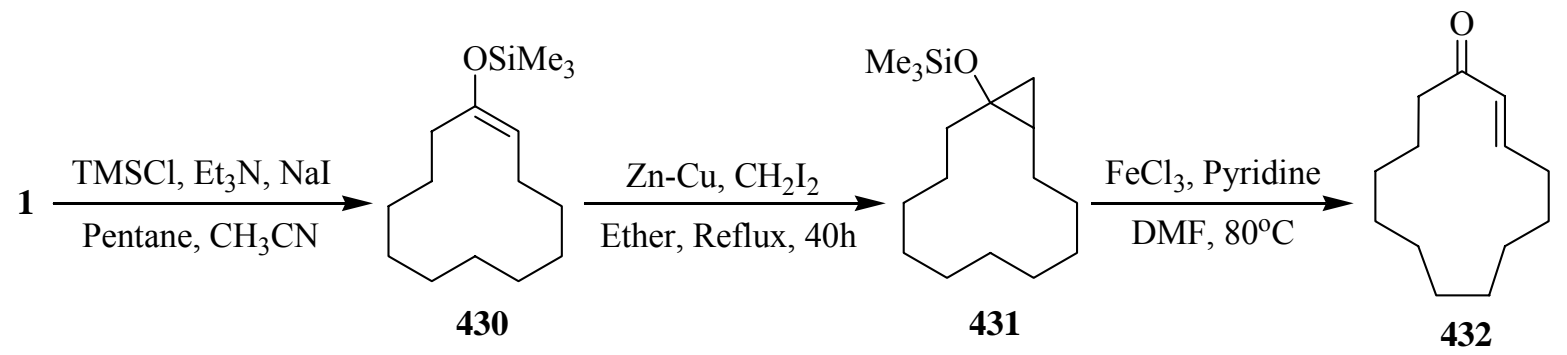

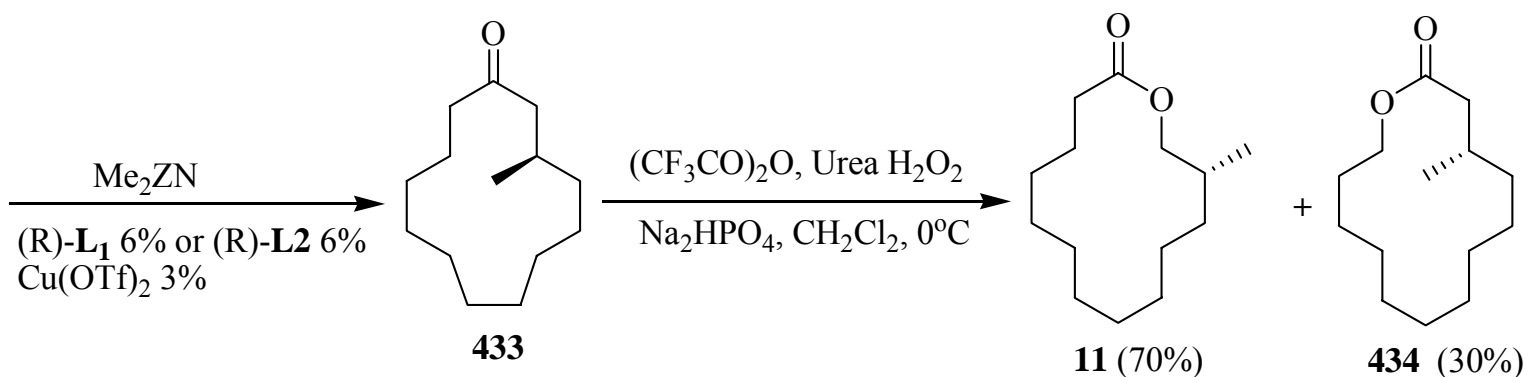<smiles></smiles>

L1<smiles>c1ccc(CN(Cc2ccccc2)p2oc3ccc4ccccc4c3c3c(ccc4ccccc43)o2)cc1</smiles>

L2

\section{Scheme 93}

\section{Conformational Characteristics of Cyclododecanone}

Knowledge of the conformation and conformational processes of 12-membered rings constitute the first step in the elucidation of the substantially unknown conformational features of large ring compounds. Some structural information is available on a rather limited number of synthetically valuable 12-membered carbocyclic compounds. For cyclododecanone 1 X-ray diffraction studies showed that it exists as a square [3333]-2-one conformation. This same conformation is also adopted by 2,12-dibromocyclododecanone and cyclododecanone oxime. Anet has reported that the low temperature ${ }^{13} \mathrm{C}$-NMR spectrum of $\mathbf{1}$ is consistent with a [3333]-2-one conformation. However, the low temperature ${ }^{1} \mathrm{H}-\mathrm{NMR}$ spectrum of $\mathbf{1}$ is complex and it cannot be fully analyzed nor can be various chemical shifts and coupling constants is determined. Furthermore, the iterative force-field calculations of 1 showed that two distinct conformational processes are needed to achieve pseudo rotation of the lowest energy [3333]-2-one conformation, ${ }^{202,203}$ (Figures 1 and 2). 


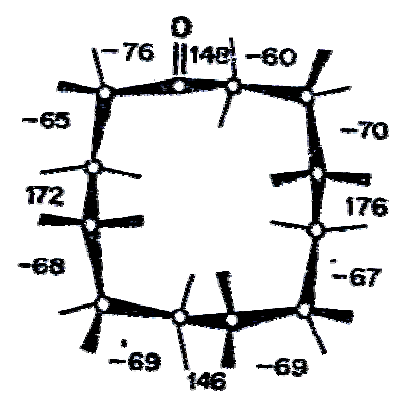

Figure 1. Lowest energy conformation of cyclododecanone, [3333]-2-one and its calculated torsional angles

Moreover, indications for the existence of preferred, distinction orientations of the carbonyl group in 5-12-membered cycloalcanones was found by Ledaal. ${ }^{204}$ The orientation of the carbonyl group seemed to change in an irregular way within the series indicating a preferred orientation for each ring size. Consequently, the result of the study indicates that in the 5-ring ketones the carbonyl group is pointing outward with an angle of $0^{\circ}$ between its dipole and the ring plane. This angle is steadily increasing for the larger ring ketones, reaching a maximum value for the 11- and 12-ring ketones, which then may have true " inside-carbonyl"-conformations, ${ }^{205}$ (Figure 2).
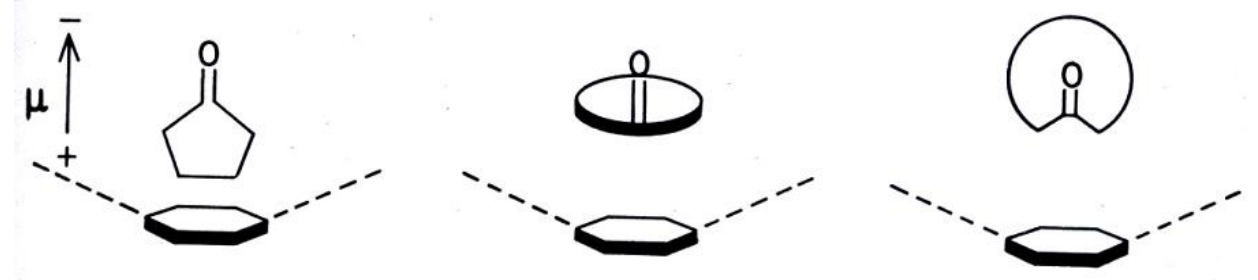

Figure 2. The angle between the carbonyl group dipole and the ring plane for cycloalkanones.

\section{Conclusions}

The present review has illuminated different aspects of cyclododecanone chemistry, the progress of some reactions of cyclododecanone and its conformational features has outlined the importance of cyclododecanone as a valuable synthetic building block for synthesis of wide range of organic classes including natural products, macrocyclic lactams and lactones and various heterocyclic systems. The vast majority of these important compounds still require further exploration and application, especially as macrocyclic fragrances, drugs, photochemistry and highly important in industrial process. 


\section{Appendix: Abbreviations and Acronyms}

\begin{tabular}{|c|c|}
\hline AIBN & Azobisisobutyronitrile \\
\hline DB-18-C-6 & Dibenzo-18-crown-6 \\
\hline DBU & 1,8-Diazabicyclo[5.4.0]undec-7-ene \\
\hline DCC & Dicyclohexylcarbodiimide \\
\hline DMPA & 4-Dimethylaminopyridine \\
\hline DME & Dimethoxyethane \\
\hline DOD & 1,1-Dihydroperoxycyclododecane \\
\hline DMPU & 1,3-Dimethyl-3,4,5,6-tetrahydro-2(1H)-pyrimidinone \\
\hline HFIP & 1,1,1,3,3,3-Hexafluoroisopropanol \\
\hline HMPA & Hexamethylphosphoramide \\
\hline LDA & Lithiumdiisopropylamide \\
\hline MCPA & $m$-Chloroperbenzoic acid \\
\hline NBS & $N$-Bromosuccinimide \\
\hline NCS & $N$-Chlorosuccinimide \\
\hline PTSA & $p$-Toluenesulfonic acid \\
\hline TBAF & Tetrabutylammonium fluoride \\
\hline TIPSCl & Triisopropylsilyl chloride \\
\hline TMSCl & Trimethylsilyl chloride \\
\hline $\mathrm{TsCl}$ & Toluenesulfonyl chloride \\
\hline
\end{tabular}

\section{References}

1. (a) Hayakawa, Y.; Kawakami, K.; Seto, H. Tetrahedron Lett. 1992, 33, 2701ЮЮ. (b) Boger, D. L.; Hong, J. J. Am. Chem. Soc. 2001, 123, 8515. (c) Fürstner, A.; Weintritt, H. J. Am. Chem. Soc. 1998, 120, 2817. (d) Boger, D. L.; Hong, J. J. Am. Chem. Soc. 2001, 123, 8515.

2. Muller, T.; Coowar, D.; Hanbali, M.; Heuschling, P.; Luu, B. Tetrahedron 2006, 62, 12025.

3. Baldwin, J. E.; Vollmer, H. R.; Lee, V. Tetrahedron Lett. 1999, 40, 5401.

4. Harmata, M. Tetrahedron. 1997, 53, 6235.

5. Harmata, M.; Elahmad, S.; Barnes, C. L. Tetrahedron Lett. 1995, 36, 1397.

6. Scafato, P.; Larocca, A.; Rosini, C. Tetrahedron: Asymmetry 2006, 17, 2511.

7. Nowicki, J. Molecules 2000, 5, 1033.

8. Shi, Z.; Qiang, J.; Li, Z. Chin. Sci. Bull. 2001, 46, 393.

9. Bollbuck, B.; Kraft, P.; Tochtermann, W. Tetrahedron 1996, 52, 4581.

10. Dowd, P.; Choi, S.-C. Tetrahedron 1992, 48, 4773.

11. Munro, D.; Newman, C. Tetrahedron Lett. 2000, 41, 1483.

12. Hafner, W.; Gebauer, H.; Markel, E.; Regiert, M. US Patent 4948 780, 1990.

13. Consortium fur Elektrochemische Industrie GmbH, US Patent 4496 748, 1985.

14. Masuyama, A.; Wu, J.; Nojima, M.; Kim, H.; Wataya, Y. Mini-Rev. Med. Chem. 2005, 5, 1035. 
15. Hamada, Y.; Tokuhara, H.; Masuyama, A.; Nojima, M.; Kim, H.; Ono, K.; Ogura, N.; Wataya, Y. J. Med. Chem. 2002, 45, 1374.

16. Ito, T.; Tokuyasu, T.; Masuyama, A.; Nojima, M.; McCullough, K. Tetrahedron 2003, 59, 525.

17. Nonami, Y.; Tokuyasu, T.; Masuyama, A.; Nojima, M.; McCullough, K.; Kim, H.; Wataya, Y. Tetrahedron Lett. 2000, 41, 4681.

18. Tsuchiya, K.; Hamada, Y.; Masuyama, A.; Nojima, M.; Tetrahedron Lett. 1999, 40, 4077.

19. Saneyoshi, H.; Miyata, K.; Seio, K.; Sekine, M. Tetrahedron Lett. 2006, 47, 8945.

20. (a) Rusu, G. High Performance Polymers 2004, 16, 569. (b) Laura, R.; Russo, S.; Orefice, G.; Riva, F. Macromol. Chem. Phys. 2001, 202, 2114. (c) Dachs, K.; Schwartz, E. Angew. Chem. Int. Ed. 1962, 1, 430.

21. Lewandowski, G.; Bartkowiak, M.; Milchert, E. Catal. Lett. 2009, 127, 213.

22. Lewandowski, G. Przem. Chem. 2003, 82, 1376.

23. Lewandowski, G. Przem. Chem. 2004, 83, 95.

24. Wilke, G.; Bogdanovic, B.; Heimbach, P.; Kroener, M.; Mueller, E. W.; Adv. Chem. Ser. 1962, $34,137$.

25. Gaube, J.; David, W.; Sanchayan, R.; Roy, S.; Muller-Plathe, F. Applied Catal. A. 2008, 343, 87.

26. Rindone, B.; Saliu, F.; Bertoa, R. S. Ozone: Sci. and Eng. 2008, 30, 165.

27. Starokon, E. V.; Shubnikov, K. S.; Dubkov, K. A.; Kharitonov, A. S.; Panov, G. I.; Kinet. Catal. 2007, 48, 376.

28. Mohammad, A. Z.; Farhad, S.; Arash, G. C. Synthesis 2006, 12, 2043.

29. Naoshi, M.; Hideo, T. Tetrahedron 2005, 61, 5915.

30. Wilke, G. Angew. Chem. Int. Ed. 1963, 2, 105.

31. Griffith, W. P.; Moreea, R. G. H.; Nogueira, H. I. S. Polyhedron 1996, 15, 3493.

32. Grzegorz, L.; Estera, G.; Eugeniusz, M. J. Hazardous Mat. A. 2005, 120, 45.

33. Balbolov, E.; Skumov, M. J. Molecular Catal. A. 1999, 137, 77.

34. Shebaldova, A. D.; Bystrenina, V. I.; Kravtsova, V. N.; Khidekel, M. L.; Izvest. Akad. Nauk SSSR, Ser. Khim. 1975, 9, 2101.

35. Zakharkin, L. I.; Korneva, V. V.; Kunitskaya, G. M. Izvest. Akad. Nauk SSSR, Otdelenie Khim. Nauk. 1961, 10, 1908.

36. Sudhir, S. A.; Suresh, B. W.; Ramaswamy, A. V. Tetrahedron Lett. 2007, 48, 1411.

37. Bauer, D. P.; Macomber, R. S. J. Org. Chem. 1975, 40, 1990.

38. Tse-lok, H.; Chiu, M. W. J. Org. Chem. 1974, 39, 562.

39. Papori, G.; Shahzad, A.; Musawwer, M. K.; Abu Taleb, K. Arkivoc 2007, xv, 82.

40. Jereb, M.; Iskra, J.; Zupan, M.; Stavber, S. Lett. Org. Chem. 2005, 2, 465.

41. Jereb, M.; Iskra, J.; Zupan, M.; Stavber, S. Chem. Commun. 2004, 22, 2614.

42. Brummond, K. M.; Gesenberg, K. D. Tetrahedron Lett. 1999, 40, 2231.

43. Biswanath, D.; Maddeboina, K.; Boyapati, V.; Bommena, R. Tetrahedron Lett. 2007, 48, 6286.

44. Jefford, C. W.; Li, Y.; Jaber, A.; Boukouvalas, J. Synth. Commun. 1990, 20, 2589.

45. Ledaal, T.; Solbjoer, T. Acta Chem. Scand. 1967, 21, 1658. 
46. Katja, Z.; Stojan, S.; Marko, Z.; Daniele, B.; Sebastien, C.; Phillipe, G.; Jernej, I. Bioorg. Med. Chem. 2006, 14, 7790.

47. Terentev, A. O.; Chodykin, S. V. Central Eur. J. Chem. 2005, 3, 417.

48. Gauthard, F.; Horvath, B.; Gallezot, P.; Besson, M. Applied Catal. A. 2005, 279, 187.

49. Alper, H. Pure \& Appl. Chem. 1988, 60, 35.

50. Terent'ev, A. O.; Platonov, M. M.; Kashin, A. S.; Nikishin, G. I. Tetrahedron 2008, 64, 7944.

51. Akira, I.; Masatoshi, O.; Yoshikazu, M.; Isao, M.; Toshiyuki, S. Bull. Chem. Soc. Jpn. 1977, 50. 726.

52. Kawada, R. S.; Watt, D. S. Synth. Commun. 1989, 19, 777.

53. Prelog, V.; Frenkiel, L. Helv. Chim. Acta 1947, 30, 1741.

54. Bauer, D. P.; Macomber, R. S. J. Org. Chem. 1975, 40, 1990.

55. Ruedi, G.; Oberli, M. A.; Nagel, M.; Weymuth, C.; Hansen, H. Synlett 2004, 13, 2315.

56. Gregoire, B.; Carre, M. C. J. Org. Chem. 1986, 5, 1419.

57. Wasserman, H. H.; Ives, J. L. J. Org. Chem. 1985, 50, 3573.

58. Carl, E. W.; Qiang, W.; Alexander, M.; Craig, R. F.; Robert, W.; Clayton, H. H. Tetrahedron 2008, 64, 124.

59. Zakharkin, L. L.; Churilova, L. M.; Antonova, G. N.; Petrovskii, P. V.; Lkonnikov, N. S. Russ. Chem. Bull. 1994, 43, 1360.

60. Nozald, H.; Mori, T.; Noyori, R.; Kawanisky, M. Canadian J. Chem. 1967, 45, 1804.

61. Borowitz, I. J.; Bandurco, V.; Heyman, M.; Rigby, R. D. Y.; Heng, S. J. Org. Chem. 1973, 38. 1234.

62. Zakharkin, L. I.; Pryanishnikov, A. P.; Guseva, V. V. Zh. Org. Khim. 1979, 15, 972.

63. Mahajan, R.; Ferreira, G. A.; Araujo, H. C.; Nunes, B. J. Synthesis 1976, 112.

64. Zakharkin, L. L.; Antonova, G. N.; Podvisotskaya, L. S. Russ. Chem. Bull. 1995, 44, 2418.

65. Zakharkin, L. L.; Churilova, L. M.; Pryanishnikov, A. P. Russ. Chem. Bull. 1993, 42, 861.

66. McAndrew, B. A.; Russel, S. W. J. Chem. Soc., Perkin Trans. I 1975, 12, 1172.

67. Nelson, P. H.; Nelson, J. T. Synthesis 1991, 192.

68. Hiyma, T.; Ozaki, J.; Nozaki, H. Tetrahedron 1974, 30, 2661.

69. Nozaki, H.; Jamamoto, H.; Mori, T. Can. J. Chem. 1969, 47, 1107.

70. Zakharkin, L. L.; Churilova, L. M.; Antonova, G. N.; Petrovskii, P. V.; Lkonnikov, N. S. Russ. Chem. Bull. 1994, 43, 1360.

71. Zakharkin, L. L.; Churilova, L. M.; Petrovskii, P. V. Russ. Chem. Bull. 1993, 425, 863.

72. Kovalskaya, S. S.; Kozlov, N. G.; Dikusar, E. A., Russ. J. General Chem. 2004, 74, 897.

73. Dikusar, E. A.; Kozlov, N. G. V.; Zelenkovskii, M.; Zhukovskaya, N. A.; Murashko, V. L.; Zalesskaya, E. G.; Moiseichuk, K. L.; Yuvchenko, A. P.; Russ. J. General Chem. 2003, 73, 1277.

74. Zakharkin, L. L.; Churilova, L. M.; Anikina, E. V. Izvest. Akad. Nauk SSSR, Ser. Khim. 1990, 5, 1089.

75. Rajesh, M.; Vinod, K. Tetrahedron Lett. 2001, 42, 7525.

76. Kazuhiko, T.; Takashi, U.; Takaki, H.; Toshio, M. Tetrahedron Lett. 1996, 37, 7049.

77. Tamejiro, H.; Yoshitaka, O.; Keizo, K.; Hitosi, N. Bull. Chem. Soc. Jpn. 1982, 55, 561. 
78. Hiyama, T.; Owki, Y.; Nozaki, H. Tetrahedron 1974, 30, 2661.

79. Spencer, T. A.; Britton, R. W.; Watt, D. S. J. Am. Chem. Soc. 1967, 89, 5727.

80. Zakharkin, L. I.; Korneva, V. V. Izvest. Akad. Nauk SSSR, Ser. Khim. 1964, 12, 2206.

81. Dimmock, J. R.; Chamankhah, M.; Seniuk, A.; Kao, G. Y.; Halleran, S. Pharmazie 1995, 50, 668.

82. Dimmock, J. R.; Sidhu, K. K.; Chen, M.; Reid, R. S.; Allen, T. M.; Kao, G. Y.; Truitt, G. A. Eur. J. Med. Chem. 1993, 28, 313.

83. Thornber, C. W. J. Chem. Soc. (Chem. Comm.) 1973, 238.

84. Kohsuke, M.; Tsuyoshi, S. Tetrahedron 2005, 61, 5067.

85. Hiroaki, T.; Hisashi, Y.; Hitosi, N. Bull. Chem. Soc. Jpn. 1977, 50, 1592.

86. Timothy, C. G.; Larry, E. O. Tetrahedron 2002, 58, 6473.

87. Robin, L.; Samuel, P.; Jacques, P. Polymer 2002, 43, 3007.

88. Nishino, M.; Kondo, H.; Miyake, A. Chem. Lett. 1973, 2, 667.

89. Kato, T.; Kondo, H.; Nishino, M.; Tanaka, M. Bull. Chem. Soc. Jpn. 1980, 53, 2958.

90. Georg, F.; Jerzy, A.; Philip, K. Tetrahedron 1998, 54, 7633.

91. Ohloff, G.; Berker, J.; Schutte-Elte, K. H. Helv. Chim. Acta 1967, 5, 705.

92. Sonawane, H. K.; Nanjundiah, B. S.; Nazeruddin, G. M. Tetrahedron Lett. 1992, 33, 1645.

93. Dowd, P.; Choi, S.-C. Tetrahedron 1992, 48, 4773.

94. (a) Huebner, C. F.; Dorfman, L.; Robinson, M. M.; Donoghue, E.; Pierson, W. G.; Strachan, P. J. Org. Chem. 1963, 28, 1459. (b) Brannock, K. C.; Burpitt, R. D.; Thweatt, J. G. J. Org. Chem. 1963, 28, 1462. (c) Brannock, K. C.; Burpitt, R. D.; Goddlett, V. W.; Thweatt, J. G. J. Org. Chem. 1963, 28, 1464.

95. Storks, G.; Sher, P. M. J. Am. Chem. Soc. 1986, 108, 303.

96. Li, C.; Chen, D.; Lu, Y.; John, X. H.; Joel, T. M. Tetrahedron 1998, $54,2347$.

97. Zakharkin, L. I.; Guseva, V. V. Izvest. Akad. Nauk SSSR, Ser. Khim. 1975, 10, 2357.

98. Conesa, T. D.; Mokaya, R.; Yang, Z.; Luque, R.; Campelo, J. M.; Romero, A. A. J. Catal. 2007, $252,1$.

99. Botella, P.; Corma, A.; Iborra, S.; Montón, R.; Rodríguez, I.; Costa, V. J. Catal. 2007, 250, 161.

100. Hong-Jun, Pi; Jin-Dong, D.; Na, An; Wenting, Du; Wei-Ping, D. Tetrahedron 2009, 65, 7790 .

101. Shiju, N. R.; Williams, H. M.; Brown, D. R. Applied Catal. B. 2009, 90, 451.

102. Eickelberg, W.; Hoelderich, W. F. J. Catal. 2009, 263, 42.

103. Sanghamitra, M.; Mahasweta, N.; Krishanu, S.; Asim, B. J. Molecular Catal. A 2009, 301, 114.

104. Liu, X.; Xiao, L.; Wu, H.; Li, Z.; Chen, J.; Xia, C. Catal. Commun. 2009, 10, 424.

105. Marthala, V. R.; Hunger, J. F. Catal. Lett. 2010, DOI:10.1007/s10562-010-0274-7.

106. Tomas, D. C.; Rafael, L.; Juan, M. C.; Diego, L.; Jose, M. M.; Antonio, A. R. J. Mater. Sci. 2009, 44, 6741 .

107. Hassankhani, A. Synth. Commun. 2006, 36, 2211.

108. Eshghi, H.; Hassankhani, A. J. Chem. Res. 2006, 4, 218.

109. Yadav, J. S.; Reddy, B. V.; U. V. Reddy, S.; Praneeth, K. Tetrahedron Lett. 2008, 49, 4742. 
110. Hoffman, R. V.; Salvador, J. M. Tetrahedron Lett. 1991, 32, 2429.

111. Muller, T.; Coowar, D.; Hanbali, M.; Heuschling, P.; Luu, B. Tetrahedron 2006, 62, 12025.

112. Kayser, M. M. Tetrahedron 2009, 65, 947.

113. Yang, J.; Wang, S.; Lorrain, M. J.; Rho, D.; Abokitse, K.; Lau, P. C. Appl. Microbiol. Biotechnol. 2009, 84, 867.

114. Giorgi, G.; Miranda, S.; Loppez-Alvarado, P.; Avendano, C.; Rodriguez, J.; Menendez, J. C. Org. Lett. 2005, 7, 2197.

115. Li, J. J.; Jin, S. H.; Liang, X. M.; Yuan, D. K.; Wang, D. Q. Chin. Chem. Lett. 2007, $18,915$.

116. Huang, J. X.; Liang, X. M.; Wang, D. Q. Chin. Chem. Lett. 2004, 15, 169.

117. Ogibin, Yu. N.; Terentev, A. O.; Nikishin, G. L. Russ. Chem. Bull. 1998, 47, 1166.

118. Ogibin, Yu. N.; Kutkin, A. V.; Terentev, A. O.; Nikishin, G. I. Russ. Chem. Bull. Int. Ed. 2002, 51, 1806.

119. Ogibin, Yu. N.; Terentev, A. O.; Ananikov, V. P.; Nikishin, G. I. Russ. Chem. Bull. Int. Ed. 2001, 50, 2149.

120. Bollbuck, B.; Kraft, P.; Tochtermann, W. Tetrahedron 1996, 52, 4581.

121. Jennifer, E. F.; Jeffrey, A. J. Org. Chem. 1999, 64, 4381.

122. Goulaouic-Dubois, C.; Guggisberg, A.; Hesse, M. Tetrahedron 1995, 51, 12035.

123. Siisse, M.; Hajicek, J.; Hesse, M. Helv. Chim. Acta 1985, 68, 1986.

124. Fohlisch, B.; Herter, R.; Wolf, E.; Stezowski, J. J.; Eckle, E. Chem. Ber. 1982, 115, 355

125. Milenkov, B.; Siisse, M.; Hesse, M. Helv. Chim. Acta 1985, 68, 2115.

126. Milenkov, B.; Guggisberg, A.; Hesse, M. Tetrahedron Lett. 1987, 28, 315.

127. Mattingly, P. G. Synthesis 1990, 366.

128. (a) Kagan, H. B. New J. Chem. 1990, 14, 453. (b) Molander, G. A. Chem. Rev. 1992, 92, 29. (c) Molander, G. A. Comprehensive Org. Synthesis; Trost, B. M.; Fleming, I.; Schreiber, S. L. Eds; Pergamon: Oxford, 1991; 1, 251. (d) Curran, D. P.; Fevig, T. L.; Jasperse, C. P.; Totleben, M. J. Synlett 1992, 943.

129. Corey, E. J.; Nicolaou, K.; Balanson, R. D.; Machida, Y. Synthesis 1975, 590.

130. Cookson, R. C.; Ray, P. S. Tetrahedron Lett. 1982, 23, 3521.

131. Manfredi, K.; Gingerich, S. B.; Jennings, P. W. J. Org. Chem. 1985, 50, 535.

132. Jaswant, R. M.; Maria, B. M. Bull. Chem. Soc. Jpn. 1978, 51, 1207.

133. Kay, M. B.; Kristen, D. G.; Joseph, L. K.; Angela, D. K. Tetrahedron Lett. 1998, 39, 8613.

134. Boivin, J.; Huppe, S.; Zard, S. Tetrahedron Lett. 1995, 36, 5737.

135. Sebastien, T.; Agnes, M.; Marie-Paule, J.; J. Jacqu, C. Tetrahedron 2002, 58, 6643.

136. Yasumasa, H.; Takayuki, S. Org. Synthesis 1990, 7, 135; 1984, 62, 191.

137. Wohllebe, J.; Garbisch, E. W.; Diakur, J. M.; Masamune, S. Org. Synthesis 1988, 6, 368; 1977, 56, 107.

138. Barba, F.; Elinson, M. N.; Escudero, J.; Feducovich, S. K. Tetrahedron Lett. 1996, $37,5759$.

139. Bondalapati, S.; Reddy, U. C.; Kundu, D. S.; Saikia, A. K. J. Fluorine Chem. 2010, 131, 320.

140. Gowravaram, S.; Reddy, K. B.; Bhikshapathi, M.; Yadav, J. S. Tetrahedron Lett. 2006, 47, 2807. 
141. Shu, H. J.; Xiao, M. L.; Xu, Y.; Fu, H. C.; Dao, Q. W. Chin. Chem. Lett. 2009, 20, 1267.

142. Song, F.; Liu, Y. J. Organometallic Chem. 2009, 694, 502.

143. Albrecht, U.; Langer, P. Tetrahedron 2007, 63, 4648.

144. Hiroyuki, S.; Masaki, S.; Seijiro, M.; Koichiro, O.; Tamejiro, H.; Hitosi, N. Bull. Chem. Soc. Jpn. 1983, 56, 3088.

145. Srivastava, P.; Srivastava, R. Catal. Commun. 2008, 9, 645.

146. Kuznetsov, A. I.; Shukkur, A. Kh. T.; Serova, M. Russ. J. Org. Chem. 2008, 44, 763.

147. Ershova, O. V.; Eremkina, A. V.; Kayukova, Ya. S.; Lyshchikova, A. N.; Nasakina, O. E.;

Tafeenkob, V. A. Russ. J. Org. Chem. 2008, 44, 570.

148. Eremkin, A. V.; Ershov, O. V.; Kayukov, Ya. S.; Sheverdov, V. P.; Nasakin, O. E.;

Tafeenko, V. A.; Nurieva, E. V. Tetrahedron Lett. 2006, 47, 1445.

149. Timothy, D. L.; Thomas, G. M.; Jolie, A. B. Tetrahedron 2007, 63, 12343.

150. Wang, M.; Zhang, N.; Hou, X.; Wang, D.; Chin. J. Struct. Chem. 2005, 24, 1254.

151. Wang, D. Q.; Hou, X. T.; Pan, C. P. Chin. J. Appl. Chem. 1996, 13, 19.

152. Ichino, T.; Arimoto, H.; Uemura, D. Chem. Commun. 2006, 16, 1742.

153. Reich, H. J.; Renga, J. M.; Reich, I. L. J. Am. Chem. Soc. 1975, 97, 5434.

154. Shinsaku, F.; Takeyuki, K.; Hitosi, N. Bull. Chem. Soc. Jpn. 1970, 43, 2596.

155. Zhu, Yu-lin; Huang, Shen-lin; Pan, Yuan-jiang Eur. J. Org. Chem. 2005, 2354.

156. Mahendra, D. C.; Lauren, J. M.; Timothy, L. M.; Joel, L.; Ray, A. O. Bioorg. Med. Chem. Lett. 2002, 12, 1563.

157. Emilia, N.; Nevena, P.; Julita, P.; Neyko, S.; Maria, L.; Boris, A. Il Farmaco 2002, 57, 189.

158. Shkil, G. P.; Sagitullin, R. S. Chem. Heterocycl. Comp. 1998, 34, 507.

159. Wayland, E. N.; Guang-Ming, X.; Kyle, R. G.; Michael, J. K.; Mary, J. W.; John, J. C.;

Dale, L. R. Tetrahedron 1996, 52, 4555.

160. Catherine, C.; Paul, C.; Sandra, I.; Mario, N.; Brigitte, J. Tetrahedron 1994, 50, 11903.

161. Marcel, K. E.; Leszek, B. J. Org. Chem. 1976, 41, 3775.

162. Zakharkin, L. L.; Churilova, L. M. Russ. Chem. Bull. 1994, 43, 608.

163. Zakharkin, L. L.; Guseva, V. V. Russ. Chem. Bull. 1994, 43, 835.

164. William, L. A.; Winton, D. J. Jr.; William, S. F. J. Heterocyclic. Chem. 1978, 15, 209.

165. Zakharkin, L. L.; Churilova, L. M.; Guseva, V. V. Izvestiya Akademii Nauk, Seriya Khimicheskaya 1992, 1, 226.

166. Abu-Orabi, S. T. J. Chem. Eng. Data 1987, 32, 130.

167. Chen, C. H.; Donatelli, B. A. J. Org. Chem. 1976, 41, 3053.

168. Rubinstein, H.; Wuerthele, M. J. Org. Chem. 1969, 34, 2762.

169. Alex, N.; Abimael, D. R.; Vilas, S.; Rathindra, G. J. Org. Chem. 1985, 50, 4218.

170. Ong, B. S. Tetrahedron Lett. 1980, 21, 4225.

171. Wilson, S. R.; Georgiadis, G. M.; Vedejs, E.; Conrad, P. C.; Beck, M. W. Org. Syn. 1990, 7, $124 ; 1983,61,74$.

172. Thummel, R. P.; Lefoulon, F.; Cantu, D.; Mahadevan, R. J. Org. Chem. 1984, 49, 2208.

173. Chai, W.; Takeda, A.; Hara, M.; Ji, S.-J.; Horiuchi, C. A. Tetrahedron 2005, 61, 2453.

174. Ji, S.-J.; Takahashi, E.; Takahashi, T. T.; Horiuchi, C. A. Tetrahedron Lett. 1999, 40, 9263. 
175. Ji, S.-J.; Matsushita, M.; Takahashi, T. T.; Horiuchi, C. A. Tetrahedron Lett. 1999, 40, 6791.

176. Kiyohide, M.; Takasi, M.; Hitosi, N. Bull. Chem. Soc. Jpn. 1971, 44, 3440.

177. Camerino, B.; Patelli, B. Experientia 1964, 15, 260.

178. Nosaki, H.; Mori, T.; Noyori, R. Tetrahedron Lett. 1967, 8, 779.

179. Hideki, S.; Naoyuki, I.; Tsuyoshi, S. Tetrahedron Lett. 2010, 51, 633.

180. Tsuyoshi, S.; Hiroaki, K.; Ayako, M.; Masanobu, Y. Tetrahedron Lett. 2009, 50, 6280.

181. Yadav, J. S.; Reddy, B. V.; Ruchi, J.; Gakul, B. Tetrahedron Lett. 2008, 49, 3015.

182. Yadav, J. S.; Reddy, B. V.; Reddy, U. V.; Krishna, A. D. Tetrahedron Lett. 2007, 48, 5243.

183. Domling, A.; Ugi, I. Angew. Chem. Int. Ed. 2000, 39, 3168.

184. Kurek-Tyrlik, A.; Marczak, S.; Michalak, K.; Wicha, J.; Zarecki, A. J. Org. Chem. 2001, 66, 6994.

185. Srikrishna, A.; Kumar, P. P. Tetrahedron 2000, 56, 8189.

186. Addie, M. S.; Taylor, R. J. K. Arkivoc 2000, v, 660.

187. Abdel-Magid, A. F.; Carson, K. G.; Harris, B. D.; Maryanoff, C. A.; Shah, R. D. J. Org. Chem. 1996, 61, 3849.

188. Petasis, N. A.; Bzowel, E. I. Tetrahedron Lett. 1993, 34, 943.

189. Stafford, J. A.; McMurry, J. E. Tetrahedron Lett. 1988, 29, 2531.

190. Ando, R.; Sugawara, T.; Shimizu, M.; Kuwajima, I. Bull. Chem, Soc. Jpn. 1984, 57, 2897.

191. Tius, M. A.; Kannangara, G. S. K.; Akella, A.; White, J. D. Org. Synthesis 1998, 9, 180; 1993, 71, 158.

192. Park, J.; Pedersen, S. F. Tetrahedron 1992, 48, 2069.

193. Trofimov, B. A.; Petrova, O. V.; Vasil'tsov, A. M.; Mikhaleva, A. I. Izvestiya Akademii

Nauk SSSR, Seriya Khimicheskaya 1990, 7, 1601.

194. Abad, A.; Agullo, C.; Arno, M.; Seoane, E. Tetrahedron 1986, 42, 2429.

195. Takayuki, T.; Saeko, I.; Hiroshi, S.; Koichiro, O. J. Org. Chem. 2000, 65, 5066.

196. Evans, D. A.; Carroll, G. L.; Truesdale, L. K. J. Org. Chem. 1974, 39, 914.

197. Bauer, D. P.; Macomber, R. S. J. Org. Chem. 1976, 40, 3059.

198. Bestmann, H. J.; Vostrowsky, O. Chem. Pflanzenschutz-Schaedlingsbekaempfungsmittel,

Berlin 1981, 6, 29; Chem. Abstr. 1982, 97, 105477s.

199. Zakharkin, L. I.; Churilova, I. M. Izvestiya Akademii Nauk SSSR, Seriya Khimicheskaya. 1984, 11, 2635.

200. Trost, B. M.; Doherty, G. A. J. Am. Chem. Soc. 2000, 122, 3801.

201. Salamone, S. G.; Dudley, G. B. Org. Lett. 2005, 7, 4443.

202. Rawdah, T. N. Tetrahedron 1991, 47, 8579.

203. Rawdah, T. N.; El-Faer, M. Z. Tetrahedron 1990, 46, 4101.

204. Ledaal, T. Tetrahedron Lett. 1967, 8, 4397.

205. Ledaal, T. Tetrahedron Lett. 1968, 9, 651. 


\section{Authors' Biographies}

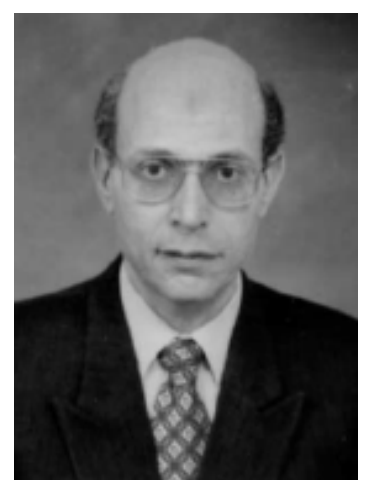

Hanafi H. Zoorob: received his $\mathrm{MSc}$ and $\mathrm{PhD}$ from Faculty of Science, Cairo University. During his job as a research assistant at Chemotherapeutic Laboratory, National Research Center, Cairo, he completed his $\mathrm{PhD}$ thesis in 1973 from the Faculty of Science, Ain Shams University, Cairo. In 1975 he joined the Staff members of the Chemistry Department at the Faculty of Science, Mansoura University, Egypt, whereby, he was prompted to Assistant Professor in 1979 then to Professor in 1986 until now. He was awarded a postdoctoral fellowship in 1977 at Tokyo Institute of Technology (Japan) with Professor Noboru Yamazaki to work on asymmetric reduction using chirally modified reagents. In 1981 he joined Dr Robert K. Griffith's group as a postdoctoral fellow for two years at the College of Pharmacy, University of Michigan, Ann Arbor, USA. Apart of Dr Griffith's group program was focused on preparation of some histamine analogues as potential inhibitors for diamine oxidase. In 2008 he was appointed as Head of Chemistry Department, Faculty of Science, Mansoura University. Moreover, he was published three review articles in the domain of heterocyclic chemistry and conducted five book reviews as well. His research topics include study and development of new methods and synthetic approaches to organic compounds and intermediates of synthetic importance. He is currently conducting research in the synthesis of heterocyclic molecules of anticipated biological applications.

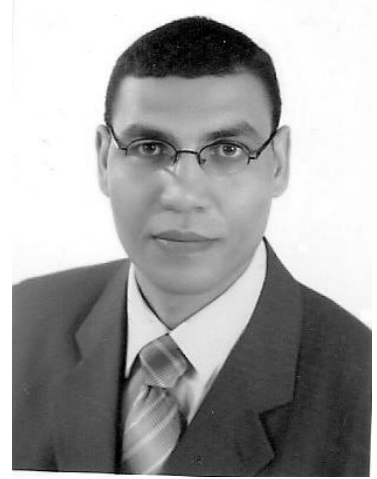

Mohammad S. Elsherbini: born in 1980, studied chemistry at chemistry department, faculty of science, Mansoura University, Egypt and completed his master in organic chemistry under the supervision of prof. Dr. Hanafi H. Zoorob and prof. Dr. Wafaa Salama Hamama in 2010. His research interests are synthesis of heterocyclic compounds of anticipated biological applications. 


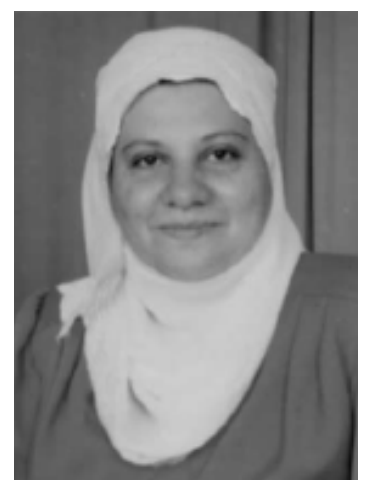

Wafaa Salama Hamama: graduated from Faculty of Science, Mansoura University where she was awarded the MSc and PhD in Chemistry from Faculty of Science, Mansoura University in 1978 and 1983, respectively. She was awarded Assistant Professor in 1988 then Professor in 2001 until now. She worked in Um-El Koura University in Saudi Arabia from 1990 to 1996. She was awarded a postdoctoral fellowship in 2009 at (DFG) with Prof N.K. Jacobs University, Germany. Her research focused on the development in the synthesis of heterocyclic organic compounds of different classes having pharmacological activity. She was published three review articles in the field of heterocyclic compounds. 